\title{
MEMOI RE
}

présenté

à

\section{L'UNIVERSTTE DU QUEBEC A CHICOUTIMI}

\author{
pour l'obtention du grade de
}

Maitre ess Sciences Appliquées

$$
\text { (M.SC.A.) }
$$

par

CHAFIQ BELOUADI

Bachelier es sciences

de 1 Universite Laval

TRAT TEMENT ANAEROBIE D'UNE EAU RESIDUAIRE SYNTHETIQUE SIMULANT LES EFFLUENTS D'UNE FABRIQUE DE PATE THERMOMECANIQUE 


\section{Bibliothèque}

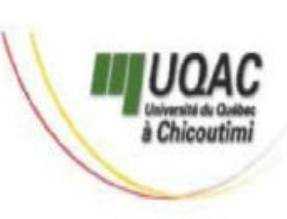

\section{Mise en garde/Advice}

Afin de rendre accessible au plus Motivated by a desire to make the grand nombre le résultat des results of its graduate students' travaux de recherche menés par ses research accessible to all, and in étudiants gradués et dans l'esprit des accordance with the rules règles qui régissent le dépôt et la governing the acceptation and diffusion des mémoires et thèses diffusion of dissertations and produits dans cette Institution, theses in this Institution, the I'Université du Québec à Université du Québec à Chicoutimi (UQAC) est fière de Chicoutimi (UQAC) is proud to rendre accessible une version make a complete version of this complète et gratuite de cette œuvre. work available at no cost to the reader.

L'auteur conserve néanmoins la The author retains ownership of the propriété du droit d'auteur qui copyright of this dissertation or protège ce mémoire ou cette thèse. thesis. Neither the dissertation or Ni le mémoire ou la thèse ni des thesis, nor substantial extracts from extraits substantiels de ceux-ci ne it, may be printed or otherwise peuvent être imprimés ou autrement reproduced without the author's reproduits sans son autorisation. permission. 


\section{RESUME}

Le procédé papetier thermomécanique (PTM) est de plus en plus utilisé dans la fabrication du papier journal. Bien que sa participation à la pollution des cours d'eaux soit relativement Eaible comparativement aux procédés chimiques et mi-chimiques, le procédé PTM génèe des polluants pour les eaux réceptrices, particulièrement certaines substances toxiques, telles les acides résiniques.

Au cours de cette étude, un traitement anaérobie a été utilisé à cause des nombreux avantages qu'il présente par rapport a un traitement aérobie. Dans un premier temps, une eau résiduaire synthétique, composée de xylane et d'acide déshydroabiétique, a été choisie pour simuler l'effluent réel d'une fabrique de pate thermomécanique, ces deux substances représentant respectivement la fraction biodégradable et toxique d'un tel effluent réel.

L'étude a démontré que ce type d'effluent synthétique est traitable par voie anaérobie et que l'acide déshydroabiétique est une substance inhibitrice pour ces bacteries.

Après avoir acclimaté une culture mixte de bactéries à diverses solutions, différentes mesures ont été effectués en fonction de la durée du traitement: demande chimique en oxygène, composition du biogaz, concentrations de xylane, d'acide déshydroabietique et de biomasse. 
Deux équations sont proposées pour représenter la vitesse spécifique de biodégradation de la xylane et la vitesse spécifique de croissance bacterienne en fonction de la concentration de xylane. Celles-ci sont des équations modifiées de Michaelis-Menten et de Monod.

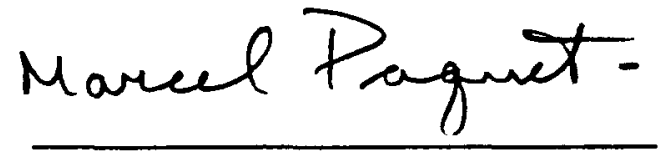

Marcel paquet

Directeur de thèse

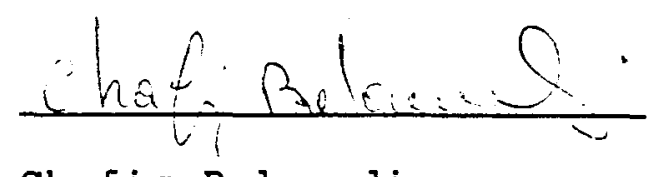

Chafiq Belouadi

Etudiant post grade

Llenis Conillaid

Denis Couillard

Co-directeur de thèse 


\section{REMERCIEMENTS}

Je tiens à remercier très sincèrement mon directeur de thèse, Monsieur Marcel Paquet, D.SC., pour le support financier et ses précieux conseils qui m'ont permis de mener á bien cette recherche.

J'adresse également mes remerciements à Monsieur Denis Couillard, co-directeur de thèse et professeur à I'INRS-Eau, pour ses commentaires judicieux.

Ma reconnaissance s'adresse aussi aux professeurs Michel J. Gagnon et André Charette de l'Université du Québec à Chicoutimi qui m'ont permis d'utiliser leurs appareils d'analyses chimiques et qui m'ont permis, avec leur aide, de mener a bien certaines analyses. 


\section{TABLE DES MATIERES}

\section{PAGES}

RESUME.............................. i

REMERCIEMENTS ........................... iv

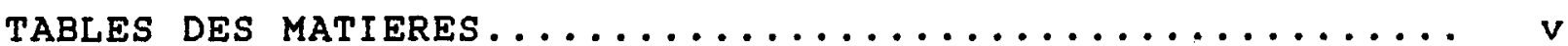

LISTE DES FIGURES.......................... viii

LISTE DES TABLEAUX .......................

CHAPITRE I - INTRODUCTION .................... I

1.1 - Impacts de 1'industrie des pates et papiers.... 1

1.1 .1 - Impact économique................. 1

1.1 .2 - Impact environnemental............. 1

1.2- Traitement des eaux résiduaires............. 4

1.2.1-Etapes de traitement des eaux résiduaires 4

1.2.2- Traitements biologiques secondaires..... 6

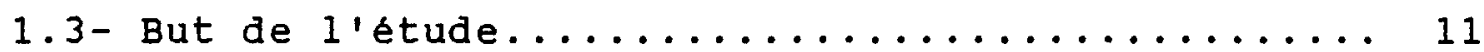

CHAPITRE II - THEORIE DE LA DIGESTION ANAEROBIE ET MODELES CINETIQUES .................... 12

2.1 - Digestion anaérobie.................. 12

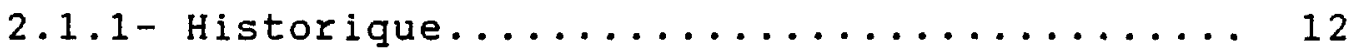

2.1.2- Etapes de la digestion anaérobie....... 13

2.1.3-Facteurs affectant la digestion anaérobie 17

2.1.3.1-Rapport carbone/azote......... 17

2.1.3.2-Temperature d'opération......... 18

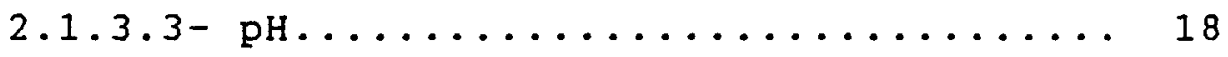

$2.1 .3 .4-$ Nature du substrat............ 18

2.1.3.5- Metaux lourds............... 19

$2.1 .3 .6-$ Nutriments...................... 19 
2.2- Modèles cinétiques.................. 20

2.2.1- Cinétique de la biodégradation d'un substrat........................ 20

2.2.2- Inhibition des réactions enzymatiques..... 23

2.2.3-Croissance bactérienne............ 25

2.2.4- Cinétique de la croissance bacterienne... 27

2.2.5-Rendement en biomasse............. 29

CHAPITRE III - CARACTERISATION DES EFFLUENTS D'UNE USINE DE PATES ET PAPIERS THERMOMECANIQUES ET

CHOIX DE L'EAU RESIDUAIRE SYNTHETIQUE...... 30

3.1-Caractérisation de l'effluent thermomécanique... 30

3.2- Choix de l'eau résiduaire synthétique......... 40

CHAPITRE IV - MATERIEL ET METHODES EXPERIMENTALES....... 42

4.1- Préparation des eaux résiduaires synthétiques... 42

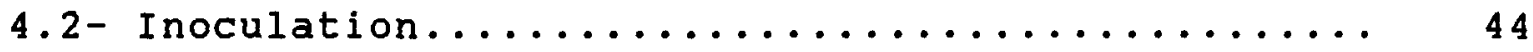

$4.3-$ Demande chimique en oxygène.............. 49

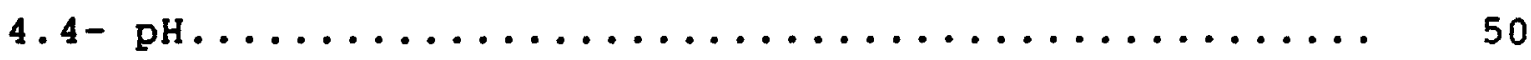

$4.5-$ volume du biogaz..................... 50

4.6 - Analyse du biogaz.................... 51

4.7- Concentration bactérienne.............. 53

4.8- Analyse des hydrates de carbone............. 54

4.9- Analyse de l'acide déshydroabiétique......... 55

CHAPITRE $V$ - RESULTATS ET DISCUSSIONS............. 57

5.1 - Traitabilité........................ 57

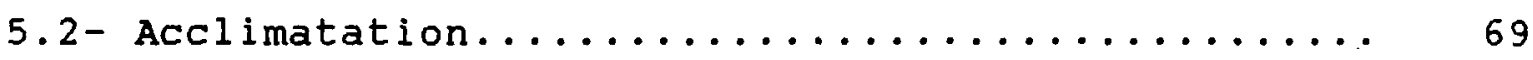


PAGE

5.3- Cinetique de la digestion anaérobie.......... 82

5.4- Rendement en biomasse................... 113

CHAPITRE VI - CONCLUSION.................... 117

ANNEXES .................................... 120

Annexe A: Composition du bois................ 120

Annexe B: Procédé thermomécanique............. 123

BIBLIOGRAPHIE............................. 127 


\section{LISTE DES FIGURES}

$\underline{\text { PAGE }}$

FIGURE 1: Etapes de traitement des eaux résiduaires....... 5

FIGURE 2: Digestion anaérobie de la matiere organique...... 14

FIGURE 3: Graphique de Lineweaver - Burk pour le modele de Michaelis-Menten.................... 21

FIGURE 4: Croissance bactérienne en fonction du temps...... 26

FIGURE 5: Chaine de celulose..................... 34

FIGURE 6: Principaux constituants des hémicelluloses...... 34

FIGURE 7: structure des hémicelluloses............... 35

FIGURE 8 : structure de la lignine................. 36

FIGURE 9: structure des acides résiniques............. 38

FIGURE 10: Schéma de l'inoculation anaérobie............ 47

FIGURE 11: Volume cumulatif de biogaz produit en fonction du temps lors des essais de traitabilité des solutions $x_{1}, x_{2}, x_{3}$ et le témoin............ 62

FIGURE 12: Volume cumulatif de biogaz produit en fonction du temps lors des essais de traitabilité des solutions $A, B, C, D, E$, et $F \ldots \ldots \ldots \ldots 6 \ldots \ldots \ldots \ldots . \ldots \ldots$

FIGURE 13: Volume cumulatif de biogaz produit en fonction du temps lors des essais de traitabilité des solutions $A, G, H, I, J$ et $K \ldots \ldots \ldots \ldots \ldots \ldots \ldots$

FIGURE 14: Volume cumulatif de biogaz produit en fonction du temps lors de l'acclimatation des bactéries anaérobies a la solution B................ 71

FIGURE 15: Volume cumulatif de biogaz produit en fonction du temps lors de l'acclimatation des bactéries anaérobies a la solution D................. 73

FIGURE 16: Volume cumulatif de biogaz produit en fonction du temps lors de l'acclimatation des bactéries

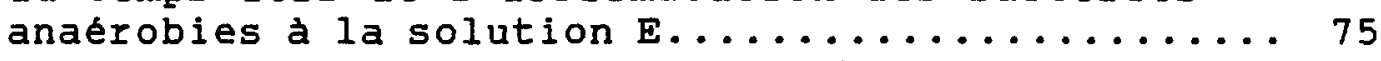


FIGURE 17: Volume cumulatif de biogaz produit en fonction du temps lors de l'acclimatation des bactéries anaerobies a la solution $G \ldots \ldots \ldots \ldots \ldots \ldots \ldots \ldots$

FIGURE 18: Volume cumulatif de biogaz produit en fonction du temps lors de l'acclimatation des bacteries anaérobies a la solution $I \ldots \ldots \ldots \ldots \ldots \ldots \ldots \ldots$

FIGURE 19: Volume cumulatif de biogaz produit en fonction du temps lors de l'acclimatation des bactéries anaérobies a la solution $\mathrm{J} . \ldots \ldots \ldots \ldots \ldots \ldots \ldots \ldots$

FIGURE 20: Variation de la DCo en fonction du temps lors de la digestion anaérobie des solutions B, D, E, G,

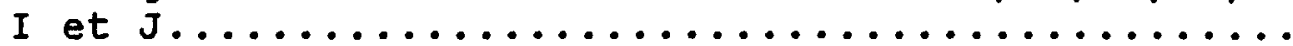

FIGURE 21: Variation de la concentration de xylane en fonction du temps pour les solutions B et G...... 90

FIGURE 22: Variation de la concentration de xylane en fonction du temps pour les solutions D et I...... 91

FIGURE 23: Variation de la concentration de xylane en fonction du temps pour les solutions $\mathrm{E}$ et $\mathrm{J} \ldots . . . .992$

FIGURE 24: Variation de la concentration de la biomasse en fonction du temps pour les solutions $B, D$,

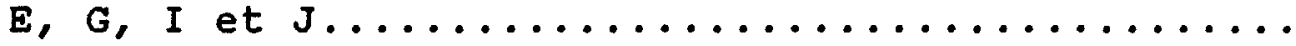

FIGURE 25: Graphique de Lineweaver-Burk, pour les solutions $B$ et $G\left(I_{0}=0 \mathrm{mg} / L\right)$, a partir de $I^{\prime e}$ equation $5.1 \ldots 103$

FIGURE 26: Graphique de Lineweaver-Burk, pour les solutions $D$ et $I\left(I_{0}=40 \mathrm{mg} / \mathrm{L}\right)$, a partir de l'équation $5.1 \ldots 104$

FIGURE 27: Graphique de Lineweaver-Burk, pour les solutions $E$ et $J\left(I_{0}=100 \mathrm{mg} / \mathrm{L}\right)$, à partir de l'équation 5.1.. 105

FIGURE 28: Graphique de Lineweaver-Burk, pour les solutions $B$ et $G\left(I_{0}=0 \mathrm{mg} / \mathrm{L}\right)$, a partir de l'équation $5.3 \ldots 108$

FIGURE 29: Graphique de Lineweaver-Burk, pour les solutions $D$ et $I\left(I_{0}=40 \mathrm{mg} / \mathrm{L}\right)$, à partir de l'équation 5.3... 109

FIGURE 30: Graphique de Lineweaver-Burk, pour les solutions $E$ et $J\left(I_{0}=100 \mathrm{mg} / \mathrm{L}\right)$, a partir de l'équation 5.3.. 110 
FIGURE 31: Composés chimiques du bois.................. 122

FIGURE 32: Procédé thermomécanique classique............ 125 


\section{LISTE DES TABLEAUX}

PAGE

TABLEAU I: Toxicité et concentration des acides résiniques dans les effluents non traités du procédé papetier thermomécanique.........

TABLEAU II: Echantillons a traiter par anaéobiose, leurs compositions et leurs DCO initiales mesurées expérimentalement....................

TABLEAU III: Solutions concentrées pour la préparation du milieu de croissance des bactéries anaérobies.

TABLEAU IV: Composition du milieu nutritif........... 46

TABLEAU V: Conditions expérimentales du biogaz par chromatographie gazeuse...............

TABLEAU VI: Conditions expérimentales d'analyse de l'acide déshydroabiétique par chromatographie liquide a haute performance (HPLC) ................

TABLEAU VII: Pourcentage de réduction de la DCo, de la concentration en xylane et de l'acide déshydroabiétique en fonction de la durée du traitement pour des solutions synthetiques lors des essais de traitabilité...........

TABLEAU VIII: Volume cumulatif de biogaz, sa composition moyenne en méthane ainsi que le rendement en $\mathrm{CH}_{4}$ obtenus lors des essais de traitabilite par anaérobiose des différentes solutions

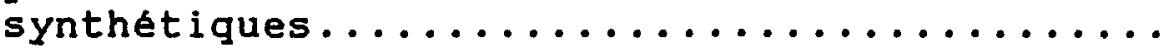

TABLEAU IX: Volume cumulatif de biogaz produit pendant les essais de biodégradabilité par vole anaérobie des solutions $x_{1}, x_{2}, x_{3}$ et le témoin (eau)..

TABLEAU X: Volume cumulatif de biogaz produit lors des essais de biodégradabilité par voie anaérobie des solutions A, B, C, D, E, F, G, H, I, J

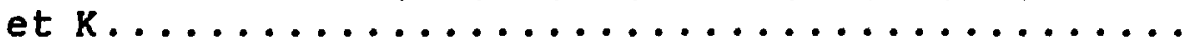

TABLEAU XI: Volume cumulatif de biogaz produit lors de l'acclimatation des bactéries anaérobies a la

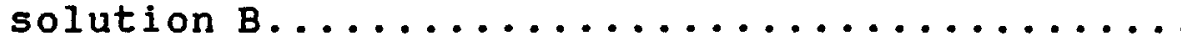


TABLEAU XII: Volume cumulatif de biogaz produit lors de 1 acclimatation des bactéries anaérobies à la

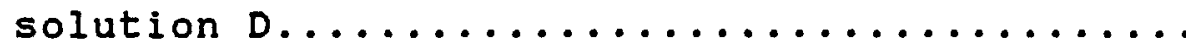

TABLEAU XIII: Volume cumulatif de biogaz produit lors de 1 'acclimatation des bactéries anaérobies a la

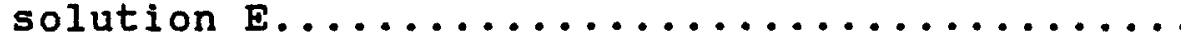

TABLEAU XIV: Volume cumulatif de biogaz produit lors de l'acclimatation des bactéries anaérobies à la

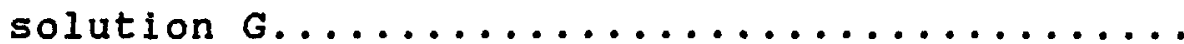

TABLEAU XV: Volume cumulatif de biogaz produit lors de l'acclimatation des bactéries anaérobies a la

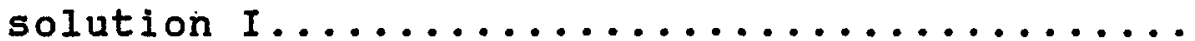

TABLEAU XVI: Volume cumulatif de biogaz produit lors de 1 'acclimatation des bactéries anaérobies à la

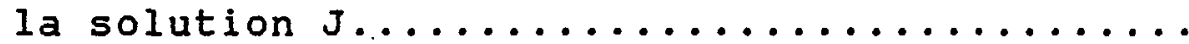

TABLEAU XVII: Pourcentage de réduction de la DCO, de la concentration en xylane et de l'acide déshydroabietique en fonction de la durée du traitement pour des eaux résiduaires synthetigues en utilisant des bactéries acclimatées à celles-ci................

TABLEAU XVIII: Volume cumulatif de biogaz, sa composition moyenne en méthane ainsi que le rendement en $\mathrm{CH}_{4}$ obtenus par digestion anaérobie des differentes solutions synthétiques par des bactéries acclimatées à ces solutions........

TABLEAU XIX: Valeurs de la DCO, de la concentration de xylane, d'acide déshydroabiétique et de biomasse en fonction du temps pour les

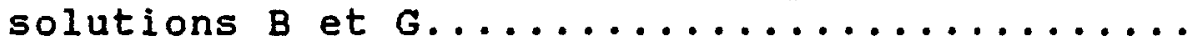

TABLEAU XX: Valeurs de la DCO. de la concentration de xylane, d'acide déshydroabietique et de biomasse en fonction du temps pour les

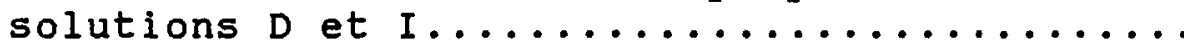

TABLEAU XXI: Valeurs de la DCO, de la concentration de xylane, d'acide déshydroabiétique et de biomasse en fonction du temps pour les solutions $E$ et $J \ldots \ldots \ldots \ldots \ldots \ldots \ldots \ldots \ldots \ldots \ldots$ 
TABLEAU XXII: Concentration moyenne en méthane dans le biogaz, en $\%$ en volume, produit en fonction du temps lors de la digestion anaerobie des solutions synthétiques................ 96

TABLEAU XXIII: Valeurs calculées de $v^{\prime}, v, d x / d t$ et $\mu$ en fonction du temps pour les solutions B et G.. 97

TABLEAU XXIV: Valeurs calculées de $v^{\prime}, v$, dx/dt et $\mu$ en fonction du temps pour les solutions D et I.. 98

TABLEAU XXV: Valeurs calculees de $V^{\prime}, V$, dX/dt et $\mu$ en fonction du temps pour les solutions E et J.. 99

TABLEAU XXVI: Valeurs utilisées pour tracer les diagrammes Lineweaver-Burk dans le cas de la vitesse de biodégradation de la xylane........... 102

TABLEAU XXVII: Valeurs utilisées pour tracer les diagrammes Lineweaver-Burk dans le cas de la vitesse de biodégradation de la croissance bactérienne...................... 107

TABLEAU XXVIII: Valeurs des constantes cinetiques $v_{m}$ et $K_{1}$, en fonction de la concentration initiale de 1 acide déshydroabiétique .............. 112

TABLEAU XXVIX: Valeurs des constantes $\mu_{m}$ et $k_{2}$ en fonction de la concentration initiale de l'acide déshydroabietique................... 112 


\section{CHAP I TRE I}

\section{INTRODUCTION}

\section{1 - Impacts de l'industrie des pates et papiers}

1.1 .1 - Impact économigue

L'industrie des pates et papiers constitue un secteur d'activités important de l'économie canadienne. Elle compte 143 usines, dont 57 au Québec, et emploie directement près de 77500 personnes (Association canadienne des producteurs de pâtes et papiers - ACPPP, 1988). Une très grande partie des pates et papiers produite au Canada est destinée a l'étranger, ce qui représente près de $9.4 \%$ - dont $5 \%$ pour le papier journal - de la valeur des exportations canadiennes, soit plus que les ventes de petrole, de blé et des produits d'aluminium et d'alliages réunis (ACPPP, 1988).

\section{1 .2 - Impact environnemental}

Malgré les progrès effectués au cours des dernières années pour diminuer la charge polluante rejetée par les usines de pates et papiers dans les cours d'eau (Betts, 1984), ce type d'industrie demeure l'un des plus polluants (Couillard et Trudel, 1981; Luonsi et al., 1986) au Canada.

Au cours des dernieres années, le changement le plus remarqué dans la fabrication des pates, a sans doute été le remplacement, dans certaines usines de fabrication de papier journal, des procédés au sulfite a bas rendement par des 
procédés thermomécaniques à haut rendement (McCubbin, 1984a). Ce remplacement a eu pour effet de diminuer la quantité de rejets des matières organiques dans les cours d'eau récepteurs (Couillard, 1980). L'utilisation des procédés thermomécaniques (PTM) qui ont un rendement moyen de 90 a $95 \%$, comparativement a 55 - $65 \%$ pour les procédés au sulfite (McCubbin, 1984b), diminue la charge polluante de 30 a $35 \%$. Un autre avantage important de cette substitution est la réduction de la consommation de bois. La majorité des usines de pates mécaniques construites au Canada depuis 1973, fabrique de la pate thermomécanique (McCubbin, 1984b). Cette tendance se poursuivra vraisemblablement durant les prochaines années (Mccubbin, 1984a), ou une très grande partie de l'expansion portera sur la production des pates thermomecaniques (PTM) pour la fabrication du papier journal. En raison de l'utilisation de plus en plus répandue de ce procédé, il est nécessaire de trouver des moyens efficaces et non dispendieux pour traiter les eaux résiduaires PTM.

Malgré sa participation relativement faible a la pollution des cours d'eau, comparativement aux procédés chimiques et mi-chimiques (Couillard, 1979), le procédé PTM génère des polluants pour les eaux réceptrices. Ces polluants peuvent etre classés en deux catégories principales, soit les matières en suspension (MES) et les matières dissoutes (MD). Les matières en suspension sont majoritairement composées de fibres de bois qui peuvent être retenues par décantation au 
cours d'un traitement primaire (McCubbin, 1984c; Couillard, 1980). Les matières dissoutes proviennent des principaux constituants du bois, qui sont l'hemicellulose, la cellulose ainsi que la lignine de faibles poids moléculaires. Les eaux résiduaires PTM contiennent aussi, en quantité moindre, des extraits toxiques du bois, tels des acides résiniques et des acides gras (Ferguson et al., 1985). Les matieres dissoutes représentent la majeure partie de la demande biochimique en oxygene apres cing jours d'incubation ( $D B q_{5}$ ) et de la demande chimique en oxygène (DCO). Si ces matieres dissoutes contenant de grandes quantités de composés biodégradables sont rejetées sans traitement biologique secondaire, elles diminuent grandement la disponibilité en oxygène dissout (OD) des cours d'eau récepteurs (Couillard et Trudel, 1981) et affectent la faune et la flore aquatiques (Couillard, 1980). Des produits toxiques pour les poissons sont présents dans les eaux résiduaires du procédé thermomécanique (Leach et Thakore, 1975). Ces produits toxiques originent principalement de la fraction acide de l'effluent. Les produits toxiques majeurs sont les acides résiniques, et à un degré moindre, les acides gras. Des études (Oīkari et al., 1980) ont montré que l'acide déshydroabiétique et d'autres acides résiniques peuvent s'accumuler de façon notable dans les poissons (plasma sanguin, foie, reins, cerveaul exposés à ces produits. D'autres études (Howard et Mounteith, 1977) portant sur l'assimilation de l'acide linoléique chez la jeune truite arc- 
en-ciel, ont montré que cet acide gras se retrouve dans les branchies, et à des niveaux moindres, dans le sang et les visceres.

\section{2 - Traitement des eaux résiduaires}

\section{2 .1 - Etapes de traitement des eaux résiduaires}

Les effluents thermomécaniques rejetés par les usines de pates et papiers, necessitent un traitement avant leur déversement dans le milieu récepteur. Il existe un grand nombre de procédés de traitement des eaux résiduaires. L'application de ces traitements dépend, a la fois des caractéristiques des eaux et du degré de traitement désiré. Les divers traitements possibles sont indiqués à la figure 1 (Eckenfelder, 1982).

Le pré-traitement et le traitement primaire sont utilisés pour éliminer les débris de bois et les matières solides en suspension. Le traitement primaire des eaux résiduaires de l'industrie papetiere peut eliminer 80 a $95 \%$ des matieres solides en suspension, ainsi qu'une partie de la demande biochimique en oxygene représentant environ $10 \%$ de la $\mathrm{DBO}_{5}$ totale (McCubbin, 1984c). Un deuxième procédé important durant le traitement primaire, est la neutralisation du pH des effluents. Le $\mathrm{pH}$ des effluents thermomécaniques varie entre 4 et 4.5 (Ferguson et al. 1985). si ce pH n'est pas neutralisé, il peut nuire aux traitements biologiques secondaires et provoquer la corrosion de la tuyauterie (McCubbin, 1984c). Les traitements secondaires ont pour but 


\begin{tabular}{|c|c|c|c|c|c|c|c|c|}
\hline \multirow{2}{*}{ Prétraitement } & \multicolumn{2}{|c|}{ Traitement primaire } & \multicolumn{2}{|c|}{ Traitement secondaire } & \multirow{2}{*}{$\begin{array}{c}\text { Traitement } \\
\text { tertiaire }\end{array}$} & \multirow{2}{*}{$\begin{array}{l}\text { Traitement } \\
\text { des boues }\end{array}$} & \multirow{2}{*}{$\begin{array}{l}\text { Destruction } \\
\text { des boues }\end{array}$} & \multirow{2}{*}{$\begin{array}{l}\text { Rejets } \\
\text { liquides }\end{array}$} \\
\hline & Chimique & Liquide & $\begin{array}{c}\text { Matières organiques } \\
\text { dissoutes }\end{array}$ & $\begin{array}{l}\text { élimination mat. } \\
\text { en suspension }\end{array}$ & & & & \\
\hline
\end{tabular}

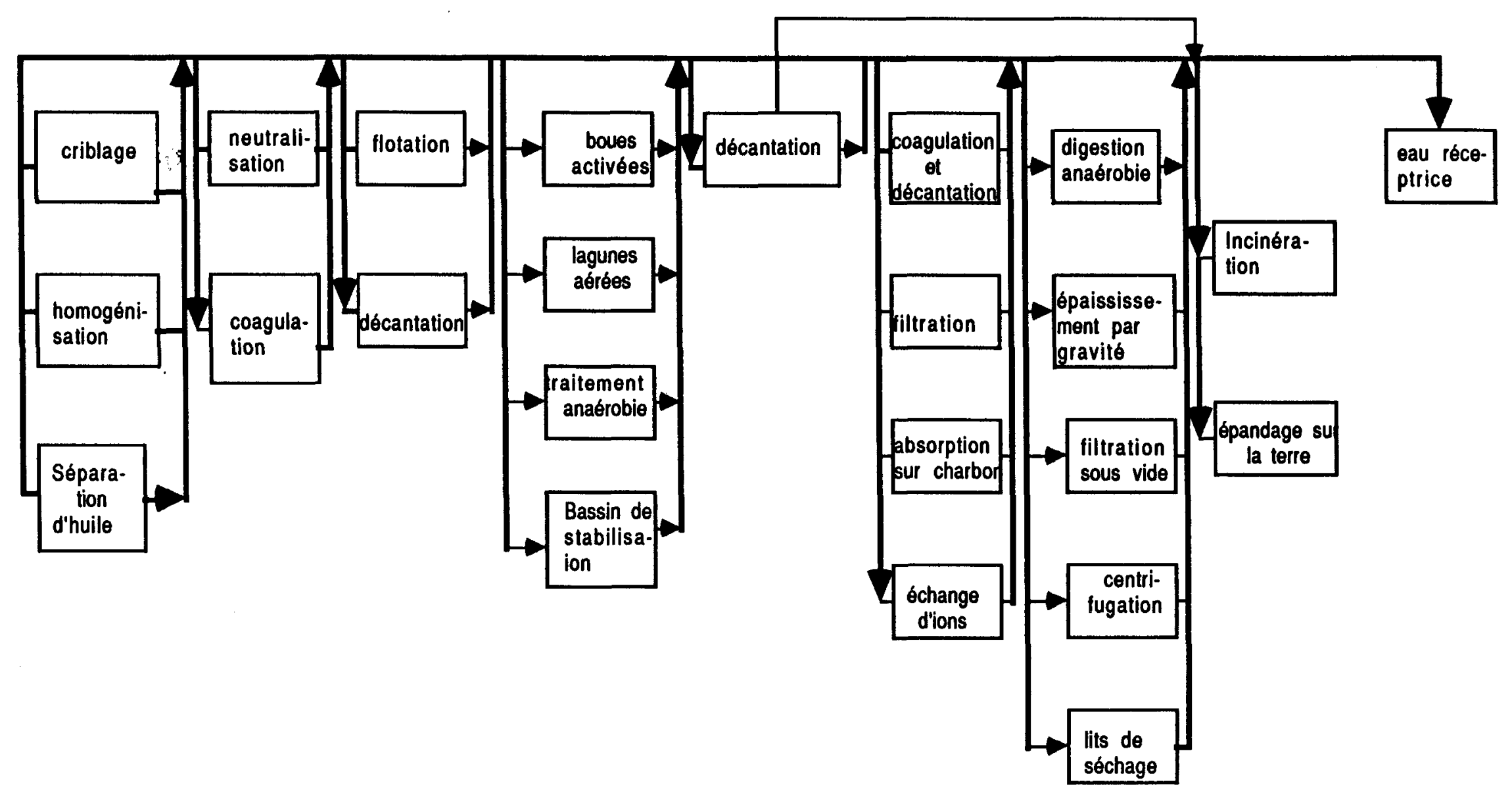

Figure 1: Étapes de traitement des eaux résiduaires.

(Eckenfelder, 1982) 
d'abaisser la demande biochimique en oxygene provoquée par les matières biogradables, ainsi que de réduire la toxicité causée par certaines substances telles que les acides résiniques et les acides gras.

Les traitements tertiaires qui sont le dernier stade des traitements des eaux résiduaires sont encore très peu utilisés dans l'industrie papetière (McCubbin, 1984c). Leur role est d'eliminer d'autres facteurs nuisibles pour les eaux réceptrices telles la couleur et l'odeur des effluents papetiers.

Au cours de cette étude, l'intérêt sera porté sur les traitements secondaires et plus particulierement sur la voie anaérobie.

\section{2 .2 - Traitements biologiques secondaires}

Les traitements biologiques secondaires disponibles actuellement pour traiter les matieres organiques dissoutes dans les eaux résiduaires d'un procédé PTM se divisent en deux catégories, soit aérobie ou anaérobie. Ces deux traitements biologiques ont pour but de réduire la toxicité et la demande biochimique en oxygène des eaux résiduaires. Auparavant, le traitement anaérobie était utilisé uniquement pour la stabilisation des boues municipales et le traitement des eaux usées fortement chargées en matières organiques, comme c'est le cas des eaux résiduaires de l'industrie alimentaire (Olthof et oleszkiewicz, 1982; Salkinoja - Salonen et al., 1984). Les 
principales raisons pour cette faible utilisation de la digestion biologique anaérobie pour le traitement des eaux résiduaires de l'industrie papetière sont: (Salkimoja-Solomen et al., 1984):

- l'industrie papetière utilise de trés grands volumes d'eau, diluant la charge polluante;

- les eaux résiduaires papetières - surtout celles des procédés chimiques - ont un faible rapport $\mathrm{DBO}_{5} / \mathrm{DCO}$, ce qui signifie qu'elles sont peu chargées en matières facilement biodégradables;

- les effluents contiennent une grande quantité de matières toxiques envers lesquelies les bactéries anaérobies, et particulièrement les bactéries méthanogènes, sont très sensibles.

Au cours des dernières années, des nouveaux procédés ont permis aux traitements biologiques anaérobies de concurrencer les traitements biologiques aérobies pour l'épuration des eaux résiduaires des fabriques de pates et papiers. En effet, des études ont montré que les bactéries anaérobies fixées sur un support (matériaux granulaires) sont moins vulnérables que les bacteries en suspension, a la toxicité des produits chimiques et aux variations de pH (Suidan et al., 1981; Tiedje et al., 1986). Salkinoja-Salomen et al. (1984) rapportent que le traitement d'un effluent d'une fabrique de pate kraft blanchie dans un lit fluidisé anaérobie, réduit la concentration des chlorophénols d'environ 80 à $90 \%$. Le méme effluent traité 
par boues activées montre une réduction des chlorophénols de 1 'ordre de 30 a $50 \%$.

Les effluents d'un procédé thermomécanique (PTM) peuvent etre traités par digestion anaéroble car ils contiennent de grandes quantités de matières facilement biodégradables (Ferguson et al., 1985; Hakulinen et Salkinoja-Salonen, 1982). L'épuration anaérobie des eaux résiduaires PTM a le potentiel de produire des effluents de qualité comparable et a coat moindre que ceux produits par aérobiose (olthof et Oleszkiewicz, 1982). En effet, certains auteurs préconisent que l'épuration biologique anaérobie est plus économique que celle aérobie pour les eaux résiduaires qui ont une demande chimique en oxygène superieure à $2000 \mathrm{mg} / \mathrm{L}$ (Anderson et Seneratne, 1985), ce qui est le cas des effluents thermomécaniques.

L'épuration anaérobie présente les avantages suivants par rapport aux traitements aéobies (Anderson et al., 1982; Anderson et Seneratne, 1985; Cocci et a1. 1982; Gunnerson et Stuckey, 1986c; Webb, 1984):

- production de gaz combustible récupérable qui peut être utilisé pour couvrir les besoins énergétiques du traitement;

- très faible production de biomasse, pres de $1 / 8$ de celle produite par épuration aérobie (Blum et al., 1985), signifiant une réduction des coats pour la stabilisation et l'élimination de cette biomasse;

- besoin nul en oxygène diminuant les coats du traitement; 
- faible besoin en nutriments;

- capacité d'utilisation périodique (les bactéries survivent en absence de substrat);

- moins de nuisances environnementales, car la digestion s'effectue dans des réacteurs hermétiques;

- diminution d'environ 908 des microorganismes pathogènes.

Les principaux désavantages de l'épuration anaérobie comparativement à celle aérobie (Olthof et Oleszkiewics, 1982) sont :

- requiert des eaux résiduaires contenant de grandes concentrations de matieres organiques facilement biodégradables;

- faible vitesse de biodégradation de matieres organiques nécessitant un long temps de retention ou un grand volume de réacteur.

Les hydrates de carbone (cellulose et hémicellulose) sont facilement biodégradés par digestion anaérobie. Une réduction supérieure a $80 \%$ des hydrates de carbone est obtenue par anaérobiose (Ferguson et a1., 1985). Environ $90 \%$ de la cellulose biodégradée est transformée en méthane (Khan et al., 1983). L'hémicellulose est facilement biodegradable par anaérobiose sous sa forme pure, mais insoluble et peu biodégradable lorsqu'elle est liée a la lignine (Gunnerson et Stuckey, 1986b). Contrairement a la cellulose et l'hémicellulose, la lignine est refractaire a la digestion anaérobie en raison de son grand poids moleculaire et 
l'incapacité des bactéries anaérobies de l'hydrolyser. Zeikus et al., (1982) ont observé une biodégradation anaérobie partielle des molécules de la lignine possédant un poids moléculaire supérieur à 300 , et aucune biodégradation pour celles dont le poids moléculaire est supérieur à 850 .

Très peu d'etudes ont été faites jusqu'à présent sur 1a biodégradation anaérobie des acides résiniques et des acides gras. L'épuration par boues activées des acides résiniques, qui sont les principaux composés toxiques des eaux résiduaires du procédé thermomécanique, ont permis de réduire la concentration de l'acide déshydroabiétique de 818 , l'acide abiétique de $75 \%$ et l'acide primarique de 728 (Junna et al., 1982). Une autre étude (Hemingway et Greaves, 1973) a montré qu'une solution contenant $40 \mathrm{mg} / \mathrm{L}$ de sel de sodium des différents acides résiniques, traitée par boues activées à une température de $27^{\circ} \mathrm{C}$ produit, après un temps de latence de 18 a 20 heures, une solution contenant une concentration des sels d'acides résiniques inférieure a la limite de détection qui était d'environ $2 \mathrm{mg} / \mathrm{L}$. Le sel de sodium de l'acide déshydroabiétique a été biodégradé plus rapidement que celui de l'acide abiétique ou néoabiétique. Les sels de sodium des acides primarique et isoprimarique sont les plus résistants a la biodégradation. D'autres études ont montré (Servizi et a1., 1986) que la digestion des acides résiniques par le champignon Mortierella isobellina produit d'autres acides stables et moins toxiques. Dans le cas de l'acide 
déshydroabiétique, les métabolites finaux produits sont: l'acide dihydroxy - 2,15 déshydroabiétique et l'acide dihydroxy $-2,16$ déshydroabiétique. L hydroxylation du carbone $\alpha$ participe grandement a la réduction de la toxicité de I'acide déshydroabiétique.

Les acides gras sont facilement biodégradables par digestion anaérobie (Ferguson et al., 1985). I ls se dégradent rapidement au cours des essais biologiques au point de nuire aux essais de toxicité (Leach et Thakore, 1977). Le taux de réduction des composés toxiques par lagune aérée suit l'ordre suivant: acides gras insaturés > acide résinique > juvabione > acides résiniques chlorés (Leach et Thakore, 1977).

1.3 But de 1'étude

Le but de cette étude est d'abord de préparer une solution synthétique simple, contenant a la fois un composé organique représentant la partie toxique ainsi qu'un composé organique représentant la partie biodégradable des eaux résiduaires d'un procédé thermomécanique. Cette solution synthétique est soumise à une digestion anaérobie en fournée (batch), pour vérifier la traitabilité et déterminer le taux de dégradation de chacun des constituants, ainsi que leur toxicité sur les diverses populations bactériennes. Cette etude a pour but aussi de mesurer les constantes cinetiques de la digestion anaérobie de la solution synthetique après acclimatation des bactéries anaérobies a cette solution, et de déduire l'effet de la concentration de l'acide déshydroabiétique sur ces constantes. 


\section{CHAP I TRE I I}

\section{Thérie de la digestion anaérobie et modèles cinétiques}

\section{1 - Digestion anaérobie}

\section{1 .1 - Historique}

Les faits marquants concernant la digestion anaérobie sont les suivants (Gunnerson et stuckey, 1986c).

En 1630, Van Helmont observa un gaz se dégageant de la surface des marécages. Pour cette raison, ce gaz fut communément appelé "gaz des marais". En 1776, Volta conclua que le volume de ce gaz dépendait de la quantité de matiere organique des plantes en décomposition se trouvant dans les sédiments. En 1804, Dalton établit, pour la premiere fois, la formule chimique du méthane. En 1868, Bechamp, un étudiant de Pasteur, a évoqué l'existence d'un lien entre la production du biogaz et des microorganismes. En 1875, Popoff fut le premier chercheur a produire du biogaz a partir de différents substrats. Il a trouvé que la digestion anaérobie de la cellulose produit un biogaz composé de méthane $\left(\mathrm{CH}_{4}\right)$, de bioxyde de carbone ( $\left.\mathrm{CO}_{2}\right)$ et à un degré moindre, d'hydrogène $\left(\mathrm{H}_{2}\right)$. La premiere utilisation commerciale du biogaz était mise au point par Donald Cameron qui, en 1895, a réusi a éclairer des rues avec l'énergie produite à partir du biogaz. En 1947, Schnellen fut le premier a isoler deux bactéries 
productrices de méthane: Methanosarcina barkeri et Methanobacterium formicium.

\subsection{2 - Etapes de la digestion anaérobie}

La digestion anaérobie des matieres organiques pour produire du biogaz, se divise en trois étapes, (figure 2): Etape 1: Hydrolyse et solubilisation

Au cours de cette phase, un premier groupe de bactéries, appelé bactéries hydrolytiques et fermentatives (Hawkes et Hawkes, 1987; Webb, 1984) agit sur les substrats complexes telles la cellulose et l'hémicellulose en les transformant en composés simples (monosaccharides) et solubles. La réaction est une hydrolyse enzymatique extracellulaire (Lester et al., 1984). Dans le cas de l'hémicellulose, les enzymes responsables de cette hydrolyse sont appelées hémicellulases (Bisaria et Ghose, 1981; Dekker, 1985). Ces hémicellulases se divisent en deux groupes:

- les exo-hémicellulases qui attaquent les polysaccharides en enlevant successivement le dernier monosaccharide. Chaque attaque réduit le degré de polymerisation de la substance par un, jusqu'à obtenir un monosaccharide;

- les endo-hémicellulases qui attaquent les polysaccharides de manière aléatoire, causant aussi une diminution du degré de polymérisation. Le polymere est progressivement dégradé jusqu'a l'obtention d'un monosaccharide. L'enzyme endohémicellulase constitue le groupe le plus important des hémicellulases. 


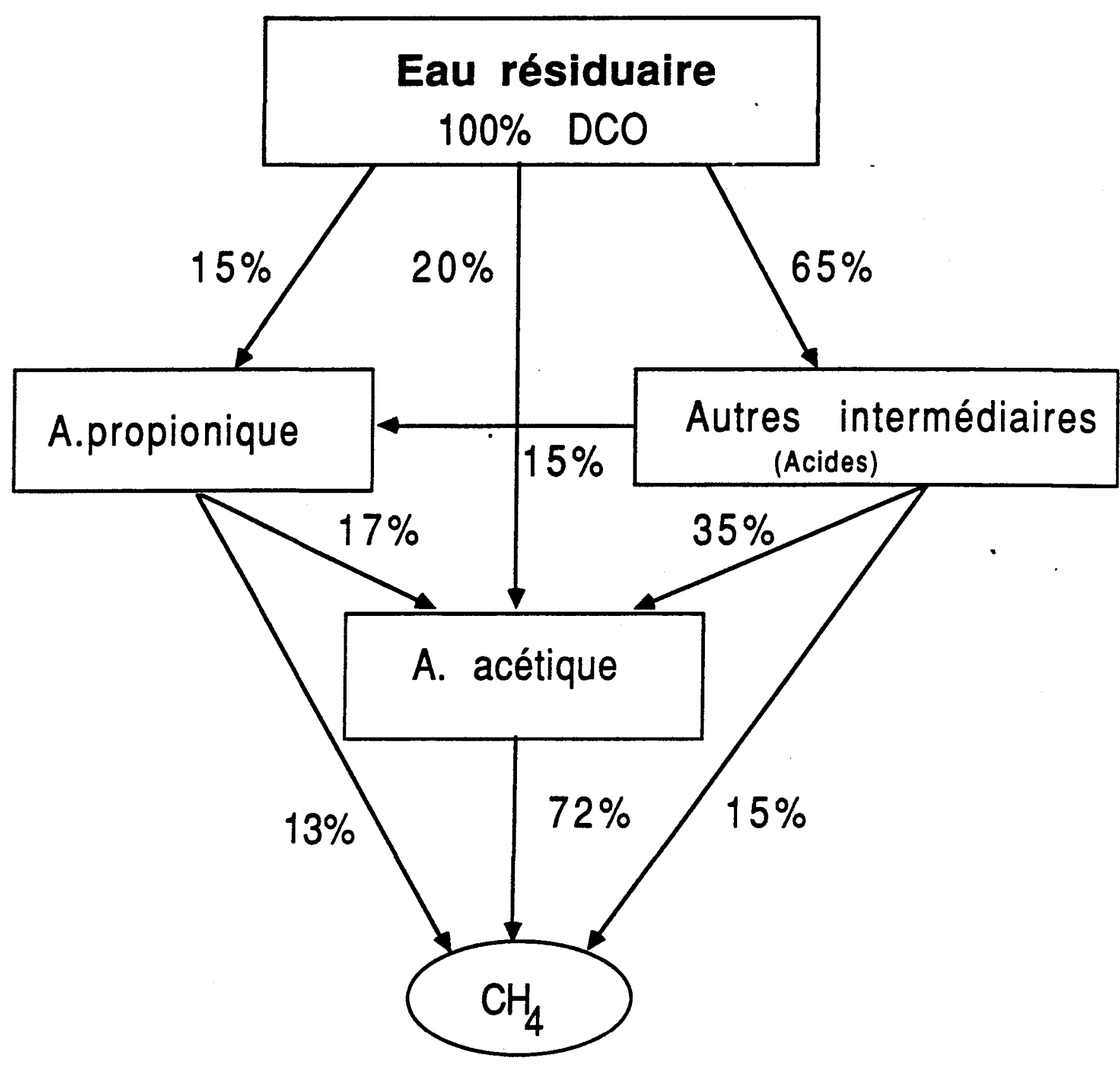

Figure 2: Digestion anaérobie de la matière organique (Cornacchio et al., 1986) 
Les bactéries responsables de la phase d'hydrolyse et de solubilisation sont généralement anaérobies facultatives (Webb, 1984), leur action étant très lente. Noike et al (1985) ont démontré que la phase d'hydrolyse est l'etape la plus lente de la croissance bactérienne anaérobie dans un milieu composé de cellulose.

\section{Etape 2: Acidification}

Au cours de cette deuxième phase, un autre groupe de bactéries appelées bactéries acidogenes s'activent. Ces bactéries transforment les composés hydrolysés et solubilisés en acides gras volatils. Ces derniers sont les acides acétique, propionique, butyrique, valérique et caproique (Grady et Lim, 1980a). Les bactéries concernées dans cette phase sont encore mal connues; parmi elles, un groupe appelé bactéries acétogènes (Hawkes et Hawkes, 1987; Webb, 1984) produit l'acide acétique et l'hydrogène. Un autre groupe, appelé bactéries homoacétogenes, produit l'acide acétique uniquement (Hawkes et Hawkes, 1987; Webbs, 1984). La phase de fermentation acide est rapide et le pH optimal de croissance est voisin de 7 (Grady et Lim, 1980a).

\section{Etape 3: Formation de méthane}

Sans cette étape, la digestion anaérobie se limiterait à une accumulation des acides volatils dans le réacteur. Les acides volatils formés pendant la seconde phase sont utilisés comme substrats par les bactéries méthanogènes (Grady et Lim, 1980a; Hawkes et Hawkes, 1987; Webb, 1984) pour produire 
principalement du méthane $\left(\mathrm{CH}_{4}\right)$ et du bioxyde de carbone $\left(\mathrm{CO}_{2}\right)$. Le temps de génération de ces bactéries est très lent (Grady et Lim, 1980a). La production du méthane provient de deux sources (Grady et Lim, 1980a; Gunnerson et Stuckey, 1986b; Hawkes et Hawkes, 1987):

- La réduction du bioxyde de carbone par les bactéries utilisant l'hydrogène gazeux, selon l'équation:

$$
\mathrm{CO}_{2}+4 \mathrm{H}_{2} \longrightarrow \mathrm{CH}_{4}+2 \mathrm{H}_{2} \mathrm{O}
$$

- La transformation de l'acide acétique en méthane par les bactéries méthanogènes, selon les équations:

$$
\begin{aligned}
& \mathrm{CH}_{3} \mathrm{COOH} \longrightarrow \mathrm{CH}_{4}+\mathrm{CO}_{2} \\
& \mathrm{CH}_{3} \mathrm{COOH}+4 \mathrm{H}_{2} \longrightarrow 2 \mathrm{CH}_{4}+2 \mathrm{H}_{2} \mathrm{O}
\end{aligned}
$$

La composition du biogaz formé lors de cette phase dépend de la nature du substrat et peut etre prédite par l'équation de Symons et Buswall (Gunnerson et Stuckey, 1986d; Stronach et al., 1986):

$$
\begin{aligned}
\mathrm{C}_{n} \mathrm{H}_{\mathrm{a}} \mathrm{O}_{\mathrm{b}}+\left(\mathrm{n}-\frac{\mathrm{a}}{4}-\frac{\mathrm{b}}{2}\right) \quad \mathrm{H}_{2} \mathrm{O} & \longrightarrow \\
& \left(\frac{\mathrm{n}}{2}-\frac{\mathrm{a}}{8}+\frac{\mathrm{b}}{4}\right) \mathrm{CO}_{2}+\left(\frac{\mathrm{n}}{2}+\frac{\mathrm{a}}{8}-\frac{\mathrm{b}}{4}\right) \mathrm{CH}_{4}
\end{aligned}
$$

La composition typique du gaz produit a partir d'hydrates de carbone est $50 \%$ de $\mathrm{CH}_{4}$ et $50 \%$ de $\mathrm{CO}_{2}$, tandis que les acides gras peuvent produire un biogaz contenant jusqu'a $75 \%$ de méthane (Gunnerson et Stuckey, 1986b). 
2.1.3 - Facteurs affectant la digestion anaérobie

Les différents groupes de bactéries travaillent en parallèle durant les trois phases de la digestion anaérobie. L'inhibition d'un groupe peut entrainer l'inhibition des autres groupes. Plusieurs facteurs peuvent affecter la performance d'un digesteur anaérobie; les plus importants sont:

- le rapport carbone/azote;

- la temperature d'opération;

- le $\mathrm{pH}$;

- la nature du substrat;

- les métaux lourds;

- les nutriments.

\subsubsection{1 - Rapport Carbone/azote}

Les bactéries anaérobies requièrent des sources de carbone et d'azote suffisantes pour se reproduire. Le rapport carbone/azote optimal est voisin de 30 (Gunnerson et stuckey, 1986a). Le carbone a un rôle essentiel lors de la digestion anaérobie car il fournit l'énergie nécessaire à la croissance des bactéries. Ces bactérles, obtenant leur énergie de la biodégradation de la matière organique, sont appelées hétérotrophes (Grady et Lim, 1980b). L'azote, quant a lui, joue un role important dans la synthèse des protéines et des acides nucléiques (ADN et ARN) (Grady et Lim, 1980b). 


\subsubsection{2 - Température d'opération}

L'activité bactérienne, lors de la digestion anaérobie augmente avec la température (Maly et Fadrus, 1971). Cependant, une très haute température peut entrainer une diminution du métabolisme bactérien en raison de la dénaturation des enzymes qui sont nécessaires a l'activité des cellules (Gunnerson et Stuckey, 1986a). La digestion anaérobie peut se produire dans trois gammes de températures, chacune reliée aux espèces de bactéries suivantes (Webb, 1984): psychrophiles (inférieure à $20^{\circ} \mathrm{C}$ ), mésophiles $\left(20\right.$ a $45^{\circ} \mathrm{C}$ ) et thermophiles $\left(45\right.$ a $\left.60^{\circ} \mathrm{C}\right)$.

$2.1 .3 .3-\mathrm{pH}$

Les bactéries anaérobies, et particulièrement les méthanogènes sont très sensibles aux variations de $\mathrm{pH}$. Le pH optimal de croissance des bactéries méthanogènes se situe entre 6.8 et 7.0 (Grady et Lim, 1980a). Les autres valeurs de $\mathrm{pH}$ peuvent nuire à l'activité bactérienne en affectant l'équilibre chimique des réactions enzymatiques, ou dans les cas extremes inhiber completement les enzymes.

2.1.3.4 - Nature du substrat

L'efficacité de la digestion anaerobie d'un substrat dépend de la nature de ce dernier. Contrairement aux hydrates de carbone tels le glucose, la cellulose et l'hémicellulose qui sont facilement biodégradables, les 
composés toxiques tels les phénols (Tiedje et al., 1986) affectent la digestion anaérobie en diminuant le métabolisme a faible concentration ou en inhibant completement ce métabolisme a haute concentration (Gunnerson et stuckey, 1986a; Tiedje et al., 1986).

\section{$2.1 .3 .5-$ Métaux lourds}

Les métaux lourds sont toxiques pour les populations bactériennes anaérobies même à de très faibles concentrations. $\mathrm{L}^{\prime}$ ion $\mathrm{Cu}^{++}$est toxique a une concentration de $10^{-16} \mathrm{mg} / \mathrm{L}, 1^{\prime}$ ion $\mathrm{zn}^{++}$a une concentration de $10^{-4} \mathrm{mg} / \mathrm{L}$ et l'ion Fe a une concentration de 1 a $10 \mathrm{mg} / \mathrm{L}$. A ces concentrations, les ions $\mathrm{Cu}^{++}, \mathrm{Zn}^{++}$et $\mathrm{Fe}^{++}$ réduisent 1 'activité des bactéries anaérobies de $50 \%$ (Grady et Lim, 1980a).

Les effluents contenant des grandes concentrations de ces métaux lourds doivent être préalablement traités avec des sulfates pour former des complexes insolubles qui peuvent être éliminés par décantation (Gunnesson et stuckey, 1986a).

\section{$2.1 .3 .6-$ Nutriments}

L'épuration anaérobie nécessite la présence de nutriments (phosphore, magnésium, sodium, calcium, manganèse, cobalt, potassium, etc...) pour favoriser la croissance bactérienne (Grady et Lim, 1980b). Le phosphore est nécessaire pour la synthèse des acides nuclélques et des phospholipides. Le potassium, le 
manganèse et le magnésium activent les enzymes. Ce dernier favorise en plus, la stabilisation des ribosomes, des membranes cellulaires et des acides nucléiques. Le cobalt est nécessaire a la formation de la vitamine $B_{12}$ qui joue un rôle important dans les réactions de transfert de carbone (Grady et Lim, 1980b).

\section{2 - Modeles cinétiques}

2.2 .1 - Cinetique de biodégradation d'un substrat

Pour exprimer la biodegradation enzymatique d'un substrat, Michaelis et Menten ont proposé l'équation suivante (Bailey et ollis, 1977; Breezonik, 1972; Sundstrom et Klei, $1979)$ :

$$
v^{\prime}=-\frac{d s}{d t}=v_{m}^{\prime} \frac{s}{k_{\dot{s}}^{\prime}+s}
$$

V': vitesse de biodégradation du substrat, masse de substrat/ volume-temps ;

$v_{m}^{\prime}$ : vitesse maximale de biodégradation du substrat, masse de substrat/volume-temps;

$S$ : concentration du substrat limitant, masse de substrat/ volume;

$K_{S}^{\prime}$ : constante de saturation, masse de substrat/volume. L'équation de Michaelis-Menten (2.1) peut s'écrire:

$$
\frac{1}{v^{\prime}}=\frac{1}{v_{m}^{\prime}}+\frac{K_{S}^{\prime}}{v_{m}^{\prime}} \cdot \frac{1}{s}
$$

Le graphique $\frac{1}{V^{\prime}}$ en fonction de $\frac{1}{S}$ (figure 3 ) appelé graphique de Lineweaver-Burk (Bailey et Ollis, 1977; 


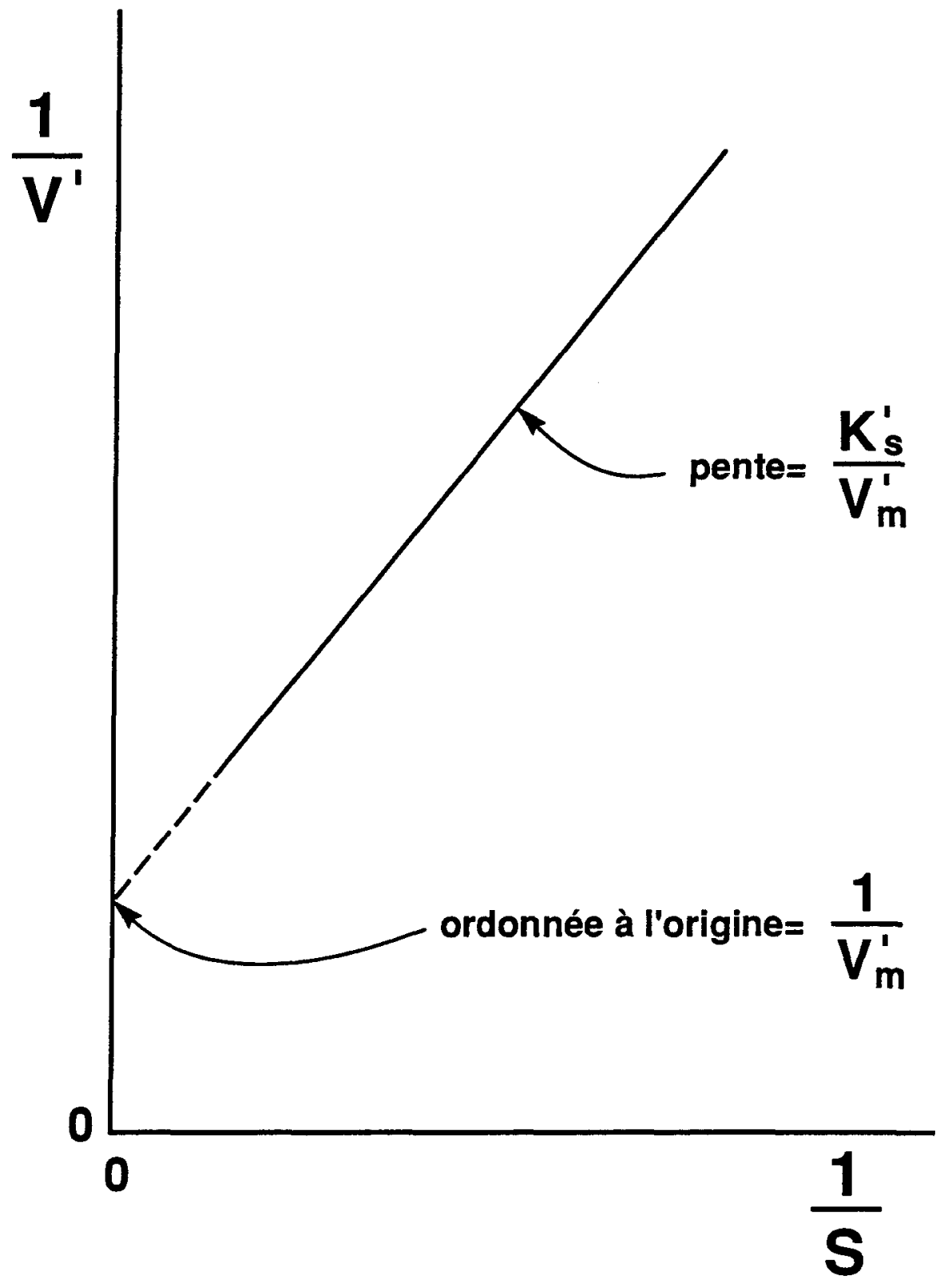

Figure 3: Graphique de Lineweaver - Burk pour le modèle de Michaelis-Menten 
Breezonik, 1972; Couillard, 1987; Sundstrom et Klei, 1979) donne $\frac{K_{S}^{\prime}}{V_{m}^{\prime}}$ comme pente et $\frac{1}{V_{m}^{\prime}}$ comme ordonnée à l'origine. A partir de ces valeurs, il est possible de déduire les constantes cinétiques $K_{S}^{\prime}$ et $V_{m}^{\prime}$.

Plusieurs auteurs dont Iin et al (1987), Cohen et al (1982), ont introduit la concentration en biomasse ( $\mathrm{X}$ ) dans l'équation de Michaelis-Menten (équation (2.1)):

$$
v^{\prime}=-\frac{d s}{d t}=v_{m} \frac{x \cdot s}{k_{s}+s}
$$

ou

$$
\frac{v^{\prime}}{x}=v=v_{m} \cdot \frac{s}{k_{s}+s}
$$

$X$ : concentration en biomasse, masse de bactéries/volume;

$\mathrm{V}$ : vitesse spécifique de biodégradation du substrat, masse de substrat/masse de bactéries-temps;

$v_{m}$ : vitesse spécifique maximale de biodégradation du substrat, masse de substrat/masse de bactéries-temps;

$K_{S}$ : constante, masse de substrat/volume.

L'équation (2.4) peut s'écrire:

$$
\frac{1}{v}=\frac{1}{\left(v^{\prime} / X\right)}=\frac{1}{v_{m}}+\frac{k_{s}}{v_{m}} \cdot \frac{1}{s}
$$

Le graphique de $\frac{1}{\left(V^{\prime} / X\right)}$ ou $\frac{1}{v}$ en fonction de $\frac{1}{s}$

( Lineweaver-Burk) donne $\frac{\mathrm{K}_{\mathrm{S}}}{\mathrm{V}_{\mathrm{m}}}$ comme pente et $\frac{1}{\mathrm{v}_{\mathrm{m}}}$ comme ordonnée 
à l'origine.

Noike et al (1985) ont proposé d'exprimer la vitesse spécifique de la biodégradation du substrat limitant, $v$, par une équation analogue à l'équation établie par Contois (1959) (equation (2.10)).

$$
v=v_{m} \frac{(s / x)}{k_{s}^{\prime \prime}+(s / x)}
$$

$V$ : vitesse spécifique maximale de la biodégradation du substrat, masse de substrat/masse de bactéries-temps; $K_{S}^{\prime \prime}$ : constante, masse de substrat/masse de bactéries.

L'équation (2.5) peut s'écrire:

$$
\frac{1}{v}=\frac{1}{v_{m}}+\frac{K_{S}^{\prime \prime}}{v_{m}^{\prime \prime}} \cdot \frac{1}{(s / x)}
$$

Le graphique $\frac{1}{V}$ en fonction de $\frac{1}{(S / X)}$ donne $\frac{K_{S}^{n}}{v_{m}}$ comme pente et $\frac{1}{v_{m}}$ comme ordonnée à l'origine.

2.2 .2 - Inhibition des réactions enzymatiques

L'activité enzymatique pour un substrat donné peut etre inhibée par la présence de composés toxiques. Il existe 3 types principaux d'inhibitions (Aiba et al., 1965; Bailey et 011 is, 1977; Breezonik, 1972; Scriban, 1984; Sundstrom et Klei, 1979). 
a) Inhibition compétitive

Une inhibition est appelée compétitive lorsque la substance inhibitrice se loge sur le site actif de l'enzyme empechant ainsi la fixation du substrat principal. La réaction ou il $y$ a absence d'inhibition s'écrit:

$$
E+S \rightleftharpoons E S \longrightarrow E+P
$$

s'il $y$ a inhibition compétitive, la réaction suivante s'ajoute:

$$
E+I \rightleftharpoons E I
$$

où $s$ : substrat;

E : enzyme;

ES: complexe actif;

P : produit final de la réaction enzymatique;

EI : complexe inactif.

Si l'on adopte l'équation de Michaelis-Menten (équation (2.1)), pour la représentation de la vitesse de biodégradation d'un substrat, l'augmentation de la concentration d'un inhibiteur competitif augmente la valeur de la constante $\mathrm{K}_{\mathrm{S}}$ mais ne modifie pas la valeur de $V_{m}$ (Breezonik, 1972;

Sundstrom et Klei, 1979).

b) Inhibition incompétitive

C'est une inhibition qui empeche la formation du produit P de la réaction enzymatique, par blocage du complexe actif ES, pour former un nouveau complexe inactif ESI. C'est une inhibition ou il $y$ a competition entre les deux réactions suivantes: 


\section{$E S+I \rightleftharpoons E S I$}

et,

$$
E S \longrightarrow E+P
$$

Pour ce type d'inhibition, l'augmentation de la concentration d'un inhibiteur incompetitif diminue les valeurs des constantes $v_{m}$ et $K_{S}$.

c) Inhibition non competitive

L'inhibition non competitive est a la fois une inhibition competitive et incompetitive. C'est l'inhibition la plus commune (Breezonik, 1972). L'inhibiteur peut se loger sur le site actif de l'enzyme (E) et sur le complexe actif ES, empechant ainsi la formation du produit $P$ de la réaction enzymatique. Les réactions caractéristiques sont les suivantes :

$$
E+I \rightleftharpoons E I
$$

et

$$
\mathrm{ES}+\mathrm{I} \rightleftharpoons \mathrm{ESI}
$$

L'augmentation de la concentration d'un inhibiteur non compétitif ne change pas la valeur de la constante $\mathrm{K}_{\mathrm{S}}$ mais diminue la valeur de $V_{m}$ (Breezonik, 1972; sundstrom et klei, $1979)$.

\subsection{3 - Croissance bactérienne}

D'après la figure 4 (Tchobanoglous, 1979), la croissance bactérienne en fournée (batch) se divise en plusieurs phases (Bailey et ollis, 1977; Couillard, 1987). Tout d'abord, après 
Phase stationnaire

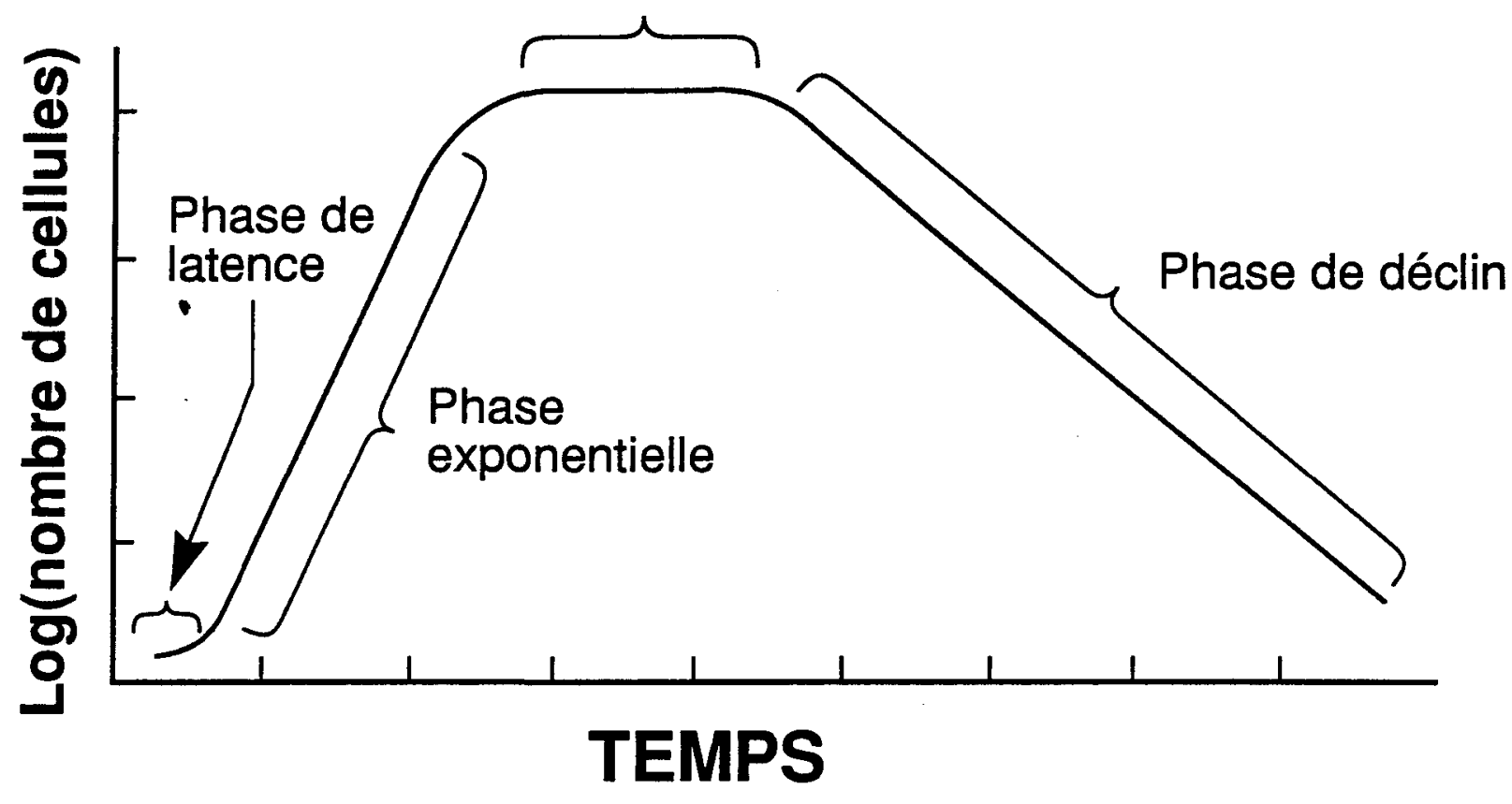

Figure 4: Croissance bactérienne en fonction du temps 
l'ensemencement, il $y$ a une phase, appelée phase de latence ou d'adaptation, dont la durée dépend a la fois de l'acclimatation des bacteries au substrat et de la nature de ce dernier. Au cours de cette premiere phase, les bacteries s'adaptent au milieu en synthétisant les enzymes nécessaires a leur développement. Pendant la phase de croissance exponentielle qui suit, la multiplication des bacteries se fait par division d'une cellule-mere en deux cellules-filles. Au cours de cette phase, la reproduction cellulaire atteint son maximum. Elle est suivie par une phase de ralentissement, puis d'une phase stationnaire pendant laquelle la reproduction des bactéries est égale a leur mortalité. La dernière phase est celle du déclin, durant laquelle le taux de mortalité des cellules excede celui de la reproduction.

\section{2 .4 - Cinétique de croissance bactérienne}

Monod (1942) a proposé d'exprimer la vitesse spécifique de la croissance bactérienne $\mu$, en fonction de la concentration du substrat $s$, par la relation empirique suivante, déduite par analogie avec l'équation (2.1) déjá proposée par Michaelis-Menten.

$$
\frac{d x}{d t} \cdot \frac{1}{x}=\mu=\mu \frac{s}{k_{m}+s}
$$

ou $\mu$ : vitesse spécifique de croissance bactérienne, temps $^{-1}$;

$\mu_{m}$ : vitesse spécifique maximale de croissance bactérienne, temps ${ }^{-1}$; 
$s$ : concentration du substrat limitant, masse de substrat/volume;

$K_{m}$ : constante de Monod, masse de substrat/volume.

L'équation de Monod peut s'écrire:

$$
\frac{1}{\mu}=\frac{1}{\mu_{m}}+\frac{k_{m}}{\mu_{m}} \cdot \frac{1}{s}
$$

Le graphique $\frac{1}{\mu}$ en fonction de $\frac{1}{s}$ donne $\frac{k_{m}}{\mu_{m}}$ comme pente et $\frac{1}{\mu_{m}}$ comme ordonnée à l'origine.

Contois (1959) a introduit la concentration en biomasse (X) dans 1'équation de Monod (équation (2.8)):

$$
\mu=\mu_{m} \frac{(s / X)}{k_{C}+(s / X)}
$$

$\mathrm{X}$ : concentration en biomasse, masse de bactéries/volume; $K_{C}$ : constante de Contois, masse de substrat/masse de bacteries.

L'équation de Contois (2.10) peut s'écrire:

$$
\frac{1}{\mu}=\frac{1}{\mu_{m}}+\frac{k_{C}}{\mu_{m}} \cdot \frac{1}{(s / x)}
$$

Le graphique $\frac{1}{\mu}$ en fonction de $\frac{1}{(s / X)}$ donne $\frac{{ }^{k}{ }}{\mu_{m}}$ comme pente et $\frac{1}{\mu_{m}}$ comme ordonnée à l'origine. 
2.2 .5 - Rendement en biomasse

On définit le rendement en biomasse (Bailey et ollis, 1977) par le rapport entre la masse de bactéries formées et par la masse de substrat consommé. Ce qui s'écrit:

$$
Y=\frac{(\Delta X)}{(\Delta s)}
$$

Sous forme différentielle, l'équation précédente peut s'écrire comme l'a fait Green et al. (1981):

$$
\mathbf{Y}=\frac{\mathrm{dx} / \mathrm{dt}}{-\mathrm{ds} / \mathrm{dt}}
$$

Le rendement en biomasse n'est pas nécessairement constant puisque, chez les bactéries, la consommation de substrat sert a trois fonctions: assimilation pour production de biomasse, production d'énergie pour les syntheses et production d'énergie pour la survie des bacteries. 


\title{
CHAP I TRE I I I
}

\author{
CARACTER ISATION DES EFFLUENTS D'UNE USINE DE \\ PATES ET PAPIERS THERMOMECANIOUES ET CHOIX DE L'EAU
}

RESIDUAIRE SYNTHETIOUE

Le procédé papetier thermomécanique (PTM) peut être décrit sommairement de la manière suivante (Annexe B): les copeaux de bois sont conditionnés dans une chambre de préchauffage sous pression, afin de les ramollir et faciliter ainsi leur défibrage dans le raffineur. Contrairement aux procédés chimiques, le procédé thermomécanique ne fait appel à aucun agent chimique.

\section{1 - Caractérisation de l'effluent thermomécanique}

Pour comprendre l'origine des composés chimiques se trouvant dans les eaux résiduaires PTM, il est nécessaire de connaitre à la fois la composition du bois et les procédés de defibrage.

Le bois est constitué principalement de trois groupes d'éléments chimiques (Annexe A), soient les hyarates de carbone (hémicellulose et cellulose), la lignine et les extraits de bois (McCubbin, 1984d). Ces composés se retrouvent dans les effluents d'usines papetières thermomécaniques. Les divers procédés de défibrage (mécanique, chimique et mi-chimique) produisent des effluents de composition différente (Couillard, 1979). Ainsi, la lignine et l'hémicellulose sont en plus grande concentration dans les effluents des procédés de défibrage chimique (faible rendement) que dans ceux des procédés de défibrage mécanique (haut rendement). 
La principale raison est que dans les procédés de défibrage chimique, tel le procédé Kraft, la lignine et l'hémicellulose sont dissoutes par des réactifs chimiques, pour ne laisser gue des fibres cellulosiques souples. Les procédés mécaniques sont, par contre, des procédés brutaux qui arrachent les composantes du bois; la majeure partie de la lignine et une bonne partie des hémicelluloses restent liées aux fibres (McCubbin, 1984b).

La composition chimique des eaux résiduaires PTM est identique a celle des effluents du procédé mécanique traditionnel. Cependant, la charge en terme de $\mathrm{DBO}_{5}$ et de DCO est supérieure dans le cas du procédé PTM à cause de la plus grande solubilisation des composés du bois (stenberg et Norberg, 1977). D'une maniére générale, la charge polluante des effluents papetiers dépend du procéde de raffinage; elle est inversement proportionnelle au rendement en pate du procédé. Les procédés chimiques qui ont un faible rendement ont une décharge en terme de $\mathrm{DBO}_{5}$ supérieure a celle des procédés mécaniques à haut rendement (Couillard, 1979; stenberg et Norberg, 1977). Le procédé mécanique, qui a un rendement de $91 \%$ à $95 \%$, ne génère dans les eaux résiduaires que 5\% a 98 du bois introduit dans le raffineur, alors que le procéde Kraft qui a un rendement de $43 \%$ a $48 \%$ (McCubbin, 1984b) génère dans l'effluent $53 \%$ a $57 \%$ du bois introduit dans le raffineur.

La charge polluante des effluents d'usines papetieres thermomécaniques rapportée dans la littérature (Beak Consultants, 1988; Ferguson et al., 1985; Servizi et Gordon, 1986; Shere et Daly, 1982; Stenberg et Norberg, 1977; Thurley et Richardson, 1978; 
Webb, 1984; Welander et Anderson, 1985; Wong, 1977) differe selon les usines papetières et varie même a l'intérieur d'une même usine. Ceci est causé par plusieurs variables qui peuvent avoir un effet sur la variation de la charge polluante des effluents PTM. En effet, la consommation en eau influence grandement la $\mathrm{DBO}_{5}$ et la DCo des effluents papetiers (Ferguson et al., 1985). Une grande consommation en eau dilue considérablement la charge polluante des eaux résiduaires. Pour le procédé thermomécanique, la pression (Jansson et Back, 1975) et la temperature (stenberg et Norberg, 1977) influencent la concentration en matieres organiques des eaux résiduaires PTM. Les augmentations de la pression et de la température entrainent une diminution du rendement en pate et, par conséquent, une augmentation de la charge polluante de l'effluent.

Pendant le procédé de défibrage thermomécanique (PTM), les fibres de bois et une partie de la lignine (Klason-lignine), sont résistantes à l'hydrolyse durant le raffinage (Jansson et Back, 1975). Ces matieres organiques de haut poids moleculaire sont souvent sous forme de fibres en suspension qui peuvent etre éliminées par décantation (McCubbin, 1984c). Contrairement aux fibres cellulosiques et a la lignine, l'hémicellulose est facilement hydrolysée et solubilisée sous l'effet de la température et de la pression, pendant le procédé de défibrage PTM (Jansson et Back, 1975). Les hydrates de carbone (cellulose et hémicellulose) qui sont composés de polysaccharides a différents degrés de polymérisation, constituent la majeure partie de la $\mathrm{DBO}_{5}$ 
(Ferguson et al., 1985). La cellulose (figure 5) est un polymere du glucose, de degré de polymérisation élevé. I'hémicellulose est composée principalement de deux groupes de polysaccharides (Jansson et Back, 1975), soit les xylanes et les glucomannanes (figures 6 et 7). La composition des xylanes et des glucomannanes dans le bois est respectivement de $40 \%$ et $60 \%$ dans le bois tendre et de $90 \%$ et $10 \%$ dans le bois dur (Jansson et Back, 1975). Les effluents PTM peuvent contenir des monosaccharides provenant directement du bois ou de l'hydrolyse de l'hémicellulose durant les procédés de raffinage. C'est principalement l'arabinose (monosaccharide) qui est présente dans les eaux résiduaires PTM à cause de la faible liaison latérale mannose-arabinose dans les xylanes (Jansson et Back, 1975). Les polysaccharides et les monosaccharides ne participent pas a la demande biochimique en oxygene de manière identique. En effet, la $\mathrm{DBO}_{5}$ calculee par unité de masse est plus élevée pour les monosaccharides que pour les polymeres correspondant (Larsson et al., 1975). Durant le procédé de défibrage thermomécanique, 4 a $11 \mathrm{~kg}$ de lignine (figure 8 ) par tonne de pate se dissolvent dans l'effluent causant une grande augmentation de la DCO et une très faible variation de la ${ }^{\mathrm{DBO}_{5}}$ (Salkinoja-Salonen et al., 1984). 


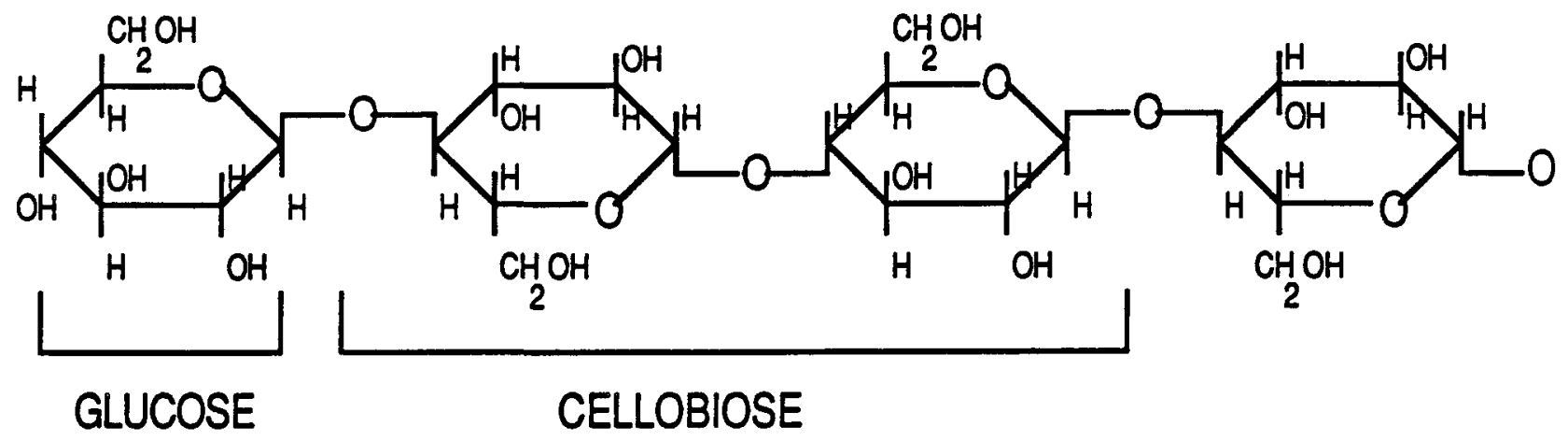

Figure 5 : Chaine de cellulose

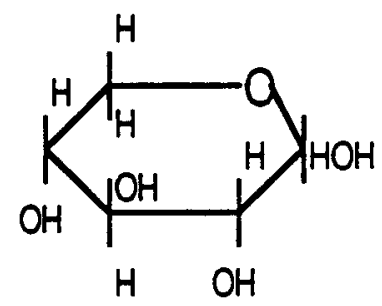

XYLOSE(X)

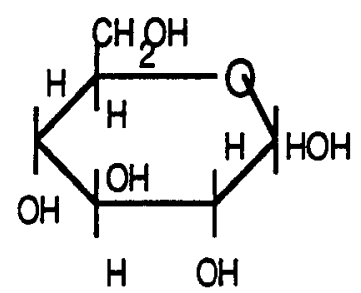

Glucose(G)

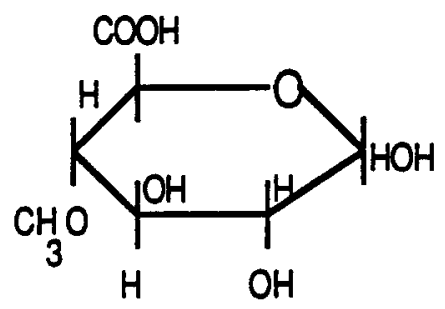

ACIDE METHYLGLUCURONIQUE(GU)

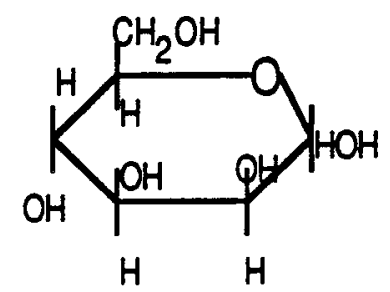

Mannose (M)

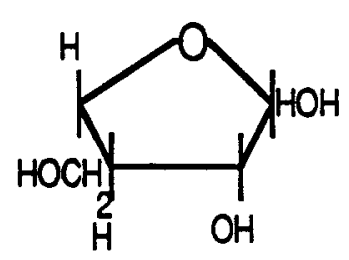

ARABINOSE(A)

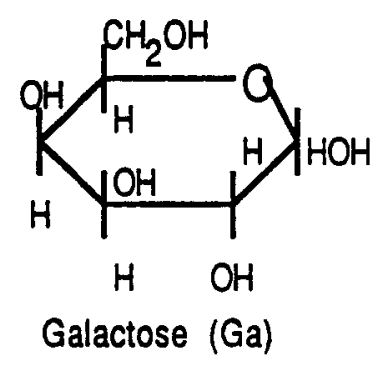

Figure 6 : Principaux constituants des hémicelluloses 
a- Xylanes
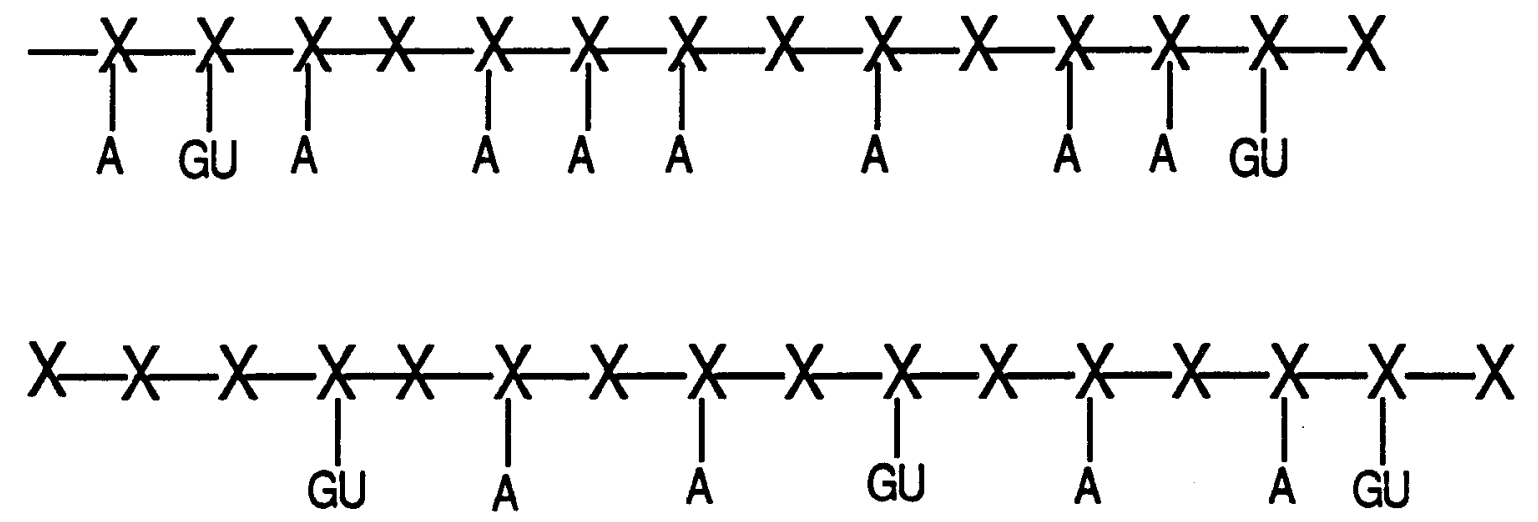

b- Glucomannanes

$M-M-G-M-G-M-M-M-M-G-M-M-G-M-$

$M-M-G-M-G-G-M-M-G-M-M-G-M-G-M-M$

FIGURE 7: Structure des hémicelluloses 


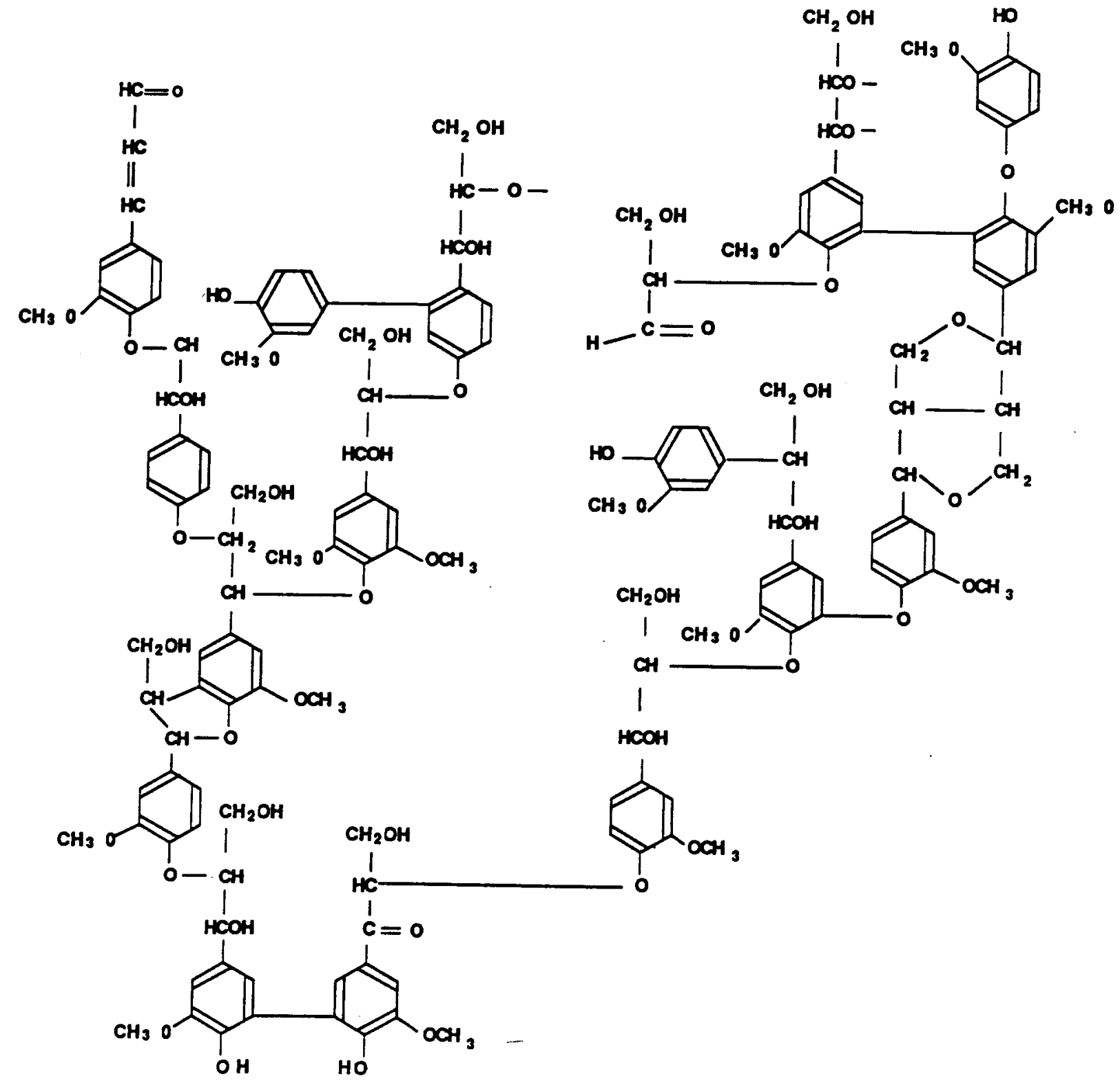

Figure 8: Structure de la lignine 
Leach et Thakore (1975) ont identifié les produits toxiques des eaux résiduaires PTM. Ils ont trouvé que 60 a $90 \%$ de la toxicité est due a la fraction acide de l'effluent qui est constituée principalement des acides résiniques (figure 9) et a un degré moindre, des acides gras. Les acides résiniques se trouvent essentiellement dans le bois tendre (Junna et al., 1982). Les acides résiniques ainsi que les autres extraits du bois, tels les acides gras, sont solubilisés durant le procédé de raffinage thermomécanique a cause de la haute temperature (Mcleay, 1987 ). Dans les effluents PTM, les acides résiniques les p'lus présents sont les acides déshydroabietique et abiétique (tableau I). D'après le tableau I, les acides résiniques dans les eaux résiduaires PTM sont souvent en concentration supérieure au $\mathrm{CL}_{50^{-}} 96 \mathrm{H}$ (concentration de produit chimique capable de tuer $50 \%$ des poissons en 96 heures), ce qui requiert un traitement de ces eaux avant leur déversement dans le milieu récepteur.

Les acides gras sont moins toxiques pour les poissons que les acides résiniques (Ferguson et al., 1985). La plupart des acides gras sont saturés, chaque molécule contenant $16,18,20,22$ ou 24 atomes de carbone. Les symboles (premier chiffre équivaut au nombre de carbone et le deuxième au nombre d'insaturation) correspondants à ces différents acides gras saturés sont: 16:0 (acide palmitique), 18:0 (acide stéarique), 20:0 (acide arachidique), 22:0 (acide béhénique) et 24:0 (acide 1ignocétique). Les acides insaturés identifiés sont: l'acide oléique (18:1), 
<smiles>CC(C)C1=CC2=CCC3C(C)(C(=O)O)CCCC3(C)C2CC1</smiles>

ACIDE ABIETIQUE<smiles>CC(C)=C1C=C2CCC3C(C)(C(=O)O)CCCC3(C)C2CC1</smiles>

ACIDE NEOABIETIQUE<smiles>C=C(C)C1(C)CCC2C(=CCC3C(C)(C(=O)O)CCCC23C)C1</smiles>

ACIDE ISOPIMARIQUE<smiles>CC(C)c1ccc2c(c1)CCC1C(C)(C(=O)O)CCCC21C</smiles>

ACIDE DEHYDROABIETIQUE<smiles>CC(C)C1=CCC2C(=C1)CCC1C(C)(C(=O)O)CCCC21C</smiles>

ACIDE LEVOPIMARIQUE

Figure 9: Structure des acides résiniques (B.C. Reasearch,1973) 
Tableau I Toxicité et concentration des acides résiniques dans les effluents non traités du procédé papetier thermomécanique.

\begin{tabular}{|l|c|c|}
\hline \multicolumn{1}{|c|}{ Acide } & $\begin{array}{c}\mathrm{CL}_{50}-96 \mathrm{H}^{\mathrm{m}, \mathrm{a}} \\
\mathrm{mg} / \mathrm{L}\end{array}$ & $\begin{array}{c}\mathrm{PTM}^{\mathrm{b}} \\
\mathrm{mg} / \mathrm{L}\end{array}$ \\
\hline Abiétique & 0.7 a 1.5 & 4.21 \\
Déshydroabiétique & 0.8 a 1.74 & 5.33 \\
Isopimarique & 0.4 a 1.0 & 2.41 \\
Lévopimarique & 0.7 a 1.0 & 2.24 \\
Néoabiétique & 0.61 a 0.73 & ---- \\
Pimarique & 0.7 a 1.2 & 2.23 \\
Sandaracopimarique & 0.36 & 0.65 \\
& & \\
\hline
\end{tabular}

m: Concentration létale médiane pour la truite arc-en-ciel dans un test biologique non renouvelé.

a: McLeay et al., 1987

b: Servizi et al., 1986 
l'acide linolérque $(18: 2)$ et l'acide linolénique $(18: 3)$. Les acides gras insaturés sont plus toxiques que ceux saturés; leur toxicité $\left(\mathrm{CL}_{50}-96 \mathrm{H}\right)$ pouvant atteindre 8 à $9 \mathrm{mg} / \mathrm{L}$ comparativement a une $\mathrm{CL}_{50}-96 \mathrm{H}$ supérieure a $20 \mathrm{mg} / \mathrm{L}$ pour les acides gras saturés (Junna et a1, 1982).

La concentration en azote et en phosphore des effluents PTM est trop basse pour supporter une croissance optimale des bactéries lors des traitements biologiques secondaires (Ferguson et al., 1985; Salkinoja-Solonen et al., 1984).

3.2 - Choix de l'eau résiduaire synthétique

L'avantage d'utiliser une eau résiduaire synthétique est de pouvoir varier indépendamment les concentrations des diverses composantes de la solution. Une eau résiduaire synthétique facilite aussi l'analyse chimique et permet de vérifier l'effet de la variation de la concentration de chaque constituant sur la toxicité et la traitabilité de la solution.

L'eau résiduaire synthétique choisie est constituée de deux composés majeurs: le premier est la xylane qui représente la partie biodégradable des eaux résiduaires PTM, le second est l'acide déshydroabiétique, représentant la partie toxique. L'hémicellulose est le composé du bois qui.se dissout facilement dans les eaux résiduaires du procédé papetier thermomécanique à cause de sa faible résistance à l'hydrolyse durant le procédé de raffinage PTM (paragraphee 3.1). L'hémicellulose, comme décrit au paragraphe 3.1 , est composée principalement des xylanes et des glucomannanes. Etant donné que les glucomannanes ne sont pas 
disponibles commercialement, les xylanes sont choisies pour la composition de l'eau résiduaire synthétique.

Les acides résiniques sont les composés chimiques du bois qui sont responsables de la majeure partie de la toxicité des eaux résiduaires du procédé papetier thermomécanique (paragraphe 3.1) L'acide déshydroabiétique est l'acide résinique qui se retrouve en plus grande concentration dans les effluents PTM, il est aussi très toxique (tableau I). 


\section{CHAP I TRE IV}

\section{MATERIEL ET METHODES EXPERIMENTALES}

\subsection{Préparation des eaux résiduaires synthétiques}

Une solution concentrée de xylane est préparée, puis réfrigérée a $4^{\circ} \mathrm{C}$ jusqu'a son utilisation. Pour préparer cette solution, $12 \mathrm{~g}$ de xylane par litre d'eau sont traités dans un autoclave (autoclave Engineers Inc.). Les conditions de température et de pression de l'autoclave sont identiques à celles existantes lors du défibrage des copeaux de bois dans le procédé thermomécanique (Annexe B), soient $120^{\circ} \mathrm{C}$ et $150 \mathrm{kPa}$.

L'acide déshydroabiétique qui représente la partie toxique des eaux résiduaires du procédé papetier thermomécanique est très peu soluble dans l'eau; il est solubilisé dans le méthanol avant d'etre introduit dans la solution de xylane. Les échantillons sont inoculés selon la méthode décrite dans le paragraphe 4.2. Les solutions finales d'eau usée synthétique et leurs concentrations sont décrites dans le tableau II. Des solutions d'eau usée synthétique de différentes concentrations de xylane $(910,2270$ et $4550 \mathrm{mg} / \mathrm{L})$ et d'acide déshydroabietique $(0,5,40,100$ et $200 \mathrm{mg} / \mathrm{L})$ sont préparées (Tableau II) pour montrer l'effet de la variation de la concentration de ces produits sur la digestion anaérobie des solutions synthétiques traités. 
Tableau II Echantillons à traiter par anaérobiose, leurs compositions et leurs DCO initiales mesurées expérimentalement

\begin{tabular}{|c|c|c|}
\hline Solution & Composition & $\begin{array}{l}\mathrm{DCO} \\
\mathrm{mg} / \mathrm{L}\end{array}$ \\
\hline$x_{1}$ & $910 \mathrm{mg} / \mathrm{L}$ de xylane & 1000 \\
\hline $\mathrm{x}_{2}$ & $2270 \mathrm{mg} / \mathrm{L}$ de $x y l a n e$ & 2500 \\
\hline$x_{3}$ & $4550 \mathrm{mg} / \mathrm{L}$ de xylane & 5000 \\
\hline A & $547 \mathrm{mg} / \mathrm{L}$ de méthanol & 800 \\
\hline B & $\begin{array}{l}547 \mathrm{mg} / \mathrm{L} \text { de méthanol et } \\
2270 \mathrm{mg} / \mathrm{L} \text { de xylane }\end{array}$ & 3300 \\
\hline C & $\begin{array}{l}\text { solution } \mathrm{B}+5 \mathrm{mg} / \mathrm{L} \text { d'acide } \\
\text { déshydroabiétique }\end{array}$ & 3315 \\
\hline$D$ & $\begin{array}{l}\text { solution } B+40 \mathrm{mg} / \mathrm{L} \text { d'acide } \\
\text { déshydroabiétique }\end{array}$ & 3415 \\
\hline $\mathbf{E}$ & $\begin{array}{l}\text { solution } B+100 \mathrm{mg} / L \text { d'acide } \\
\text { déshydroabiétique }\end{array}$ & 3570 \\
\hline $\mathbf{F}$ & $\begin{array}{l}\text { solution } B+200 \mathrm{mg} / \mathrm{L} \text { d'acide } \\
\text { déshydroabiétique }\end{array}$ & 3850 \\
\hline G & $\begin{array}{l}547 \mathrm{mg} / \mathrm{L} \text { de méthanol et } \\
4550 \mathrm{mg} / \mathrm{L} \text { de xylane }\end{array}$ & 5790 \\
\hline$H$ & $\begin{array}{l}\text { solution } \mathrm{G}+5 \mathrm{mg} / \mathrm{L} \text { d'acide } \\
\text { déshydroabiétique }\end{array}$ & 5800 \\
\hline$I$ & $\begin{array}{l}\text { solution } \mathrm{G}+40 \mathrm{mg} / \mathrm{L} \text { d'acide } \\
\text { déshydroabiétique }\end{array}$ & 5900 \\
\hline $\mathrm{J}$ & $\begin{array}{l}\text { solution } \mathrm{G}+100 \mathrm{mg} / \mathrm{L} \text { d'acide } \\
\text { déshydroabiétique }\end{array}$ & 6070 \\
\hline K & $\begin{array}{l}\text { solution } G+200 \mathrm{mg} / \mathrm{L} \text { d'acide } \\
\text { déshydroabiétique }\end{array}$ & 6340 \\
\hline
\end{tabular}


4.2 - Inoculation

La culture mixte de bactéries anaérobies a été prélevée de l'usine de digestion des boues municipales de la ville de DeuxMontagnes (Québec). Elle a été conservée à $4^{\circ} \mathrm{C}$ jusqu'à son utilisation.

L'inoculation des solutions d'eau usée synthétique a traiter par voie anaérobie est réalisée dans des bouteilles de sérum de $160 \mathrm{~mL}$ selon la méthode décrite par Cornacchio et al. (1986). Des solutions concentrees en nutriment sont utilisées pour la préparation du milieú nutritif des bactéries anaérobies (tableau III). Ces solutions sont conservées à $4^{\circ} \mathrm{C}$. La journée même de l'inoculation, le milieu nutritif est préparé selon le tableau IV. La culture mixte de bactéries anaérobies, l'échantillon d'eau usée synthétique a traiter et le milieu nutritif sont amenés a $37^{\circ} \mathrm{C}$. Avant de procéder aux essais de la digestion anaérobie, le pH des échantillons est ajusté a 6.7 à l'aide d'une solution concentrée d'hydroxyde de sodium. L'inoculation est réalisée sous atmosphere d'azote, afin de maintenir un milieu anaérobie (figure 10). Après barbotage d'azote pendant $10 \mathrm{~min}$. dans les différentes solutions, nous avons mélangé dans chaque bouteille de sérum, $33 \mathrm{~mL}$ d'échantillon, $0.4 \mathrm{~mL}$ du milieu nutritif, $34 \mathrm{mg}$ de bicarbonate de sodium, $0.5 \mathrm{~mL}$ de la solution de $\mathrm{Na}_{2} \mathrm{~s}$ et $8 \mathrm{~mL}$ de de la culture mixte. Un bouchon de caoutchouc est inséré dans les bouteilles de sérum en même temps que le tube d'alimentation en azote est retiré. Les bouteilles sont ensuite encapsulees puis mises dans un bain 
Tableau III solutions concentrées pour la préparation du milieu de croissance des bactéries anaérobies

\begin{tabular}{|c|c|c|}
\hline Solution & Composé chimique & $\begin{array}{l}\text { Concentration dans } \\
\text { 'eau distillee, g/L }\end{array}$ \\
\hline $\begin{array}{l}s_{1}(1) \\
s_{2}(2) \\
s_{3}(2) \\
s_{4}(3) \\
s_{5}(3)\end{array}$ & 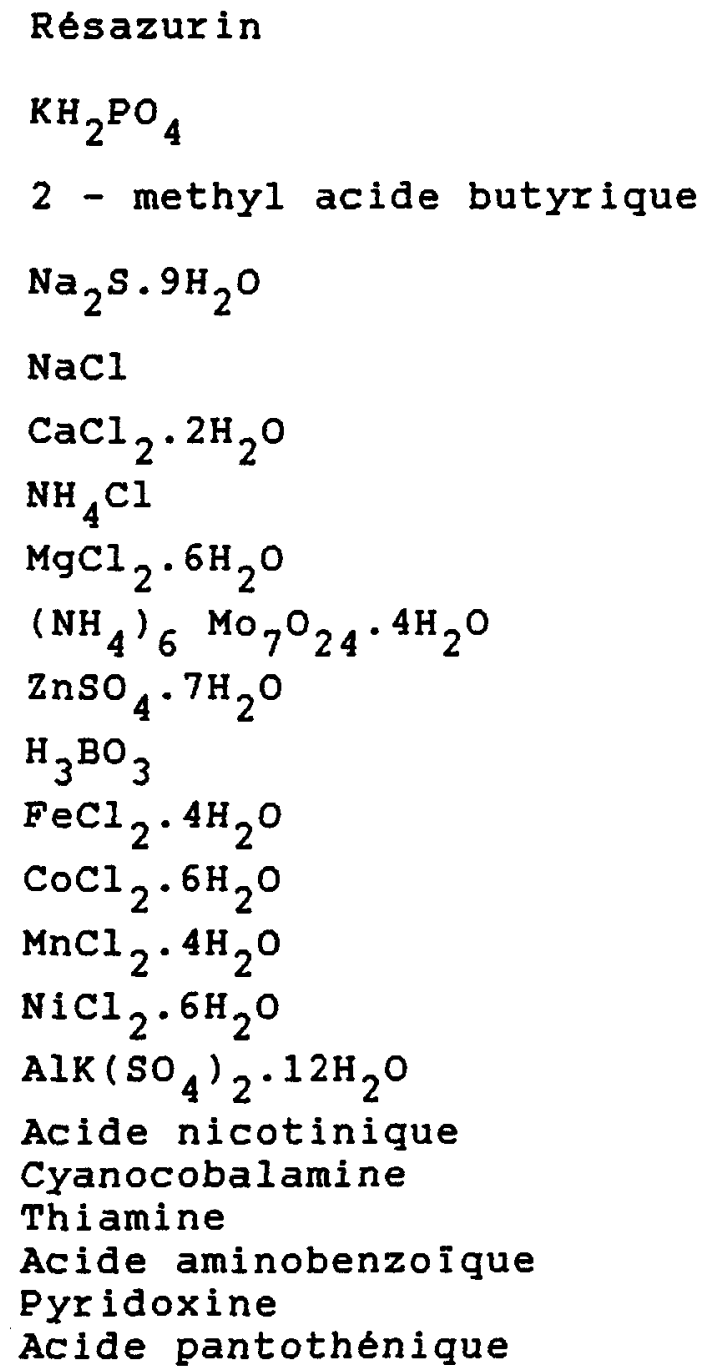 & $\begin{array}{c}0.1 \\
50.0 \\
102.0 \\
25.0 \\
50.0 \\
10.0 \\
189.4 \\
10.0 \\
10.0 \\
0.1 \\
0.3 \\
1.5 \\
10.0 \\
0.03 \\
0.03 \\
0.1 \\
0.1 \\
0.1 \\
0.05 \\
0.05 \\
0.25 \\
0.025\end{array}$ \\
\hline
\end{tabular}

(1) Préparer en petite quantité dans l'eau bouillante juste avant son utilisation.

(2) Ajusté à un $\mathrm{pH}=6.5$ à l'aide de $\mathrm{NaOH}$ IN.

(3) Dissout dans HCl $0.01 \mathrm{M}$ 
Tableau IV: Composition du milieu nutritif

\begin{tabular}{|cc|}
\hline Solution & $\substack{\text { Volume } \\
\text { mL }}$ \\
\hline$s_{1}$ & 15.0 \\
$s_{2}$ & 10.0 \\
$s_{3}$ & 1.0 \\
$s_{5}$ & 10.0 \\
$s_{6}$ & 1.0 \\
$s_{7}$ & 1.0 \\
\hline
\end{tabular}




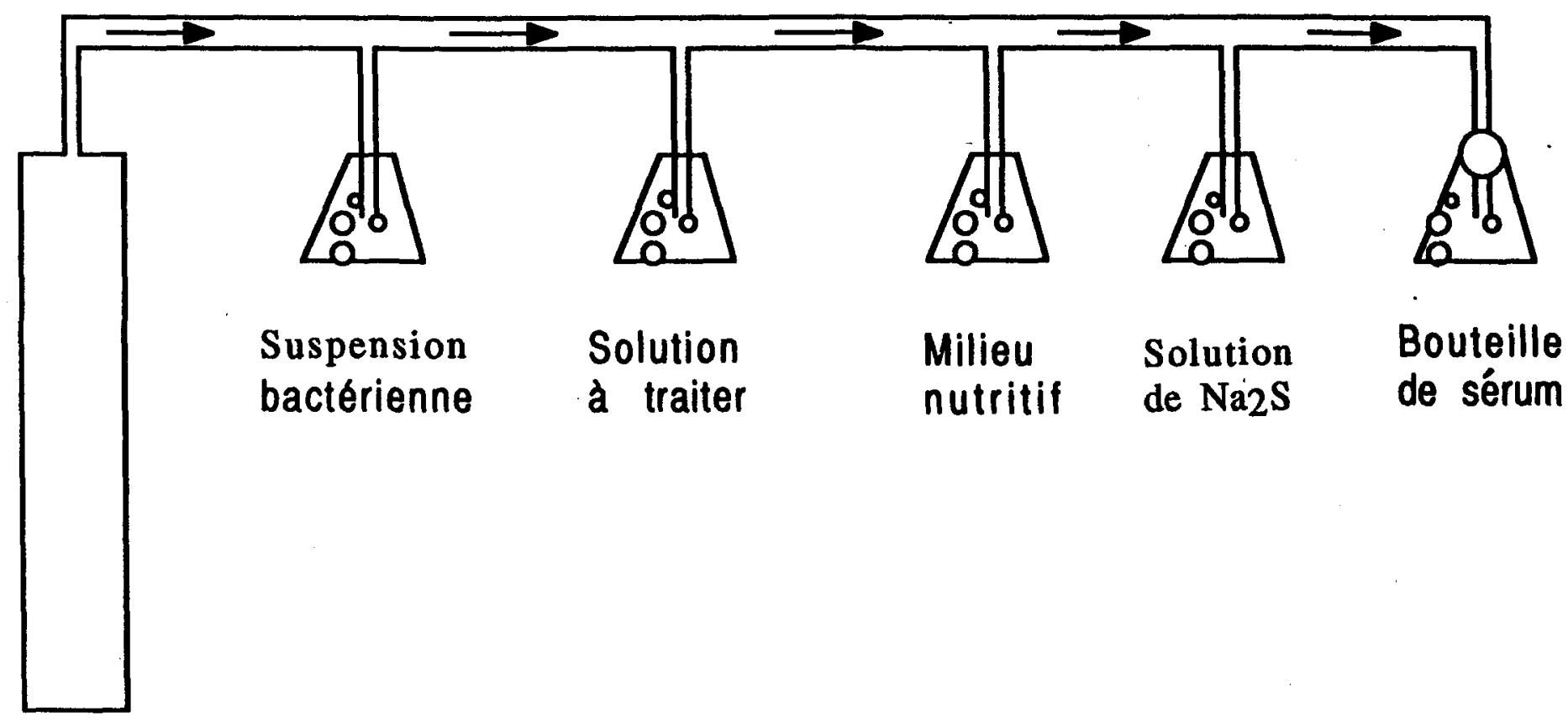

Azote

Figure 10: Schéma de l'inoculation anaérobie 
d'eau a $37^{\circ}$. Les bouteilles sont agitées mécaniquement (environ $20 \mathrm{rpm})$. Après $45 \mathrm{~min}$. d'incubation, la pression dans les bouteilles est équilibrée avec la pression atmosphérique en introduisant l'aiguille d'une seringue a travers le bouchon de caoutchouc de chaque bouteille. Le surplus de pression est alors évacué.

Lors des essais de traitabilité des eaux résiduaires synthétiques, le volume cumulatif de biogaz produit est mesuré, selon la méthode décrite au paragraphe 4.5 , chaque jour durant la premiere semaine de la digestion, puis de 2 a 3 fois par semaine jusqu'a la fin du traitement. Quand la production du biogaz cesse, la DCO est mesurée selon la méthode décrite dans le paragraphe 4.3.

Apress un premier traitement (premier passage) d'environ 5 a 6 jours lors de l'acclimatation des bactéries anaérobies aux différentes solutions d'eau usée synthétique, la DCo, la concentration en xylane et en acide déshydroabiétique sont dosées selon les méthodes décrites aux paragraphes $4.3,4.8$ et 4.9 respectivement. La quantité de méthanol biodégradé est déterminée en mesurant la DCO, avant et après traitement, d'un témoin composé uniquement de méthanol. Le témoin a la méme concentration initiale en méthanol que l'eau usée synthétique. Une partie des solutions synthétiques traitées est remplacée, sous atmosphère d'azote (figure 10), de manière à retrouver les concentrations initiales décrites au tableau II. De la même façon que pour le premier traitement (premier passage), $0.4 \mathrm{~mL}$ du milieu nutritif, $34 \mathrm{mg}$ de bicarbonate de sodium et $0.5 \mathrm{~mL}$ de $\mathrm{Na}_{2} \mathrm{~s}$ sont ajoutés pendant le 
remplacement de la solution synthétique. Les bouteilles sont ensuite encapsulées et un deuxième traitement ( 2 ième passage) débute. Après 45 min. d'incubation, la pression dans les bouteilles est équilibrée avec la pression atmosphérique. Avant chaque traitement (passage), et jusqu'à acclimatation des bactéries anaérobies aux différentes solutions, une partie des eaux résiduaires synthétiques est remplacée, de la méme façon que pour le deuxième passage, de manière a retrouver les concentrations initiales décrites au tableau II.

A chaque traitement d'acclimatation (passage), deux bouteilles ne subissent pas de remplacement de solutions synthétiques. Les eaux résiduaires dans ces bouteilles sont traitées jusqu'à arret de production de biogaz (et non pendant 5 a 6 jours). Ces bouteilles serviront à composer le volume cumulatif de biogaz produit, pour chaque solution synthétique, lors de chaque passage d'acclimatation (figures 14 à 19). Lorsque le volume cumulatif de biogaz produit pendant le traitement des solutions synthétiques varie peu après 2 passages successifs, les bactéries sont acclimatées à ces solutions.

\section{3 - Demande chimigue en oxygène}

La demande chimique en oxygène (DCO) représente les composés chimiques contenus dans l'échantilion d'eau usée synthétique à traiter qui sont susceptibles d'etre oxydés. Le bichromate de potassium est utilisé lors de la mesure de la DCO; ce composé est préféré aux autres composés chimiques à cause de son grand pouvoir oxydant. Le principe de la mesure de la DCo est le suivant: 
le dichromate de potassium qui contient initialement du chrome hexavalent $\left(\mathrm{Cr}^{6+}\right.$ ) est de couleur jaune. Lorsqu'il est en contact avec des produits chimiques oxydables, il y a formation d'ions trivalents $\mathrm{Cr}^{3+}$ selon la réaction:

$$
\text { matiere organique }+\mathrm{Cr}_{2} \mathrm{O}_{7}^{2-} \longrightarrow \mathrm{CO}_{2}+\mathrm{H}_{2} \mathrm{O}+\mathrm{Cr}_{2} \mathrm{O}_{4}^{2-}
$$

Les ions trivalents correspondant à la forme réduite du bichromate de potassium, donnent une coloration verte a la solution. La quantité de chrome trivalent apparaissant, correspond a la quantité de bichromate de potassium consommée par l'oxydation des substances organiques et, par conséquent, a la demande chimique en oxygène (DCO). La quantité de bichromate de potassium consommée est calculée après dosage volumétrique à l'aide d'une solution de sulfate d'ammonium ferreux, en utilisant le phénanthroline comme indicateur de couleur. Toutes les mesures de la DCo ont été faites sur des échantillons filtrés (filtre wathman approprié) et déterminées selon la méthode décrite dans le "standard Methods", section 508A (APHA - AWWA - WPCF, 1980).

\section{$4.4-\underline{\mathrm{pH}}$}

Toutes les mesures de $\mathrm{pH}$ ont été réalisées à l'aide d'un pHmetre Fisher 320. La calibration du pH-metre est faite a la temperature de la piece en utilisant une solution tampon de $\mathrm{pH}=7$, puis une autre solution tampon de $\mathrm{pH}=4$.

\section{5 - Volume du biogaz}

La quantité de biogaz produite dans chaque bouteille de sérum est mesurée en introduisant l'aiguille d'une seringue Becton- 
Dikinson 10cc à travers le bouchon de caoutchouc. Lors de la mesure, la seringue est maintenue droite et le piston se déplace sous l'effet de l'évacuation du biogaz. La lecture est vérifiée en tirant le piston de la seringue jusqu'a dépasser le point d'équilibre: en lachant le piston, ce dernier revient a la position d'équilibre.

\section{6 - Analyse du biogaz}

Le biogaz produit pendant la digestion anaérobie est analysé dans un chromatographe VARIAN 3400 muni d'un détecteur à conductivité thermique (TCD). Le detecteur est relié a un intégrateur VARIAN 4270. Les conditions expérimentales d'analyse du biogaz sont décrites au tableau $v$. Le principe du fonctionnement d'un détecteur à conductivité thermique peut être résumé comme suit: un courant de gaz porteur circule dans le filament du détecteur; le voltage est alors ajusté a environ omv par un pont potentiometrique, ce qui correspond a la ligne de base sur l'intégrateur; après injection de $500 \mu L$ de biogaz a l'aide d'une seringue Hamilton, le potentiometre, relié au détecteur, enregistre une variation de voltage; cette variation est transmise a lintégrateur qui la traduit par un pic dont la surface est proportionnelle à la concentration du gaz.

La méthode d'analyse choisie est celle du standard interne. La calibration consiste a injecter séparément des échantillons de méthane et de bioxyde de carbone de concentrations connues, permet- 
Tableau $V$ Conditions experimentales du biogaz par chromatographie gazeuse.

Chromatographe

Détecteur

Colonne *

Volume d'injection

Température d'injection

Temperature de la colonne

Température du détecteur

Gaz porteur

Débit du gaz porteur

Atténuation

* Chromatographic specialties
Varian 3400

Conductivité thermique (TCD)

Haye sept

$0.5 \mathrm{~mL}$

$32^{\circ} \mathrm{C}$

$32^{\circ} \mathrm{C}$

$50^{\circ} \mathrm{C}$

Hélium

$30 \mathrm{~mL} / \mathrm{min}$.

8 
tant ainsi d'évaluer le facteur de réponse $R F_{i}$ :

$$
R F_{i}=\frac{A_{i}}{C_{i}}
$$

$\mathrm{RF}_{\mathrm{i}}$ : Facteur de réponse du gaz i $A_{i}:$ Surface sous le pic du gaz $i$ $C_{i}$ : Quantité du gaz i (en pourcentage)

Après injection du biogaz de concentration inconnue, la quantité $c_{i}$ de chaque composé de ce biogaz est trouvée par:

$$
C_{i}=\frac{A_{i}}{R F_{i}}
$$

La valeur de $c_{i}$ est exprimée dans les mémes unités que celles utilisees lors de la calibration (pourcentage). La valeur de $C_{i}$ est donnée directement par l'intégrateur.

\section{7 - Concentration bactérienne}

La concentration bactérienne est calculée selon la méthode des solides suspendus, decrite dans le "standard Methods" à la section 209 (APHA - WPCF, 1980). Un creuset contenant un volume connu (10 $\mathrm{mL}$ d'échantillon est séché à $103^{\circ} \mathrm{C}$ dans un four Gallenkamp ov-160 pendant au moins une heure. Le creuset est ensuite refroidi dans un dissicateur à la température de la pièce $\left(\approx 22^{\circ} \mathrm{C}\right)$. Il est ensuite pesé à l'aide d'une balance Gram-atic (Fisher), puis de nouveau mis dans le four a $103^{\circ} \mathrm{C}$ pendant environ $20 \mathrm{~min}$. Ce cycle se répetera jusqu'a l'obtention d'une variation de masse entre deux pesées inférieure à 4\%. Le creuset est ensuite mis dans un four Gallenkamp $F R-520$ a $550^{\circ} \mathrm{C}$ pendant environ $20 \mathrm{~min}$, ensuite il est 
refroidi et pesé de la même façon que plus haut, jusqu'à obtenir une variation de masse inférieure à 4\%. La quantité de masse disparue entre le séchage à 103 et $550^{\circ} \mathrm{C}$ représente la matière organique viable, non-viable et inerte. Dans notre cas, la matière organique inerte se trouvant dans les echantilions, est composée de sucre et/ou d'acide déshydroabietique et de ses métabolites. Le méthanol qui est évaporé a une température inférieure à $103^{\circ} \mathrm{C}$, ne fait pas partie de la matiere organique inerte disparue entre le séchage à $103^{\circ} \mathrm{C}$ et à $550^{\circ} \mathrm{C}$. La quantité résiduelle de sucre et d'acide déshydroabiétique peut etre dosée selon les méthodes décrites dans les paragraphes 4.8 et 4.9 . Après soustraction de la masse résiduelle de xylanes et d'acide déshydroabiétique de la masse organique totale, trouvée après séchage a $550^{\circ} \mathrm{C}$, on obtient une mesure de la matiere organique viable et non-viable.

\section{8 - Analyse des hydrates de carbone}

Les hydrates de carbone sont dosés selon la méthode standard décrite par Herbert et al. (1971). La méthode est la suivante: $1 \mathrm{~mL}$ de phénol à $5 \%$ et $5 \mathrm{~mL}$ d'acide sulphurique concentré sont ajoutés à $1 \mathrm{~mL}$ de solutions standards contenant des quantités de glucose connues variant entre 0 et $100 \mu \mathrm{g}$. Les solutions sont mélangées vigoureusement pendant $10 \mathrm{min.}$, puis placées dans un bain d'eau a $30^{\circ} \mathrm{C}$ pendant $20 \mathrm{~min}$. L'absorption de la couleur jaune, qui est stable pour plusieurs heures, est mesurée sur un spectrophotometre Coleman 124 (Perkin-Elmer) à une longueur d'onde de $488 \mathrm{~nm}$. Les mesures effectuées permettent de tracer la courbe standard (concentration glucose vs absorption de lumiere). Par la 
suite, des échantillons de concentrations inconnues en hydrates de carbone sont dosés de la méme façon que les solutions standards. La concentration en équivalent de glucose dans les échantillons est déterminée a partir de la courbe standard.

\section{9 - Analyse de l'acide déshydroabiétique}

Avant d'analyser l'acide déshydroabiétique, l'échantillon est soumis a une extraction à l'éther diéthylique selon la méthodologie de Holmbom (1980). L'échantilion est acidifié a un pH de 2 a I'aide d'une solution de $\mathrm{HCl}$ O.IN. L'échantilion est ensuite extrait a l'éther diéthylique. L'extraction se fait en quatre étapes: une premiere avec un volume de $150 \mathrm{~mL}$ et les trois autres avec des volumes de $50 \mathrm{~mL}$ chacune d'éther diethylique. Les phases organiques sont ensuite mélangées puis évaporées à $30^{\circ} \mathrm{C}$ dans un évaporateur rotatif. Quand le volume atteint environ $2 \mathrm{~mL}$, la solution est transférée dans un vial, puis évaporée sous atmosphère d'azote. L'extrait est dissout dans $800 \mu \mathrm{L}$ d'acétonitrile (grade HPLC) avant d'etre analysé par chromatographie liguide à haute performance (HPLC) Perkin-Elmer, série 4, relié à un détecteur UVvisible Perkin-Elmer LC-85 et a un intégrateur Perkin-Elmer sigma15. La concentration d'acide déshydroabiétique est trouvée en comparant la surface sous le pic avec ceux des standards de concentration connus de cet acide. Les conditions expérimentales d'analyse de l'acide déshydroabiétique sont présentées au tableau VI (Richardson et al., 1983). 
Tableau VI Conditions expérimentales d'analyse de l'acide de déshydroabiétique par chromatographie liquide a haute performance (HPLC)

Chromatographe

Détecteur

Longueur d'onde

Colonne *

Composition de la

phase mobile

itesse de la

phase mobile

* Chromatographic specialties.
Perkin-Elmer série 4

Ultra-violet

$200 \mathrm{~nm}$

MicroPak $(15.0 \times 040 \mathrm{~cm})$

65\% acétonitrile

34.98 eau et

$0.1 \%$ acide acétique

$2.0 \mathrm{~mL} / \mathrm{min}$. 


\section{CHAP I TRE V}

\section{RESULTATS ET DISCUSSION}

\subsection{Traitabilité}

Le test de traitabilité montre le taux de biodégradation d'une eau résiduaire ainsi que la concentration a laquelle cette eau est toxique pour la population bactérienne.

La méthode de la digestion anaérobie en fournée (batch) constitue un moyen simple et économique pour évaluer la biodégradabilité d'une eau résiduaire. Cette méthode utilise un faible volume d'eau résiduaire et plusieurs essais peuvent etre faits en parallele. La digestion en fournée est aussi très flexible, car les concentrations de l'eau usée a traiter, du milieu nutritif et de la culture mixte de bactéries peuvent etre variées. A l'échelle industrielle, ces essais nécessiteraient plusieurs digesteurs en parallele - ce qui serait excessivement coateux comparativement à quelques bouteilles de sérum dans le cas de la méthode en fournée.

Le tableau VII montre la réduction de la DCO, de la xylane et de l'acide déshydroabiétique par digestion anaérobie des solutions synthétiques. Le tableau VIII donne le volume cumulatif de biogaz, sa composition moyenne en méthane ainsi que le rendement en $\mathrm{CH}_{4}$ obtenus lors des essais de traitabilité par anaérobiose des différentes solutions. La xylane est facilement biodégradée (tableau VII); elle n'est pas toxique pour les bactéries car 
Tableau VII Pourcentage de reduction de la DCO, de la concentration en xylane et de l'acide déshydroabiétique en fonction de la durée du traitement pour des solutions synthetiques lors des essais de traitabilité.

\begin{tabular}{|c|c|c|c|c|c|c|c|}
\hline \multirow[b]{2}{*}{ Solution } & \multirow[b]{2}{*}{$\begin{array}{l}\text { Durée } \\
\text { jour }\end{array}$} & \multicolumn{2}{|c|}{$\mathrm{DCO}$} & \multicolumn{2}{|c|}{ Xylane } & \multicolumn{2}{|c|}{$\mathrm{ADA}^{a}$} \\
\hline & & $\begin{array}{c}(\mathrm{DCO})_{\mathrm{o}}^{\mathrm{b}} \\
\mathrm{mg} / \mathrm{L}\end{array}$ & $\begin{array}{c}\text { Réduc- } \\
\text { tion } \\
8\end{array}$ & $\begin{array}{c}s_{0}^{b} \\
m g / L\end{array}$ & $\begin{array}{c}\text { Reduc- } \\
\text { tion } \\
\text { \& }\end{array}$ & $\begin{array}{c}I_{0}^{b} \\
m g / L\end{array}$ & $\begin{array}{c}\text { Réduc- } \\
\text { tion } \\
\text { o }\end{array}$ \\
\hline$x_{1}$ & 19.3 & 1000 & 96 & 910 & 97 & --- & -- \\
\hline$x_{2}$ & 21.0 & 2500 & 96 & 2270 & 96 & --- & -- \\
\hline$x_{3}$ & 23.0 & 5000 & 95 & 4550 & 95 & --- & -- \\
\hline A & 21.0 & 800 & 88 & ---- & -- & --- & -- \\
\hline B & 21.0 & 3300 & 92 & 2270 & 95 & --- & -- \\
\hline $\mathrm{C}$ & 21.0 & 3315 & 90 & 2270 & 93 & 5 & 60 \\
\hline D & 21.0 & 3415 & 86 & 2270 & 90 & 40 & 55 \\
\hline $\mathbf{E}$ & 21.0 & 3570 & 73 & 2270 & 78 & 100 & 35 \\
\hline F & 21.0 & 3850 & 48 & 2270 & 55 & 200 & 20 \\
\hline G & 23.0 & 5790 & 92 & 4550 & 95 & --- & -- \\
\hline $\mathrm{H}$ & 23.0 & 5800 & 88 & 4550 & 91 & 5 & 60 \\
\hline I & 23.0 & 5900 & 82 & 4550 & 86 & 40 & 53 \\
\hline $\mathrm{J}$ & 23.0 & 6070 & 68 & 4550 & 73 & 100 & 32 \\
\hline $\mathrm{K}$ & 23.0 & 6340 & 42 & 4550 & 50 & 200 & 18 \\
\hline
\end{tabular}

a: ADA: acide déshydroabietique

b: $\mathrm{DCO}_{0^{\prime}} \mathrm{S}_{\mathrm{o}}$ et $\mathrm{I}_{\mathrm{o}}$ : concentration initiale 
Tableau VII Volume cumulatif de biogaz, sa composition moyenne en méthane ainsi que le rendement en $\mathrm{CH}_{4}$ obtenus lors des essais de traitabilité par anaérobiose des differentes solutions synthétiques.

\begin{tabular}{|c|c|c|c|c|}
\hline \multirow[b]{2}{*}{ Solution } & \multirow[b]{2}{*}{ jour } & \multicolumn{2}{|c|}{ Biogaz produit } & \multirow{2}{*}{$\begin{array}{l}\text { Rendement en } \mathrm{CH}_{4} \\
\mathrm{~m}^{3} \mathrm{de} \mathrm{CH}_{4} / \mathrm{kg} \text { de } \\
\text { DCo réduit }\end{array}$} \\
\hline & & $\begin{array}{l}\text { Volume } \\
\text { cumulatif } \\
\text { mL }\end{array}$ & $\begin{array}{l}\text { Composition } \\
\text { moyenne en } \mathrm{CH}_{4} \\
8\end{array}$ & \\
\hline$x_{1}$ & 19.3 & 23.1 & 60 & 0.35 \\
\hline$x_{2}$ & 21.0 & 57.7 & 60 & 0.34 \\
\hline$x_{3}$ & 23.0 & 106.5 & 60 & 0.32 \\
\hline $\mathbf{A}$ & 21.0 & 17.1 & 78 & 0.45 \\
\hline B & 21.0 & 73.1 & 65 & 0.37 \\
\hline C & 21.0 & 72.1 & 65 & 0.37 \\
\hline D & 21.0 & 71.9 & 65 & 0.38 \\
\hline $\mathbf{E}$ & 21.0 & 64.2 & 65 & 0.38 \\
\hline $\mathbf{F}$ & 21.0 & 43.6 & 65 & 0.37 \\
\hline G & 23.0 & 124.9 & 63 & 0.35 \\
\hline $\mathrm{H}$ & 23.0 & 123.4 & 63 & 0.36 \\
\hline I & 23.0 & 120.9 & 63 & 0.38 \\
\hline $\mathrm{J}$ & 23.0 & 110.4 & 63 & 0.40 \\
\hline $\mathrm{K}$ & 23.0 & 64.6 & 63 & 0.37 \\
\hline
\end{tabular}


l'augmentation de 1 a concentration de $910 \mathrm{mg} / \mathrm{L}$ a $4550 \mathrm{mg} / \mathrm{L} \mathrm{n}$ 'a qu'un effet très négligeable sur le pourcentage de réduction de la DCo. Le tableau IX montre le volume cumulatif du biogaz produit pendant la digestion anaérobie des solutions synthétiques composées de xylane $\left(x_{1}, x_{2}, x_{3}\right)$ et du témoin. Le témoin contient, en plus du milieu nutritif et de la culture mixte de bactérie, de l'eau distillée au lieu des solutions résiduaires synthétiques. Le volume du biogaz produit par le témoin est da a l'activité bactérienne dans le milieu nutritif. La figure 11 montre que la digestion de la xylane nécessite une période de latence d'environ 14 heures. Au cours de cette période, les bactéries s'acclimatent à leur milieu en faisant la synthèse des enzymes nécessaires à la digestion de la xylane. Pour une même période de traitement, le volume du biogaz produit lors de la digestion anaérobie est fonction de la concentration en xylane. La majeure partie du biogaz est produite durant les dix premiers jours. Ce biogaz est composé d'environ 608 de méthane $\left(\mathrm{CH}_{4}\right)$ et $40 \%$ de bioxyde de bioxyde de carbone $\left(\mathrm{CO}_{2}\right)$ (tableau VIII). La composition thérique du biogaz produit par fermentation anaérobie des hydrates de carbone trouvée a l'aide de l'équation de symons et Buswall, est de $50 \%$ de $\mathrm{CH}_{4}$ et $50 \%$ de $\mathrm{CO}_{2}$ Cette différence dans la composition du biogaz, déja constatée auparavant (Gunnerson et stuckey, 1986b; Webb, 1984), est due à la solubilité du bioxyde de carbone dans les solutions aqueuses. Le rendement en méthane de la digestion des 
Tableau IX - Volume cumulatif de biogaz produit pendant les essais de biodégradabilité par voie anaérobie des solutions $x_{1}, x_{2}, x_{3}$, et le témoin (eau)

\begin{tabular}{|c|c|c|c|c|}
\hline $\begin{array}{l}\text { Temps } \\
\text { jour }\end{array}$ & $\begin{array}{l}x_{1} \\
m L\end{array}$ & $\begin{array}{l}x_{2} \\
m L\end{array}$ & $\begin{array}{l}x_{3} \\
m L\end{array}$ & $\begin{array}{c}\text { Témo in } \\
\mathrm{mL}\end{array}$ \\
\hline 0.8 & 0.7 & 0.8 & 0.8 & 0 \\
\hline 1.9 & 6.2 & 14.0 & 22.0 & 0 \\
\hline 4.5 & 11.4 & 27.8 & 47.5 & 0 \\
\hline 6.7 & 15.5 & 38.0 & 63.5 & 0.8 \\
\hline 8.2 & 18.4 & 44.1 & ---- & --- \\
\hline 9.8 & ---- & 47.5 & 75.0 & 1.5 \\
\hline 11.3 & 19.8 & 49.9 & ---- & 1.8 \\
\hline 12.5 & ---- & ---- & 86.2 & --- \\
\hline 14.3 & 22.0 & 54.7 & 93.8 & 1.9 \\
\hline 16.7 & 22.5 & 56.6 & 102.0 & 2.2 \\
\hline 18.0 & 23.0 & 57.5 & 103.7 & 2.4 \\
\hline 19.2 & 23.1 & --- & 104.3 & 2.6 \\
\hline 19.3 & 23.1 & --- & $-\cdots$ & $-\infty$ \\
\hline 21.0 & ---- & 57.7 & 105.3 & 2.8 \\
\hline 23.0 & ---- & ---- & 106.5 & 3.0 \\
\hline
\end{tabular}




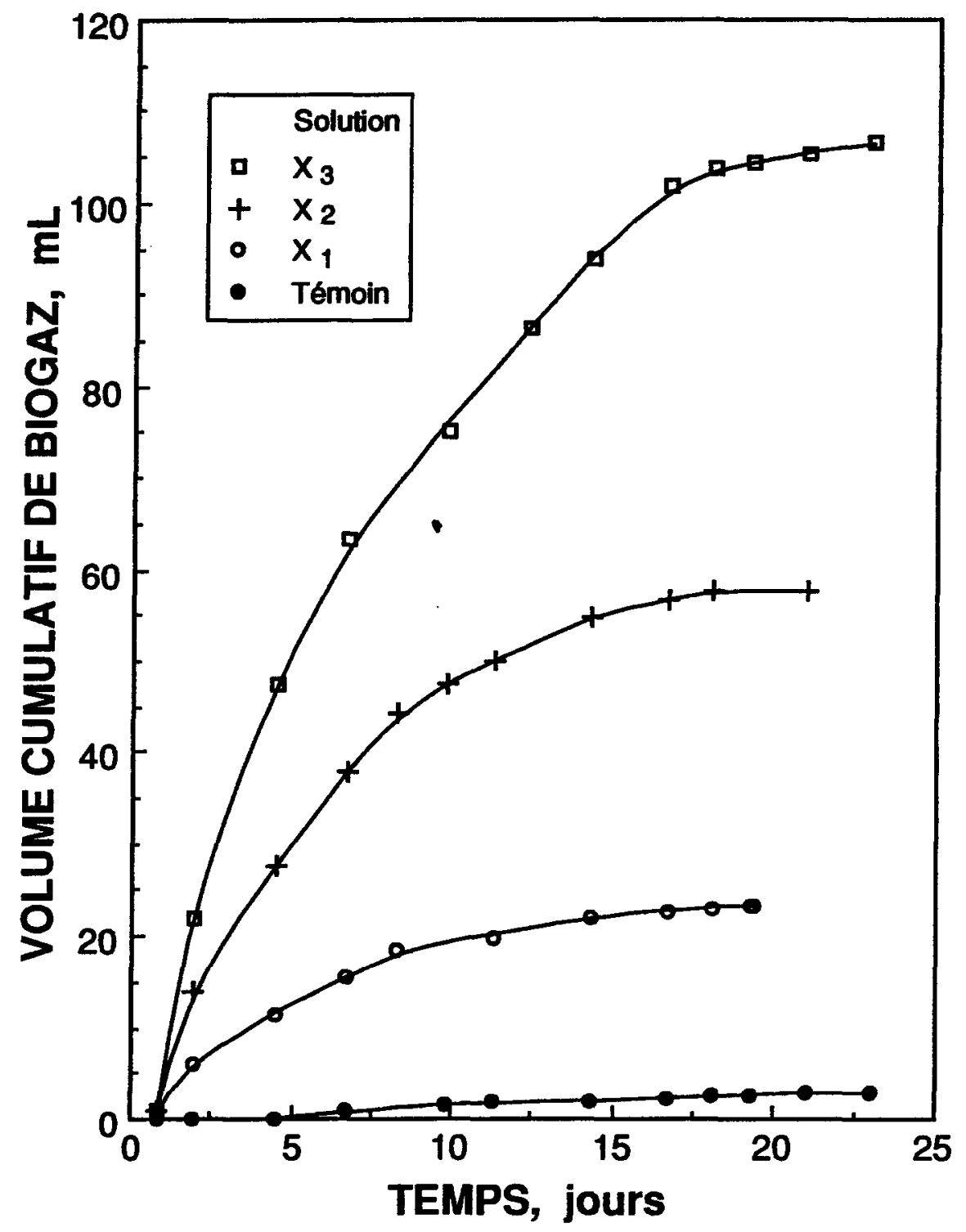

Figure 11: Volume cumulatif de biogaz produit en fonction du temps lors des essais de traitabilité des solutions $x_{1}, x_{2}, x_{3}$ et le témoin 
solutions de xylane varie entre 0.32 et $0.35 \mathrm{~m}^{3}$ de $\mathrm{CH}_{4}$ produit par $\mathrm{kg}$ de DCO réduit (tableau VIII). La valeur généralement rapportée dans la littérature (Anderson et al., 1982; Beak Consultants Limited, 1988; Ferguson et al., 1985; Owen et al. 1979) pour la digestion anaérobie des effluents des usines de pate et papier est de $0.35 \mathrm{~m}^{3}$ de $\mathrm{CH}_{4}$ par $\mathrm{kg}$ de DCO réduite.

Les réductions de la demande chimique en oxygène (DCO) diminuent avec l'augmentation de la concentration de l'acide déshydroabiétique (tableau VII). Les solutions $B$ et G, ou la concentration en acide déshydroabiétique est nulle, subissent une réduction de la DCo de $92 \%$, alors que celle des solutions $F$ et $K$, où la concentration en acide déshydroabiétique est de $200 \mathrm{mg} / \mathrm{L}$, ne subissent qu'une reduction de 48 et 428 respectivement. La baisse de la performance des bactéries anaérobies est due a la toxicité de l'acide déshydroabiétique. La biodégradation de ce dernier diminue avec l'augmentation de sa concentration (tableau VII), elle passe de $60 \%$ pour les solutions $C$ et $H$, où la concentration en acide déshydroabiétique est de $5 \mathrm{mg} / \mathrm{L}$, à environ $20 \%$ pour les solutions $F$ et $\mathrm{K}$ ou la concentration en acide déshydroabiétique est de 200 $\mathrm{mg} / \mathrm{L}$.

Le tableau $x$ et les figures 12 et 13 indiquent le volume cumulatif de biogaz produit pendant la digestion anaérobie des solutions synthétiques A, B, C, D, E, F, G, H, I, J et K. Le volume de biogaz produit peut etre utilisé comme moyen pour 
Tableau $X$ Volume cumulatif de biogaz produit lors des essais de biodégradabilité par voie anaérobie des solutions $A$, $B, C, D, E, F, G, H, I, J$ et $K$.

\begin{tabular}{|c|c|c|c|c|c|c|}
\hline \multirow[b]{2}{*}{$\begin{array}{l}\text { Temps } \\
\text { jour }\end{array}$} & \multicolumn{6}{|c|}{ SOLUTION } \\
\hline & $\begin{array}{l}\mathrm{A} \\
\mathrm{mL}\end{array}$ & $\begin{array}{l}\mathrm{B} \\
\mathrm{mL}\end{array}$ & $\begin{array}{l}\mathrm{C} \\
\mathrm{mL}\end{array}$ & $\begin{array}{l}\mathrm{D} \\
\mathrm{mL}\end{array}$ & $\begin{array}{l}\mathbf{E} \\
\mathrm{mL}\end{array}$ & $\begin{array}{l}F \\
\mathrm{~mL}\end{array}$ \\
\hline 0.8 & 0 & 0.8 & 0 & 0 & 0 & 0 \\
\hline 1.5 & 0 & 14.9 & 8.0 & 4.0 & 0 & 0 \\
\hline 2.0 & 1.7 & ---- & ---- & --- & 6.2 & 0 \\
\hline 4.3 & 7.5 & 37.3 & 36.8 & 34.4 & 29.2 & 10.0 \\
\hline 5.2 & 9.1 & --- & --- & --- & --- & --- \\
\hline 6.7 & 11.1 & 51.1 & 51.0 & 48.7 & 45.3 & 23.9 \\
\hline 8.9 & 12.8 & 58.1 & 57.9 & 57.4 & 53.9 & 29.4 \\
\hline 12.0 & 14.4 & 65.0 & 65.1 & 64.7 & 59.4 & 36.9 \\
\hline 15.1 & 16.5 & 69.1 & 69.3 & 68.9 & 61.9 & 41.4 \\
\hline 16.2 & 17.0 & 72.2 & 71.5 & 71.3 & 63.4 & 42.8 \\
\hline 19.1 & 17.1 & 73.0 & 72.0 & 71.7 & 64.0 & 43.3 \\
\hline 21.0 & 17.1 & 73.1 & 72.1 & 71.9 & 64.2 & 43.6 \\
\hline 23.0 & ---- & --- & ---- & ---- & --- & $-\cdots$ \\
\hline
\end{tabular}

suite page 65 
Tableau X (suite)

\begin{tabular}{|c|c|c|c|c|c|}
\hline \multirow[b]{2}{*}{$\begin{array}{l}\text { Temps } \\
\text { jour }\end{array}$} & \multicolumn{5}{|c|}{ SOLUTION } \\
\hline & $\begin{array}{l}\mathbf{G} \\
\mathrm{mL}\end{array}$ & $\begin{array}{l}\mathrm{H} \\
\mathrm{mL}\end{array}$ & $\begin{array}{l}\mathrm{I} \\
\mathrm{mL}\end{array}$ & $\begin{array}{l}\mathrm{J} \\
\mathrm{mL}\end{array}$ & $\begin{array}{l}\mathrm{K} \\
\mathrm{mL}\end{array}$ \\
\hline 0.8 & 0.9 & 0 & 0 & 0 & 0 \\
\hline 1.5 & --- & 9.0 & 4.0 & 0 & 0 \\
\hline 2.0 & 23.8 & 23.5 & 17.5 & 10.0 & 0 \\
\hline 4.3 & 53.0 & 52.5 & 47.5 & 37.9 & 15.0 \\
\hline 5.2 & ---- & ---- & --- & --- & -- \\
\hline 6.7 & 75.5 & 74.7 & 69.9 & 62.1 & 34.5 \\
\hline 8.9 & 90.0 & 89.0 & 85.6 & 77.9 & 43.1 \\
\hline 12.0 & 105.0 & 103.7 & 100.9 & 92.5 & 52.5 \\
\hline 15.1 & 114.0 & 112.6 & 110.0 & 101.1 & 58.1 \\
\hline 16.2 & 118.0 & 116.5 & 114.0 & 104.0 & 59.0 \\
\hline 19.1 & 122.4 & 121.0 & 118.7 & 108.6 & 62.5 \\
\hline 21.0 & 124.0 & 122.7 & 120.1 & 109.9 & 63.8 \\
\hline 23.0 & 124.9 & 123.4 & 120.9 & 110.4 & 64.6 \\
\hline
\end{tabular}




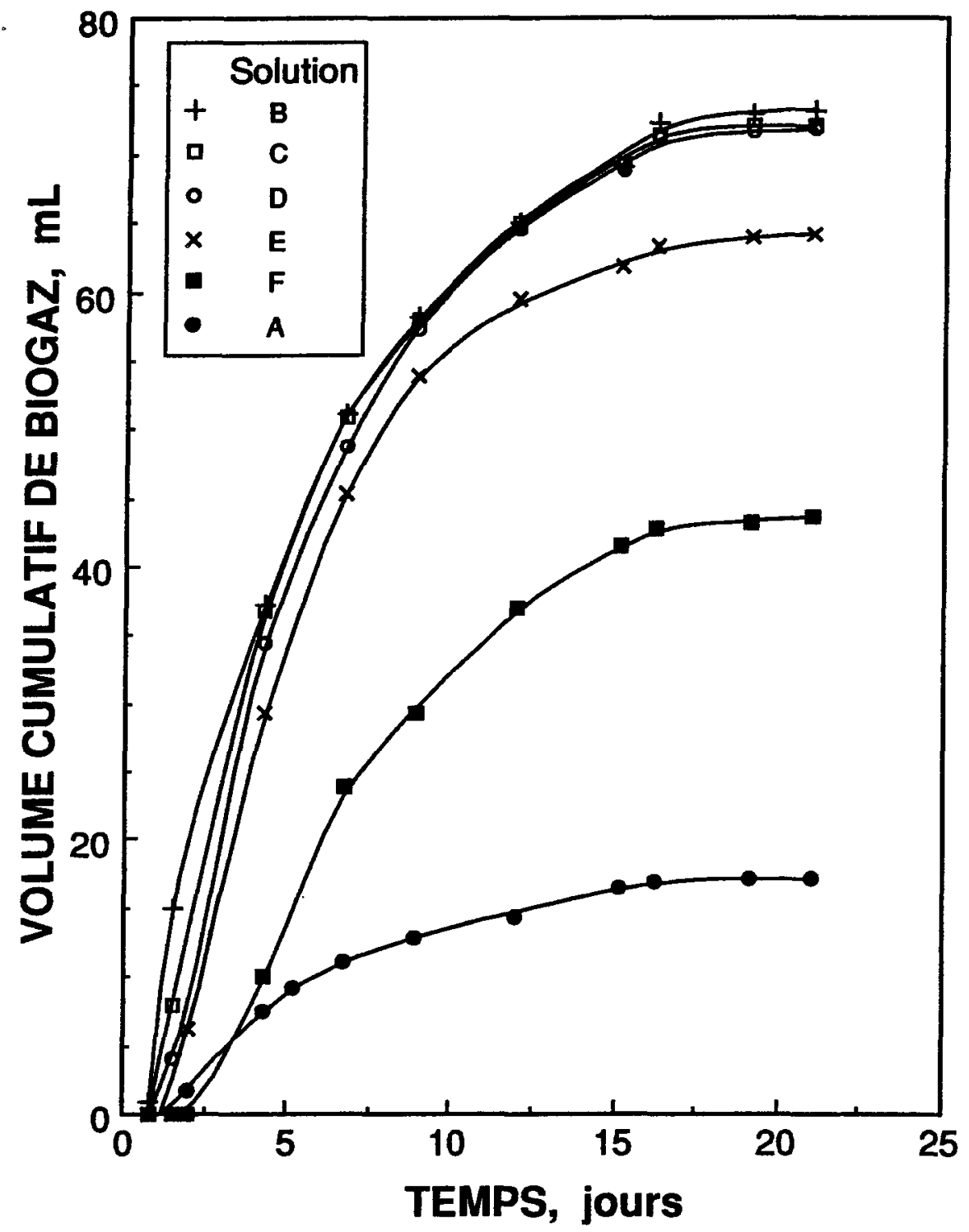

Figure 12: Volume cumulatif de biogaz produit en fonction du temps lors des essais de traitabilité des solutions A, B, C, D, E et F 


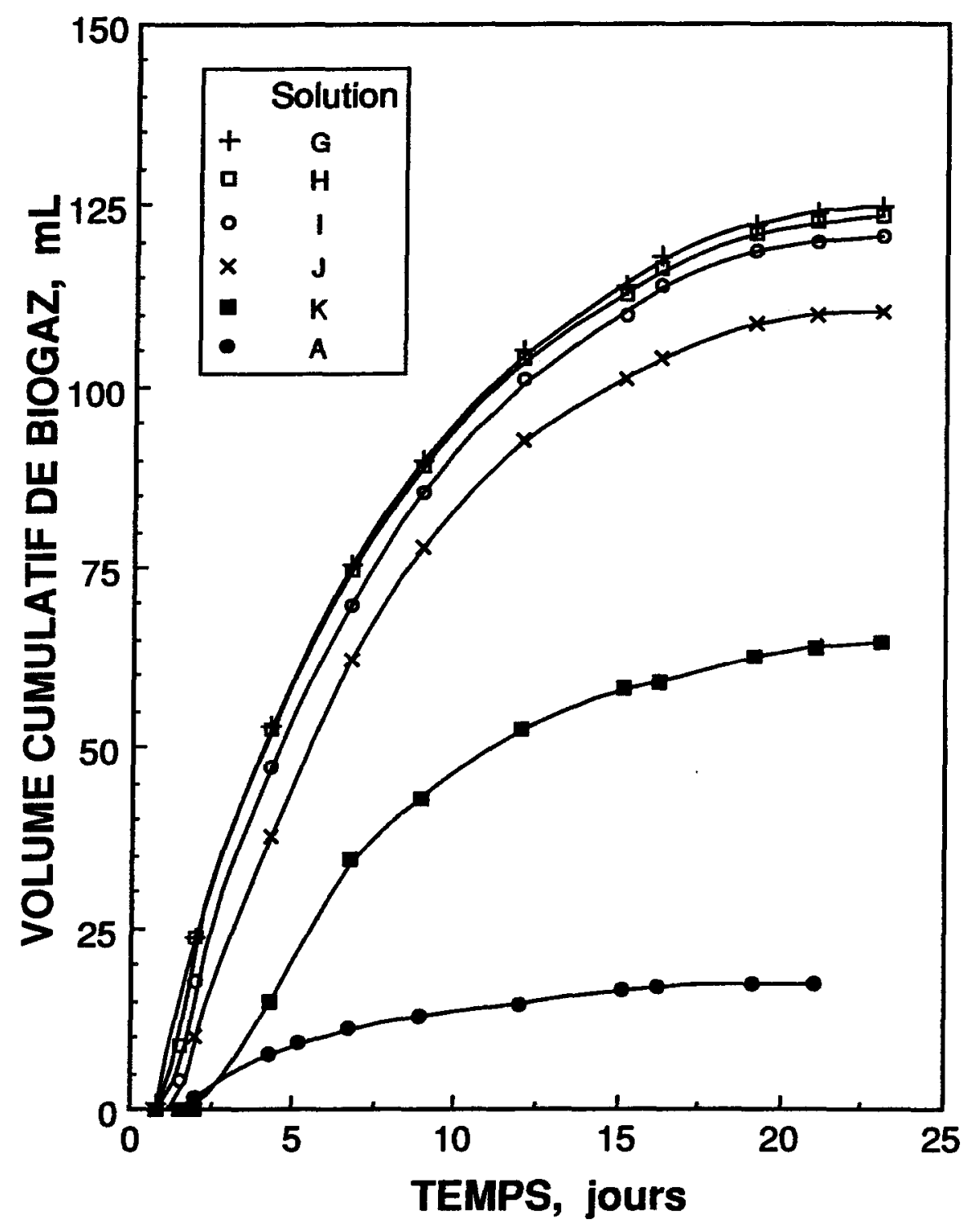

Figure 13: Volume cumulatif de biogaz produit en fonction du temps lors des essais de traitabilité des solutions A, G, H, I, J et $R$ 
vérifier la toxicité de l'acide déshydroabiétique. En effet, plus la concentration de cet acide augmente, plus le volume du biogaz produit est faible (tableau $x$, figures 12 et 13). La digestion du méthanol produit un biogaz composé d'environ 788 de méthane, alors que la xylane, produit un biogaz ne contenant qu'environ $60 \%$ de méthane (tableau VIII). Ia composition en méthane du biogaz produit par digestion anaerobie des différentes solutions synthétiques est inversement proportionnelle à la valeur du rapport concentration de $x y l a n e / c o n c e n t r a t i o n ~ d e ~ m e ́ t h a n o l ~\left(C_{x} / C_{m}\right)$. En effet, la composition moyenne en méthane du biogaz produit par digestion des solutions $B, C, D, E$, et $F\left(C_{x} / C_{m}=4.2\right)$ est de $65 \%$ alors qu'elle n'est que de $63 \%$ pour les solutions $G, H, I$, J et $K$ $\left(C_{x} / C_{m}=8.3\right)$

Ia concentration en acide déshydroabietique des eaux résiduaires synthétiques traitées par anaérobiose n'a aucune influence sur la composition du biogaz produit (tableau VIII). Le rendement en méthane des solutions contenant l'acide déshydroabiétique (C, D, E, F, H, J et K) varie entre 0.36 et $40 \mathrm{~m}^{3} \mathrm{de} \mathrm{CH}_{4}$ par $\mathrm{kg}$ de DCo réduit (tableau VIII). Ce rendement qui est superieur a celui obtenu par fermentation anaérobie des solutions composées uniquement de xylane -0.32 a $0.34 \mathrm{~m}^{3}$ de $\mathrm{CH}_{4}$ par $\mathrm{kg}$ de DCo réduit - résulte de la présence du méthanol dans les solutions synthétiques. La digestion du méthanol donne un rendement de $I^{\prime}$ ordre de $0.45 \mathrm{~m}^{3}$ de $\mathrm{CH}_{4} / \mathrm{kg}$ de DCo réduit (tableau VI I I). 
La phase de latence de la digestion des eaux résiduaires synthétiques est proportionnelle a la concentration de l'acide déshydroabiétique (figures 12 et 13 ). La phase de latence est inférieure à 24 heures pour les solutions B et G (concentration en acide déshydroabiétique nulle) et augmente à près de 60 heures pour les solutions $F$ et $K$ (concentration en acide deshydroabietique de $200 \mathrm{mg} / \mathrm{L})$.

\section{2 - Acclimatation}

L'utilisation de bactéries acclimatées aux eaux résiduaires à traiter, réduit considérablement la période de digestion car la vitesse maximale de la croissance bactérienne est atteinte dès le début du traitement. Cette proprieté est trés importante dans le cas des traitements des eaux résiduaires des usines de pates et papiers. Ces usines rejettent de grands volumes d'effluents; ce qui exige un très court temps de séjour dans le digesteur.

Les tableaux XI à XVI et les figures 14 a 19 montrent le volume cumulatif de biogaz produit lors de l'acclimatation des bactéries anaérobies aux solutions B, D, E, G, I et J. Après que les solutions eussent subi un premier traitement - premier passageune partie de ces solutions est remplacée de manièe à retrouver les concentrations initiales decrites dans le tableau II (chapitre IV). De la même façon, une partie des solutions est remplacée après le deuxième et le troisième passages. L'acclimatation des bactéries anaérobies aux différentes solutions traitées diminue considérablement la période de latence de l'activité bactérienne (figures 14 à 19). Par exemple dans le cas des solutions $E$ et $J$ 
Tableau XI Volume cumulatif de biogaz prodult lors de l'acclimatation des bactéries anaérobies a la solution B.

\begin{tabular}{|c|c|c|c|c|}
\hline \multirow[b]{2}{*}{$\begin{array}{l}\text { Temps } \\
\text { jour }\end{array}$} & \multicolumn{4}{|c|}{ Volume cumulatif, $\mathrm{mL}$} \\
\hline & $\begin{array}{l}\text { Passage } 1 \\
\mathrm{~mL}\end{array}$ & $\begin{array}{c}\text { Passage } 2 \\
\mathrm{~mL}\end{array}$ & $\begin{array}{c}\text { Passage } 3 \\
\mathrm{~mL}\end{array}$ & $\begin{array}{c}\text { Passage } 4 \\
\mathrm{~mL}\end{array}$ \\
\hline 0.8 & 0.8 & 8.0 & 7.8 & 7.9 \\
\hline 1.5 & 14.9 & 15.2 & 15.0 & 15.2 \\
\hline 4.2 & ---- & 39.9 & --- & ---- \\
\hline 4.3 & 37.3 & --- & 40.2 & 40.9 \\
\hline 6.7 & 51.1 & 53.4 & 53.0 & 53.2 \\
\hline 8.9 & 58.1 & 61.4 & 61.0 & 61.2 \\
\hline 12.0 & 65.0 & ---- & 67.2 & 67.5 \\
\hline 12.1 & ---- & 67.1 & ---- & ---- \\
\hline 15.1 & 69.9 & --- & ---- & ---- \\
\hline 16.2 & 72.2 & --- & ---- & ---- \\
\hline 19.1 & 73.0 & 74.8 & 74.6 & 75.0 \\
\hline 21.0 & 73.1 & 75.0 & 74.7 & 75.2 \\
\hline
\end{tabular}




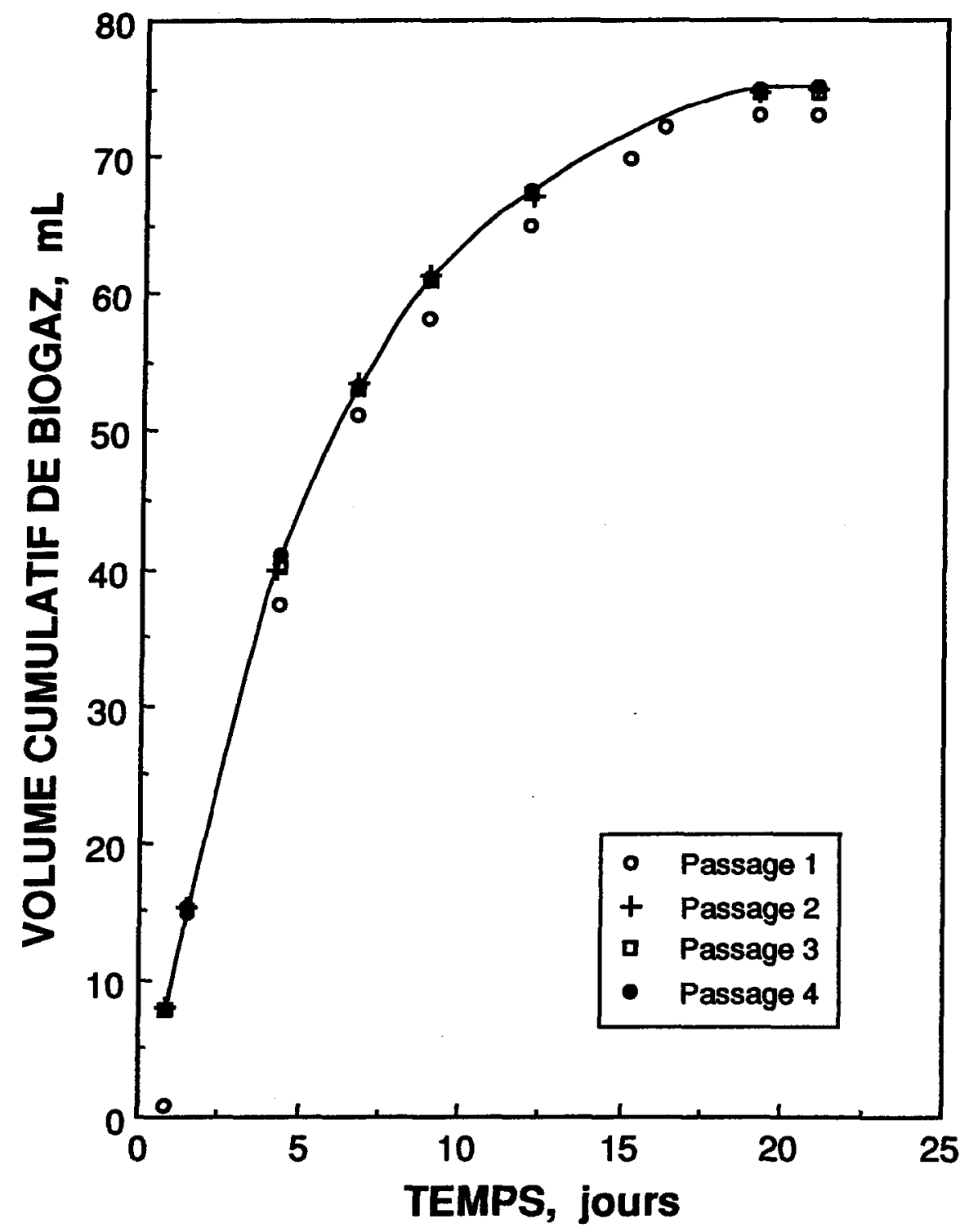

Figure 14: Volume cumulatif de biogaz prodult en fonction du temps lors de l'acclimatation des bactéries anaérobies à la solution B 
Tableau XII - Volume cumulatif du biogaz produit lors de l'acclimatation des bactéries anaérobies à la solution $D$.

\begin{tabular}{|c|c|c|c|c|}
\hline \multirow[b]{2}{*}{$\begin{array}{l}\text { Temps } \\
\text { jour }\end{array}$} & \multicolumn{4}{|c|}{ Volume cumulatif, $\mathrm{mL}$} \\
\hline & $\begin{array}{c}\text { Passage } 1 \\
m L\end{array}$ & $\begin{array}{c}\text { Passage } 2 \\
\mathrm{~mL}\end{array}$ & $\begin{array}{c}\text { Passage } 3 \\
\mathrm{~mL}\end{array}$ & $\begin{array}{c}\text { Passage } 4 \\
\mathrm{~mL}\end{array}$ \\
\hline 0.7 & ---- & 7.7 & ---- & 7.5 \\
\hline 0.8 & 0 & --- & 7.8 & ---- \\
\hline 1.5 & 4.0 & --- & 16.8 & 16.6 \\
\hline 1.6 & ---- & 16.3 & --- & ---- \\
\hline 4.2 & ---- & 37.9 & $\cdots$ & 38.0 \\
\hline 4.3 & 34.4 & ---- & 38.4 & ---- \\
\hline 6.5 & ---- & 50.9 & --- & 51.0 \\
\hline 6.7 & 48.7 & ---- & 51.4 & ---- \\
\hline 8.9 & 57.4 & ---- & ---- & ---- \\
\hline 12.0 & 64.7 & 66.9 & 67.2 & 67.0 \\
\hline 15.0 & 68.9 & --- & 71.8 & $-\cdots$ \\
\hline 15.1 & --- & 71.5 & ---- & 71.7 \\
\hline 19.0 & --- & 73.8 & --- & ---- \\
\hline 19.1 & 71.7 & ---- & 74.6 & --- \\
\hline 20.9 & ---- & 74.3 & --- & ---- \\
\hline 21.0 & 71.9 & ---- & 75.0 & 74.7 \\
\hline
\end{tabular}




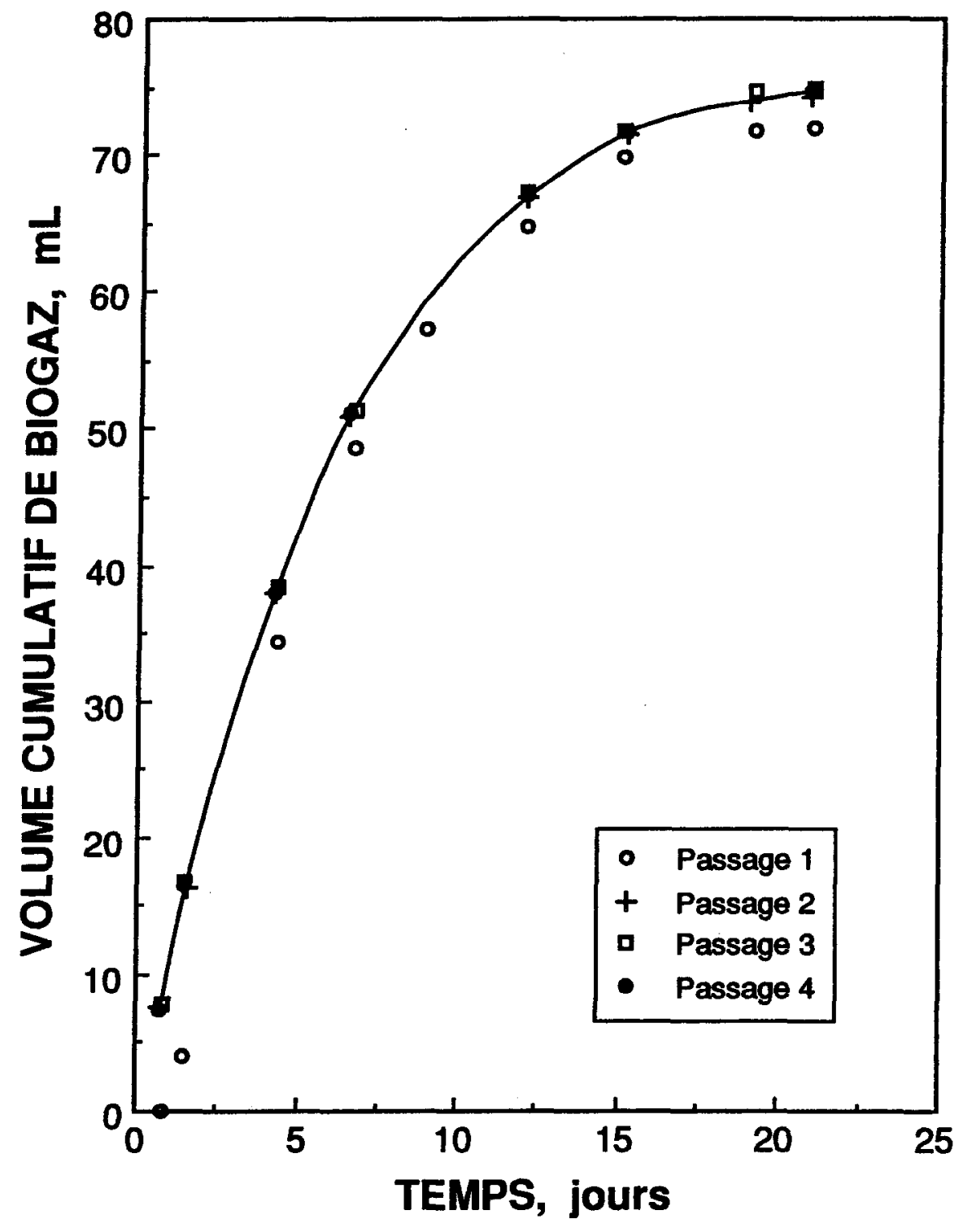

Figure 15: Volume cumulatif de biogaz produt en fonction du temps lors de l'acclimatation des bactéries anaérobies à la solution D 
Tableau XIII - Volume cumulatif de biogaz produit lors de l'acclimatation des bactéries anaérobies à la solution $E$.

\begin{tabular}{|c|c|c|c|c|}
\hline \multirow[b]{2}{*}{$\begin{array}{l}\text { Temps } \\
\text { jour }\end{array}$} & \multicolumn{4}{|c|}{ Volume cumulatif, mL } \\
\hline & $\begin{array}{c}\text { Passage } 1 \\
\text { mL }\end{array}$ & $\begin{array}{c}\text { Passage } 2 \\
\mathrm{~mL}\end{array}$ & $\begin{array}{c}\text { Passage } 3 \\
\mathrm{~mL}\end{array}$ & $\begin{array}{c}\text { Passage } 4 \\
\mathrm{~mL}\end{array}$ \\
\hline 0.8 & 0 & 6.0 & 6.4 & 6.3 \\
\hline 1.5 & 0 & ---- & 14.4 & 14.4 \\
\hline 1.6 & ---- & 14.0 & ---- & ---- \\
\hline 1.7 & 5.0 & --- & ---- & ---- \\
\hline 4.2 & ---- & 33.2 & --- & 33.9 \\
\hline 4.3 & 29.2 & --- & 34.2 & $-\cdots$ \\
\hline 6.5 & ---- & 47.0 & 48.1 & --- \\
\hline 6.7 & 45.3 & ---- & ---- & 48.5 \\
\hline 8.9 & 53.9 & ---- & 56.8 & --- \\
\hline 9.0 & ---- & 56.1 & ---- & 56.7 \\
\hline 12.0 & 59.4 & 61.6 & 62.0 & 62.1 \\
\hline 15.0 & ---- & 63.7 & $-\cdots$ & 64.2 \\
\hline 15.1 & 61.9 & ---- & 64.2 & ---- \\
\hline 19.1 & 64.0 & 65.2 & 65.4 & 65.3 \\
\hline 21.0 & 64.2 & 66.2 & 66.5 & 66.3 \\
\hline
\end{tabular}




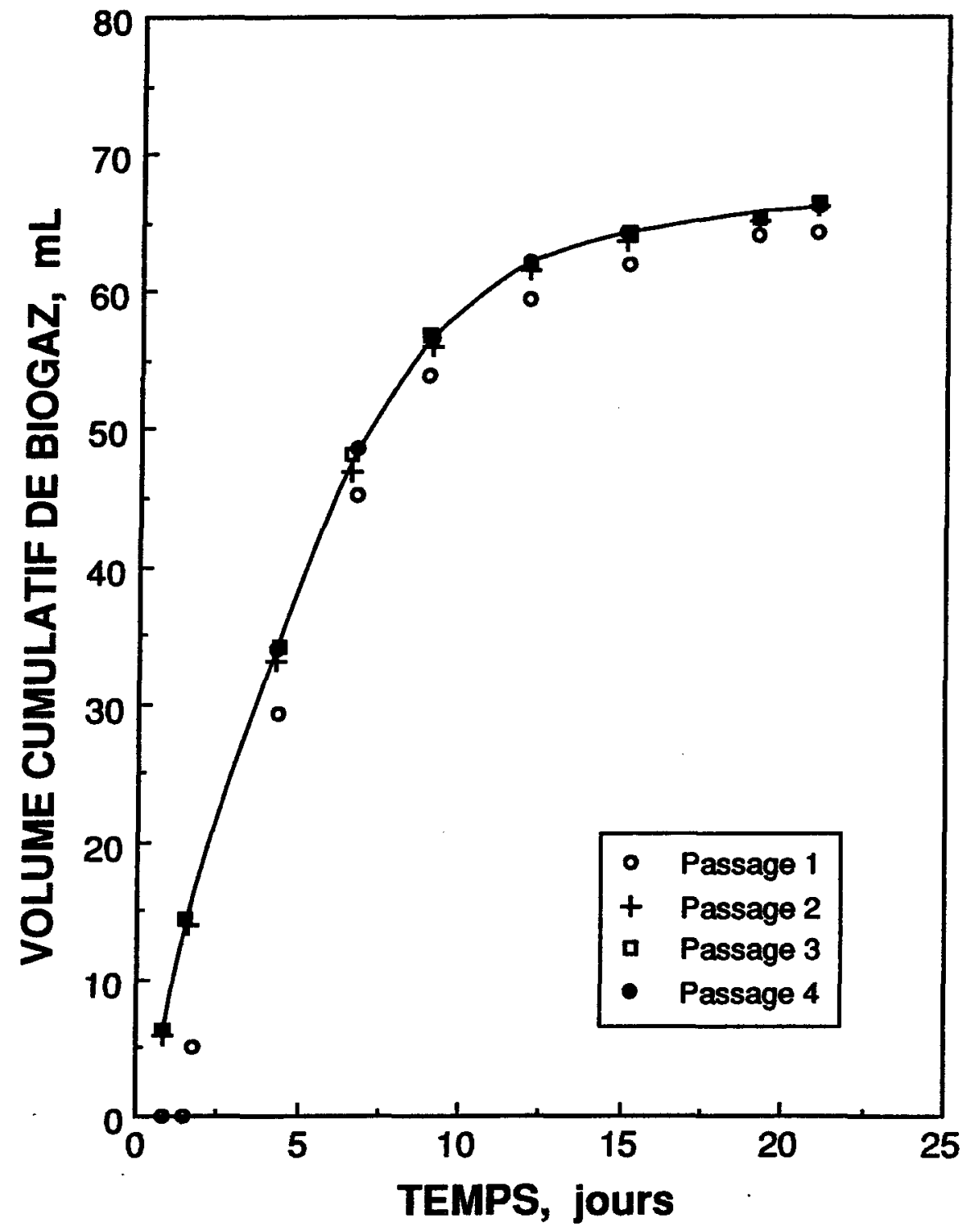

Figure 16: Volume cumulatif de blogaz produit en fonction du temps lors de l'acclimatation des bactéries anaérobies à la solution $E$ 
Tableau XIV - Volume cumulatif de biogaz produit lors de l'acclimatation des bactéries anaérobies à la solution $\mathbf{G}$.

\begin{tabular}{|c|c|c|c|c|}
\hline \multirow[b]{2}{*}{$\begin{array}{l}\text { Temps } \\
\text { jour }\end{array}$} & \multicolumn{4}{|c|}{ Volume cumulatif, $\mathrm{mL}$} \\
\hline & $\begin{array}{c}\text { Passage } 1 \\
\text { mL }\end{array}$ & $\begin{array}{c}\text { Passage } 2 \\
\mathrm{~mL}\end{array}$ & $\begin{array}{c}\text { Passage } 3 \\
\mathrm{~mL}\end{array}$ & $\begin{array}{c}\text { Passage } 4 \\
\mathrm{~mL}\end{array}$ \\
\hline 0.8 & 0.9 & 12.0 & 12.1 & 12.2 \\
\hline 2.0 & 23.8 & 30.2 & 30.0 & 30.4 \\
\hline 4.3 & 53.0 & 57.4 & 57.0 & 57.9 \\
\hline 6.7 & 75.5 & 79.9 & 80.0 & 81.0 \\
\hline 8.9 & 90.0 & 92.4 & 92.0 & 93.0 \\
\hline 12.0 & 105.0 & 106.9 & 106.4 & 107.2 \\
\hline 15.1 & 114.0 & 115.9 & 115.6 & 116.2 \\
\hline 16.2 & 118.0 & 119.2 & 119.0 & 120.0 \\
\hline 19.1 & 122.4 & 123.6 & 124.3 & 125.0 \\
\hline 21.0 & 124.0 & ---- & ---- & ----- \\
\hline 23.0 & 124.9 & 126.0 & 125.9 & 126.5 \\
\hline
\end{tabular}




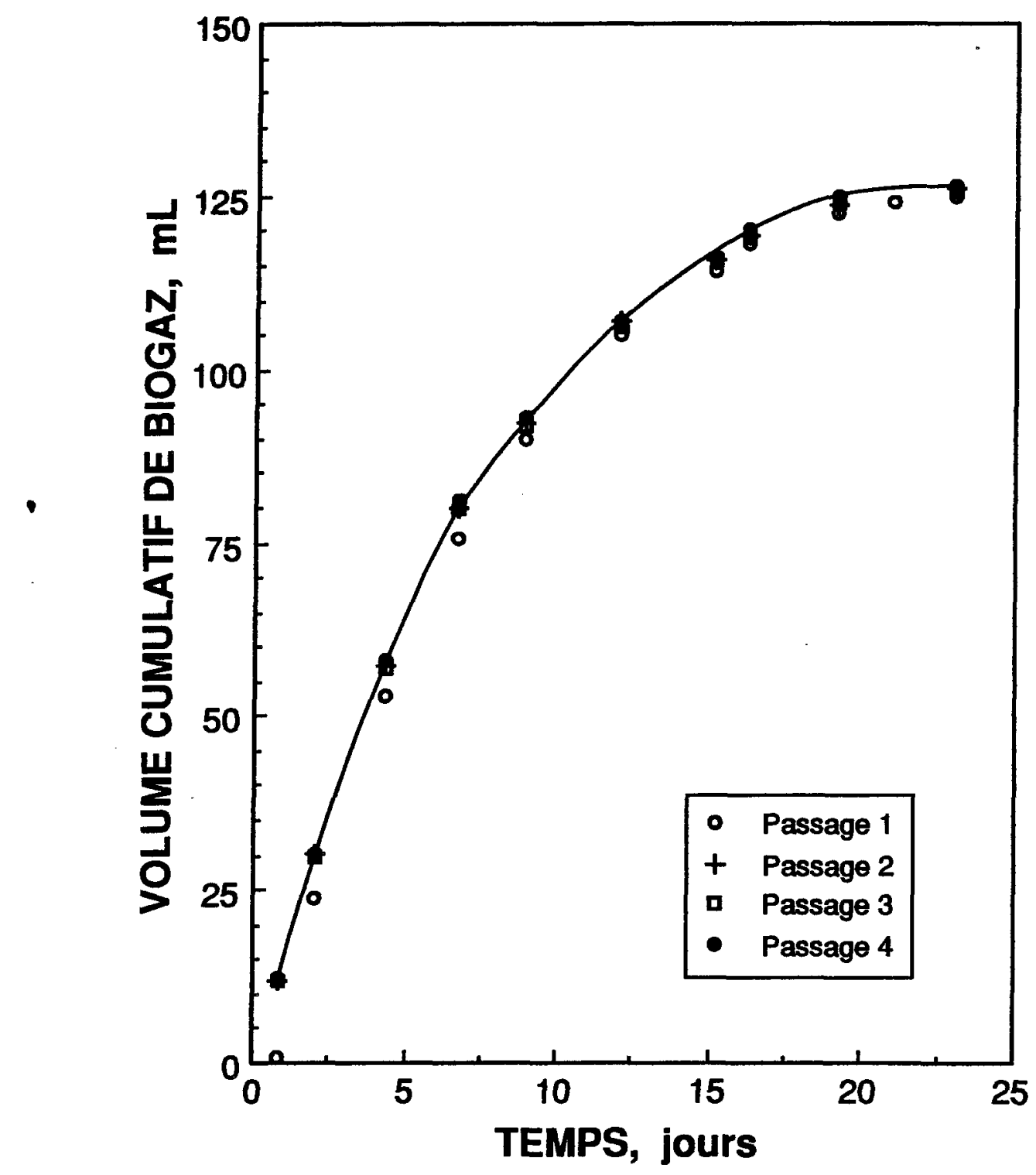

Figure 17: Volume cumulatif de biogaz prodult en fonction du temps lors de l'acclimatation des bactéries anaérobies à la solution $G$ 
Tableau XV Volume cumulatif de biogaz prodult lors de l'acclimatation des bactéries anaérobies à la solution $I$.

\begin{tabular}{|c|c|c|c|c|}
\hline \multirow[b]{2}{*}{$\begin{array}{l}\text { Temps } \\
\text { jour }\end{array}$} & \multicolumn{4}{|c|}{ Volume cumulatif, $\mathrm{mL}$} \\
\hline & $\begin{array}{c}\text { Passage } \\
\mathrm{mL}\end{array}$ & $\begin{array}{c}\text { Passage } 2 \\
\mathrm{~mL}\end{array}$ & $\begin{array}{c}\text { Passage } 3 \\
\mathrm{~mL}\end{array}$ & $\begin{array}{cc}\text { Passage } & 4 \\
\mathrm{~mL} & \end{array}$ \\
\hline 0.7 & --- & 8.2 & ---- & 8.3 \\
\hline 0.8 & 0 & --- & 8.5 & $-\cdots$ \\
\hline 1.5 & 4.0 & ---- & 19.8 & 19.6 \\
\hline 1.6 & --- & 19.8 & --- & $-\cdots$ \\
\hline 2.0 & 17.5 & --- & --- & --- \\
\hline 4.2 & --- & 49.7 & $-\cdots$ & 49.9 \\
\hline 4.3 & 47.5 & $-\cdots$ & 50.4 & $-\cdots$ \\
\hline 6.7 & 69.9 & 71.6 & 72.5 & 71.9 \\
\hline 8.9 & 85.6 & $-\cdots$ & $-\cdots$ & --- \\
\hline 12.0 & 100.9 & 104.0 & 104.9 & 104.4 \\
\hline 15.0 & --- & 113.1 & 113.7 & $-\cdots$ \\
\hline 15.1 & 110.0 & $-\cdots$ & --- & 113.0 \\
\hline 19.1 & 118.7 & $-\cdots$ & 124.2 & $-\cdots$ \\
\hline 20.9 & $-\cdots$ & 123.5 & $-\cdots$ & 123.8 \\
\hline 21.0 & 120.1 & --- & --- & $-\cdots$ \\
\hline 23.0 & 120.9 & 124.3 & 124.9 & 124.5 \\
\hline
\end{tabular}




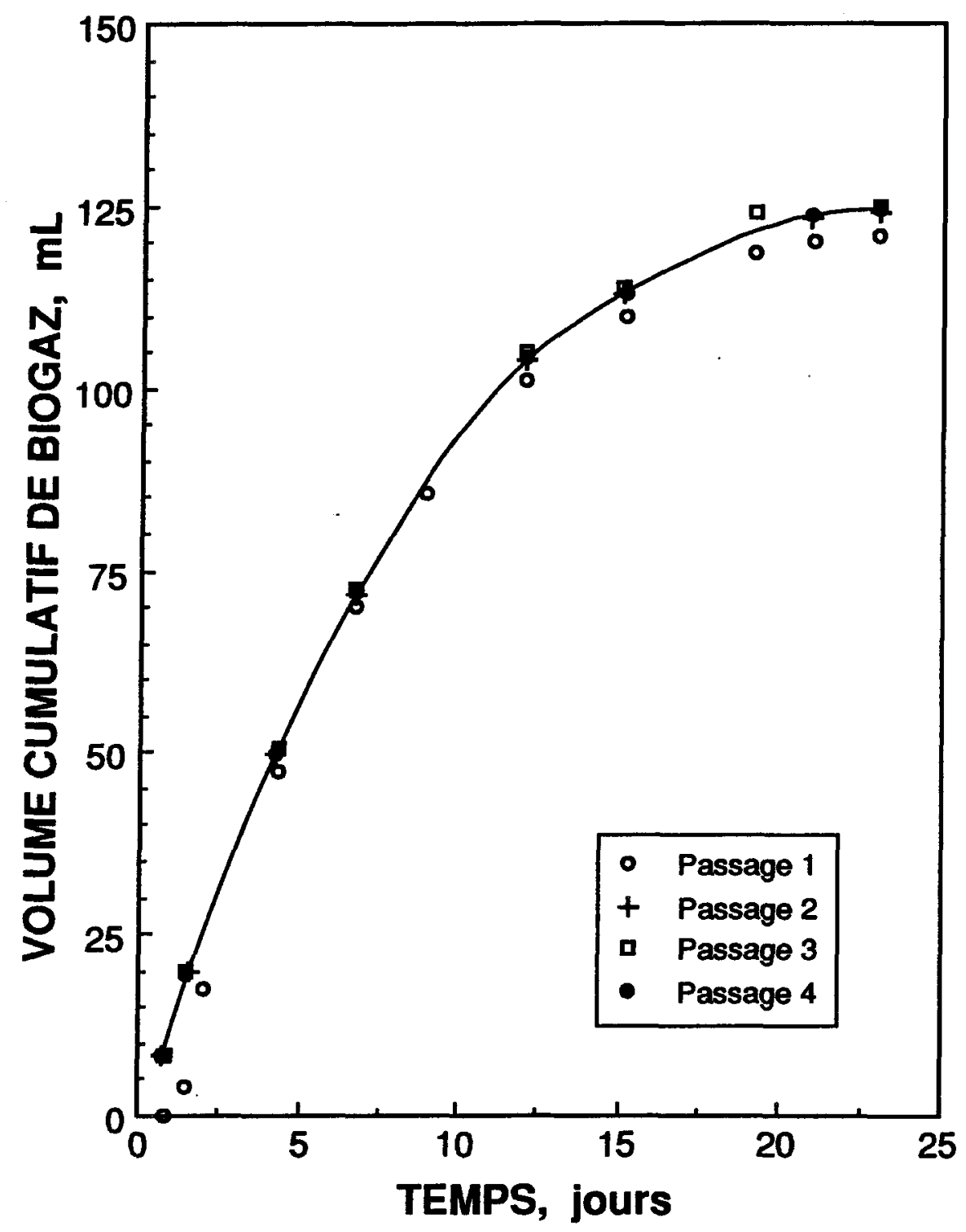

Figure 18: Volume cumulatif de biogaz produit en fonction du temps lors de l'acclimatation des bactéries anaérobies à la solution I 
Tableau XVI - Volume cumulatif de biogaz produit lors de l'acclimatation des bactéries anaérobies à la solution $\mathrm{J}$.

\begin{tabular}{|c|c|c|c|c|}
\hline \multirow[b]{2}{*}{$\begin{array}{l}\text { Temps } \\
\text { jour }\end{array}$} & \multicolumn{4}{|c|}{ Volume cumulatif, $\mathrm{mL}$} \\
\hline & $\begin{array}{c}\text { Passage } 1 \\
\mathrm{~mL}\end{array}$ & $\begin{array}{c}\text { Passage } 2 \\
\mathrm{~mL}\end{array}$ & $\begin{array}{c}\text { Passage } 3 \\
\mathrm{~mL}\end{array}$ & $\begin{array}{c}\text { Passage } 4 \\
\mathrm{~mL}\end{array}$ \\
\hline 0.7 & 0 & 7.3 & 7.5 & 7.4 \\
\hline 1.5 & 0 & ---- & ---- & ---- \\
\hline 1.9 & ---- & 19.8 & --- & 20.5 \\
\hline 2.0 & 10.0 & ---- & 21.6 & ---- \\
\hline 4.1 & ---- & 41.3 & --- & 42.0 \\
\hline 4.3 & 37.9 & ---- & 42.0 & --- \\
\hline 6.5 & ---- & 64.5 & ---- & 64.8 \\
\hline 6.7 & 62.1 & ---- & 65.0 & ---- \\
\hline 8.9 & 77.9 & ---- & 80.3 & ---- \\
\hline 9.0 & ---- & 80.0 & ---- & 80.5 \\
\hline 12.0 & 92.5 & --- & 94.9 & ---- \\
\hline 12.2 & --- & 94.3 & ---- & 95.3 \\
\hline 16.0 & ---- & 105.7 & ---- & ---- \\
\hline 16.2 & 104.0 & ---- & 106.9 & 106.5 \\
\hline 19.0 & ---- & 110.2 & 110.5 & 110.6 \\
\hline 19.1 & 108.6 & ---- & ---- & ---- \\
\hline 21.0 & 109.9 & 111.4 & 111.9 & 111.7 \\
\hline 23.0 & 110.4 & 112.0 & 112.5 & 112.5 \\
\hline
\end{tabular}




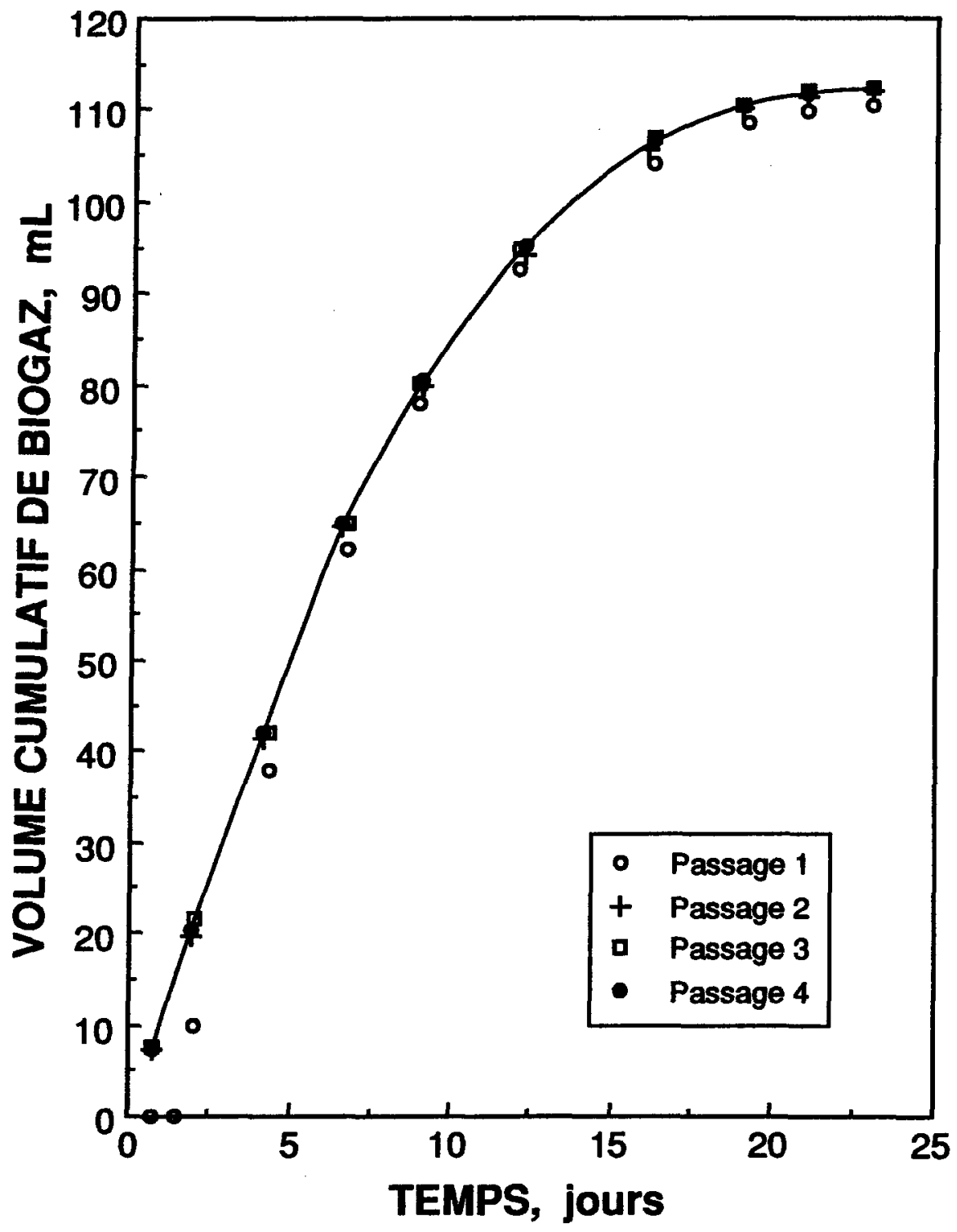

Figure 19: Volume cumulatif de biogaz produtt en fonction du temps lors de l'acclimatation des bactéries anaérobies à la solution J 
(figures 16 et 19), la période de latence qui est près de 40 heures avec des bactéries non acclimatees (premier passage) disparait avec des bactéries acclimatées (quatrieme passage). Par contre, l'acclimatation des bactéries n'a qu'un faible effet sur le volume de biogaz produit par digestion des differentes solutions (tableaux XI a XVI). En effet, le volume produit après acclimatation (quatrième passage) n'a subit qu'une augmentation minime, de l'ordre de 2\%, par rapport au volume de gaz produit avant acclimatation (premier passage ) .

Le tableau XVII donne les pourcentages de réduction de la DCO, de la xylane et de l'acide deshydroabiétique des solutions synthétiques en utilisant des bactéries acclimatées à ces solutions. L'acclimatation des bactéries n'a qu'une très faible influence de l'ordre de 1 a $3 \%$, sur le degré de réduction de la DCO et de la concentration en xylane (tableaux VII et XVII). Les bactéries acclimatées aux différentes solutions synthétiques traitées donnent une réduction de l'acide deshydroabiétique de l'ordre de 5 a $8 \%$ supérieure a la réduction obtenue en utilisant des bactéries non acclimatées aux solutions traitées (tableaux VII et XVII). La composition du biogaz produit lors de la digestion des solutions synthetiques ne dépend pas de l'état de l'acclimatation des bactéries a ces solutions (tableaux VIII et XVIII).

5.3 - Cinetique de la digestion anaérobie

Les tableaux XIX, XX et XXI donnent la DCo ainsi que les concentrations en xylane (S), en acide déshydroabiétique (I) en 
Tableau XVII Pourcentage de réduction de la DCO, de la concencentration en xylane et de l'acide déshydroabiétique en fonction de la durée du traitement pour des eaux résiduaires synthétiques en utilisant des bactéries acclimatées à celles-ci.

\begin{tabular}{|c|c|c|c|c|c|c|c|}
\hline \multirow[b]{2}{*}{ solution } & \multirow[b]{2}{*}{$\begin{array}{l}\text { Durée } \\
\text { jour }\end{array}$} & \multicolumn{2}{|c|}{ DCO } & \multicolumn{2}{|c|}{ Xylane } & \multicolumn{2}{|c|}{$\mathrm{ADA}^{1}$} \\
\hline & & $\begin{array}{c}(\mathrm{DCO})_{0}^{2} \\
\mathrm{mg} / \mathrm{L}\end{array}$ & $\begin{array}{c}\text { Réduc- } \\
\text { tion } \\
\quad \%\end{array}$ & $\mathrm{~s}_{\mathrm{o}}^{2} / \mathrm{L}$ & $\begin{array}{c}\text { Reduc- } \\
\text { tion } \\
\\
q\end{array}$ & $\begin{array}{c}I_{0}^{2} \\
m g / L\end{array}$ & $\begin{array}{c}\text { Réduc- } \\
\text { tion } \\
\text { \% }\end{array}$ \\
\hline $\mathbf{B}$ & 21.0 & 3300 & 93 & 2270 & 95 & 0 & -- \\
\hline D & 21.0 & 3415 & 88 & 2270 & 91 & 40 & 60 \\
\hline $\mathbf{E}$ & 21.0 & 3570 & 77 & 2270 & 79 & 100 & 42 \\
\hline G & 23.0 & 5790 & 93 & 4550 & 94 & 0 & -- \\
\hline I & 23.0 & 5900 & 84 & 4550 & 87 & 40 & 58 \\
\hline $\mathbf{J}$ & 23.0 & 6070 & 71 & 4550 & 74 & 100 & 40 \\
\hline
\end{tabular}

1: ADA: acide déshydroabiétique

2: $\mathrm{DCO}_{0}, \mathrm{~S}_{0}$ et $I_{0}:$ concentrations initiales 
Tableau XVIII Volume cumulatif de biogaz, sa composition moyenne en methane ainsi que le rendement en $\mathrm{CH}_{4}$ obtenus par digestion anaérobie des différentes solutions synthétiques par des bactéries acclimatées à ces solutions.

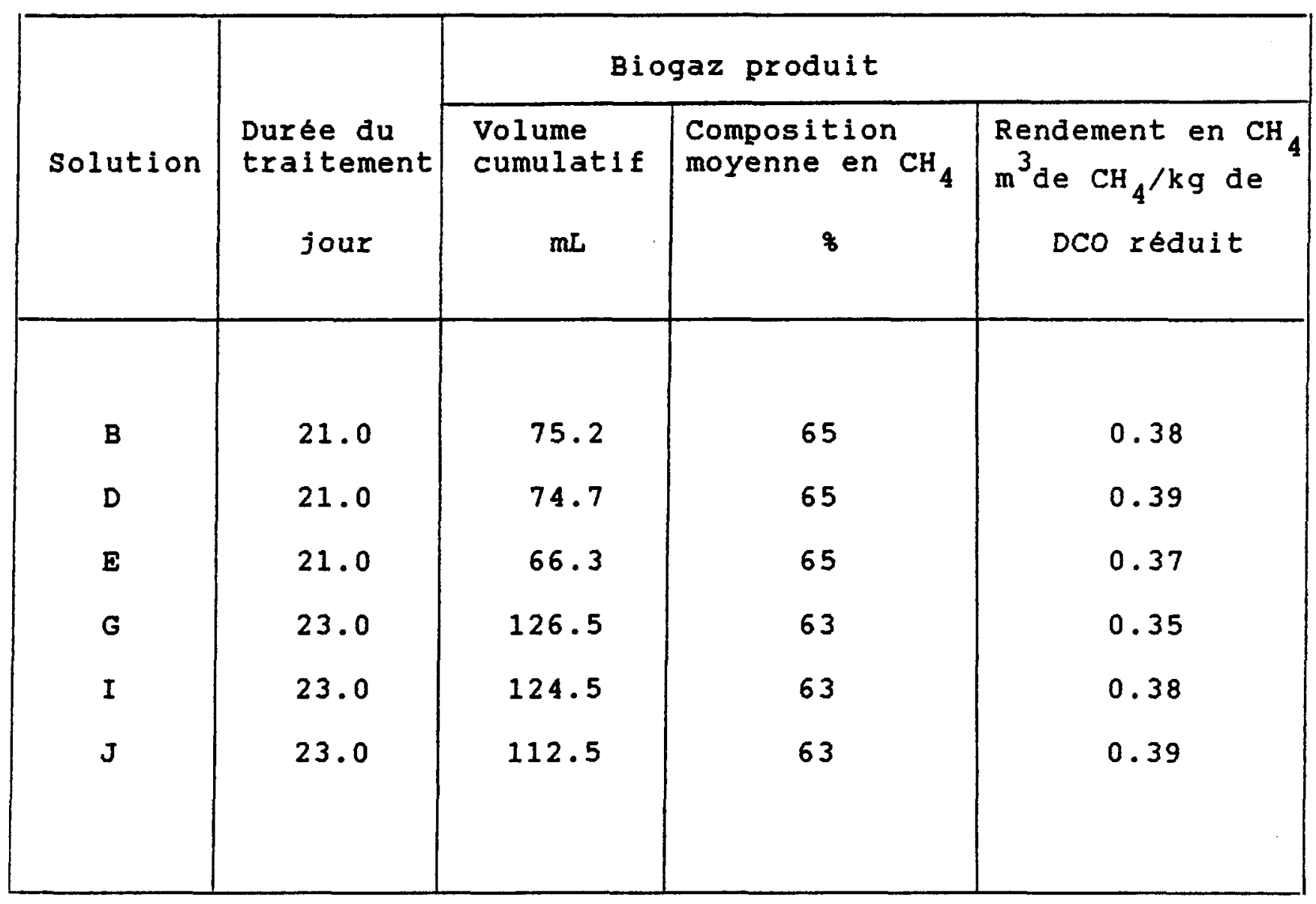


Tableau XIX Valeurs de la DCo, de la concentration de xylane, d'acide déshydroabiétique et de biomasse en fonction du temps pour les solutions $B$ et $G$.

\begin{tabular}{|c|c|c|c|c|c|}
\hline $\begin{array}{l}\text { Temps } \\
\text { jour }\end{array}$ & $\begin{array}{l}\mathrm{DCO} \\
\mathrm{mg} / \mathrm{L}\end{array}$ & $\begin{array}{c}\text { Xylane } \\
\mathrm{mg} / \mathrm{L}\end{array}$ & $\begin{array}{l}\mathrm{ADA}^{1} \\
\mathrm{mg} / \mathrm{L}\end{array}$ & $\begin{array}{c}\text { Bi omasse } \\
\mathrm{mg} / \mathrm{L}\end{array}$ & $\mathrm{pH}$ \\
\hline \multicolumn{6}{|c|}{ Solution B } \\
\hline 0 & 3300 & 2270 & 0 & 820 & 6.7 \\
\hline 0.9 & 2250 & 1460 & 0 & 982 & 6.5 \\
\hline 1.4 & 1810 & 1100 & 0 & 1070 & 6.4 \\
\hline 1.8 & 1300 & 750 & 0 & 1154 & 6.2 \\
\hline 2.2 & 980 & 630 & 0 & 1209 & 6.1 \\
\hline 2.6 & 890 & 530 & 0 & 1242 & 6.2 \\
\hline 3.0 & 770 & 450 & 0 & 1267 & 6.3 \\
\hline 4.0 & 500 & 330 & 0 & ---- & 6.4 \\
\hline \multicolumn{6}{|c|}{ Solution $G$} \\
\hline 0 & 5790 & 4550 & 0 & 810 & 6.7 \\
\hline 0.9 & 4820 & 3690 & 0 & 988 & 6.5 \\
\hline 1.4 & 4130 & 3160 & 0 & 1115 & 6.3 \\
\hline 1.8 & 3460 & 2640 & 0 & 1241 & 6.1 \\
\hline 2.2 & 2990 & 2300 & 0 & 1330 & 6.0 \\
\hline 2.6 & 2590 & 2000 & 0 & 1405 & 6.1 \\
\hline 3.0 & 2150 & 1660 & 0 & 1487 & 6.1 \\
\hline 4.0 & 1480 & 1070 & 0 & 1616 & 6.2 \\
\hline
\end{tabular}

1: ADA: acide déshydroabiétique 
Tableau XX Valeur de la DCo, de la concentration de xylane, d'acide déshydroabiétique et de biomasse en fonction du temps pour les solutions $D$ et I.

\begin{tabular}{|c|c|c|c|c|c|}
\hline $\begin{array}{l}\text { Temps } \\
\text { Jour }\end{array}$ & $\begin{array}{l}\mathrm{DCO} \\
\mathrm{mg} / \mathrm{L}\end{array}$ & $\begin{array}{l}\text { Xylane } \\
\mathrm{mg} / \mathrm{L}\end{array}$ & $\begin{array}{l}\mathrm{ADA}{ }^{1} \\
\mathrm{mg} / \mathrm{L}\end{array}$ & $\begin{array}{c}\text { Biomasse } \\
\mathrm{mg} / \mathrm{L}\end{array}$ & $\mathrm{pH}$ \\
\hline \multicolumn{6}{|c|}{ Solution D } \\
\hline 0 & 3415 & 2270 & 40 & 830 & 6.7 \\
\hline 0.9 & 2530 & 1550 & 37 & 986 & 6.5 \\
\hline 1.4 & 2100 & 1200 & 36 & 1062 & 6.3 \\
\hline 1.8 & 1720 & 870 & 35 & 1128 & 6.2 \\
\hline 2.2 & 1380 & 740 & 34 & 1194 & 6.1 \\
\hline 2.6 & 1140 & 670 & 31 & 1238 & 6.1 \\
\hline 3.0 & 950 & 570 & 29 & 1275 & 6.2 \\
\hline 4.0 & 610 & 490 & 28 & 1326 & 6.3 \\
\hline \multicolumn{6}{|c|}{ Solution I } \\
\hline 0 & 5900 & 4550 & 40 & 815 & 6.7 \\
\hline 0.9 & 4930 & 3800 & 38 & 993 & 6.5 \\
\hline 1.4 & 4305 & 3300 & 37 & 1108 & 6.3 \\
\hline 1.8 & 3770 & 2790 & 36 & 1209 & 6.0 \\
\hline 2.2 & 3310 & 2450 & 35 & 1294 & 6.0 \\
\hline 2.6 & 2880 & 2200 & 32 & 1373 & 6.1 \\
\hline 3.0 & 2550 & 1870 & 30 & 1438 & 6.0 \\
\hline 4.0 & 1830 & 1230 & 29 & 1572 & 6.2 \\
\hline
\end{tabular}


Tableau XXI Valeurs de la DCO, de la concentration de xylane, d'acide déshydroabietique et de biomasse en fonction du temps pour les solutions $E$ et $J$.

\begin{tabular}{|c|c|c|c|c|c|}
\hline $\begin{array}{l}\text { Temps } \\
\text { jour }\end{array}$ & $\begin{array}{l}\mathrm{DCO} \\
\mathrm{mg} / \mathrm{L}\end{array}$ & $\begin{array}{c}\text { Xylane } \\
\text { mg/L }\end{array}$ & $\begin{array}{l}\mathrm{ADA}^{1} \\
\mathrm{mg} / \mathrm{L}\end{array}$ & $\begin{array}{c}\text { biomasse } \\
\mathrm{mg} / \mathrm{L}\end{array}$ & $\mathrm{pH}$ \\
\hline \multicolumn{6}{|c|}{ Solution E } \\
\hline 0 & 3570 & 2270 & 100 & 820 & 6.7 \\
\hline 0.9 & 2800 & 1740 & 97 & 954 & 6.4 \\
\hline 1.4 & 2490 & 1380 & 96 & 1004 & 6.3 \\
\hline 1.8 & 1955 & 1030 & 93 & 1105 & 6.1 \\
\hline 2.2 & 1590 & 920 & 90 & 1172 & 6.0 \\
\hline 2.6 & 1330 & 840 & 89 & 1219 & 6.0 \\
\hline 3.0 & 1130 & 720 & 88 & 1255 & 6.2 \\
\hline 4.0 & 880 & 600 & 86 & 1296 & 6.3 \\
\hline \multicolumn{6}{|c|}{ Solution J } \\
\hline 0 & 6070 & 4550 & 100 & 815 & 6.7 \\
\hline 0.9 & 5250 & 3950 & 97 & 965 & 6.4 \\
\hline 1.4 & 4700 & 3460 & 95 & 1067 & 6.1 \\
\hline 1.8 & 4040 & 2930 & 93 & 1190 & 6.0 \\
\hline 2.2 & 3500 & 2600 & 91 & 1290 & 5.8 \\
\hline 2.6 & 3100 & 2360 & 90 & 1364 & 6.0 \\
\hline 3.0 & 2790 & 2030 & 89 & 1422 & 6.0 \\
\hline 4.0 & 2170 & 1400 & 85 & 1540 & 6.1 \\
\hline
\end{tabular}

1: ADA: acide déshydroabietique 
biomasse $(X)$ et le $\mathrm{pH}$ en fonction du temps lors de la digestion anaérobie des différentes solutions synthétiques. La figure 20 montre le taux de variation de la DCo des solutions traités en fonction du temps. La vitesse de disparition de la DCo durant les premiers jours diminue en fonction de la concentration de l'acide résinique. Après 1.4 jours, la réduction de la DCo de la solution G (la concentration en acide déshydroabietique est nulle) est de $1660 \mathrm{mg} / \mathrm{L}$ alors qu'elle est de seulement $1370 \mathrm{mg} / \mathrm{L}$ pour la solution $J$ (la concentration initiale en acide deshydroabiétique est 100 $\mathrm{mg} / \mathrm{L})$. Pour une même solution, la DCO réduite par jour diminue en fonction du temps. Par exemple, lors du traitement de la solution G, la réduction de la DCo passe de près de $1100 \mathrm{mg} / \mathrm{L}$ durant le premier jour à seulement $670 \mathrm{mg} / \mathrm{L}$ du troisieme au quatrième jour de la fermentation. Cette baisse de la performance bactérienne est due au fait que le rapport $D C O / X$ diminue en fonction du temps. Pour la solution G (tableau XIX), le rapport DCo/X est voisin de 7 au début de la fermentation et chute a 1.4 après 3 jours de traitement. La chute du rapport $\mathrm{DCO} / \mathrm{X}$ en fonction du temps est due non seulement a la diminution de la DCO mais aussi a l'augmentation de la concentration des cellules bactériennes au cours de la fermentation.

Les figures 21,22 et 23 illustrent la variation de la concentration en xylane en fonction du temps. L'allure générale de ces courbes ressemble beaucoup a celle de la figure 20 . Il y a quand même de légères différences car pour une solution donnée, 


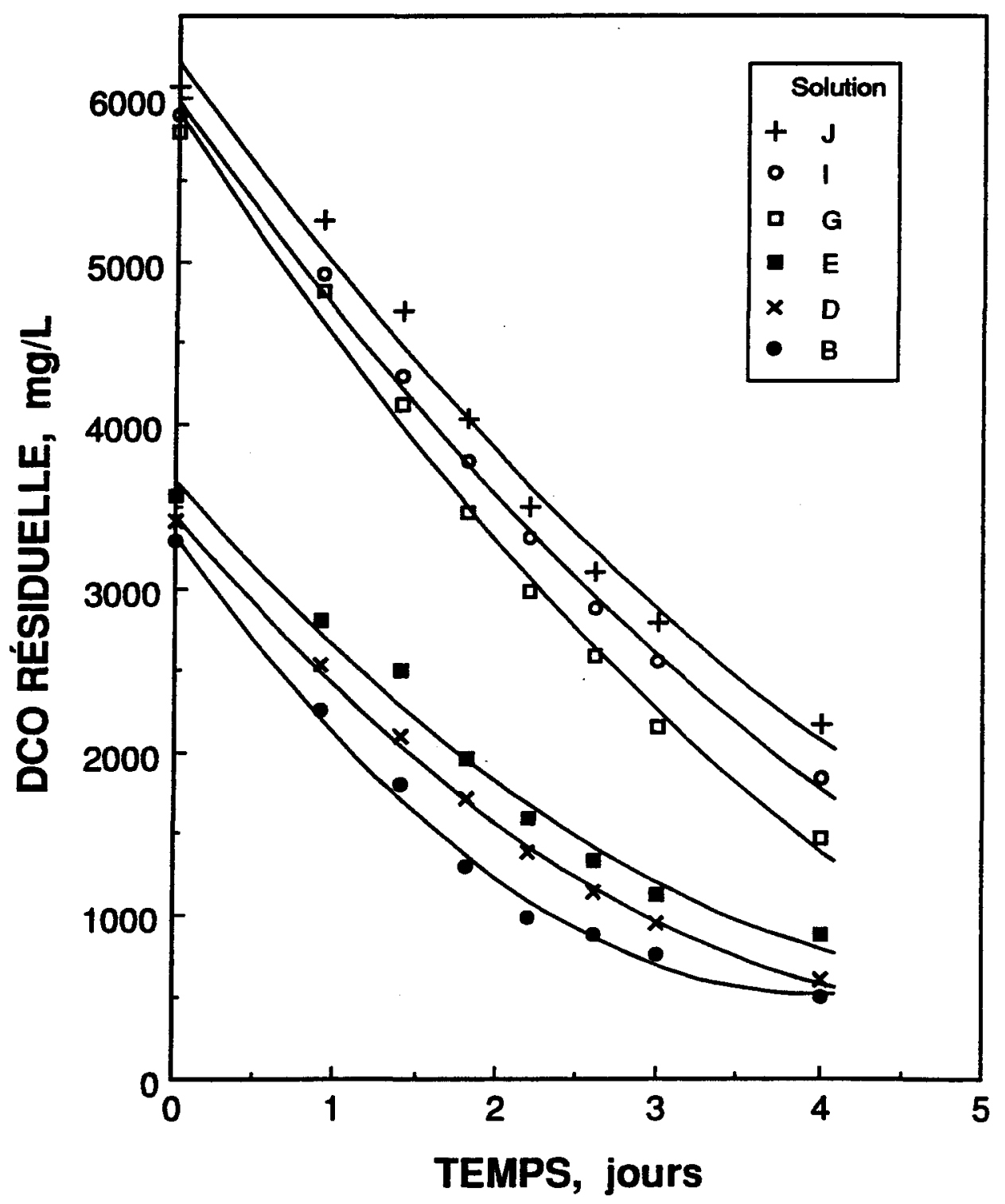

Figure 20: Variation de la DCo en fonction du tempe lore de la digestion anaérobie des solutions $B, D, E, G$, I et $\mathrm{J}$ 


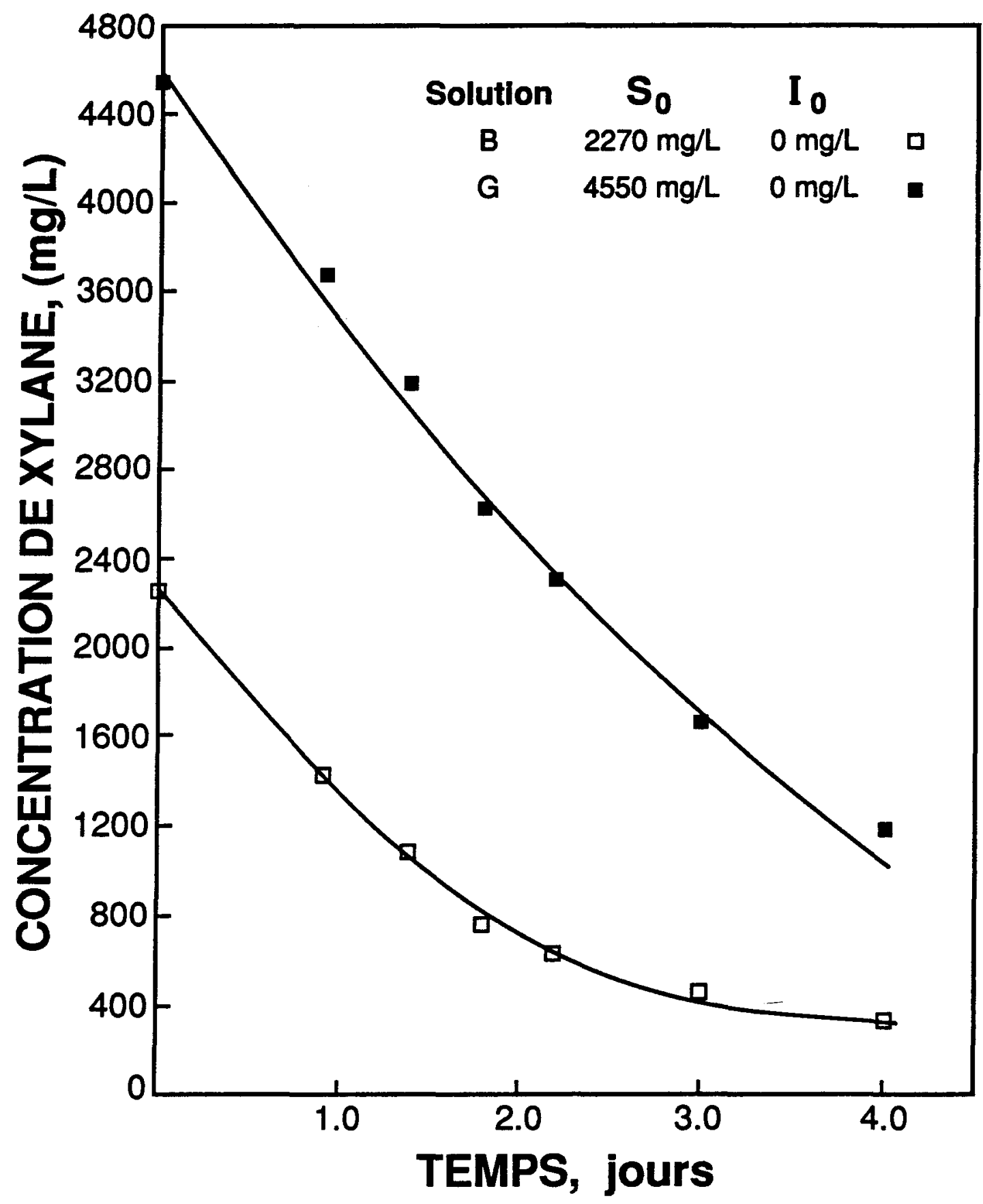

Figure 21: Variation de la concentration de xylane en fonction du temps pour les solutions $B$ et $G$. 


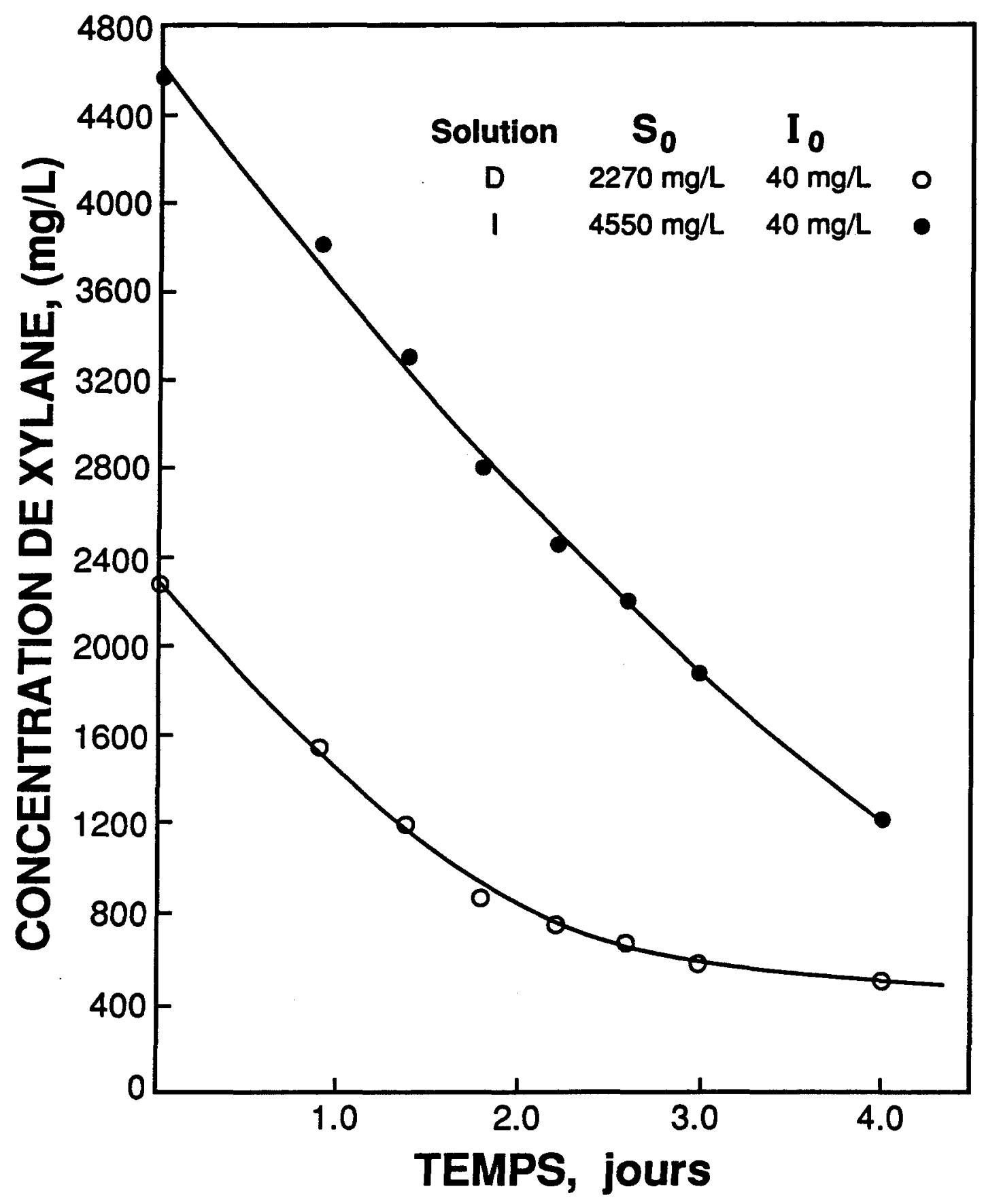

Figure 22: Variation de la concentration de xylane en fonction du temps pour les solutions D et I. 


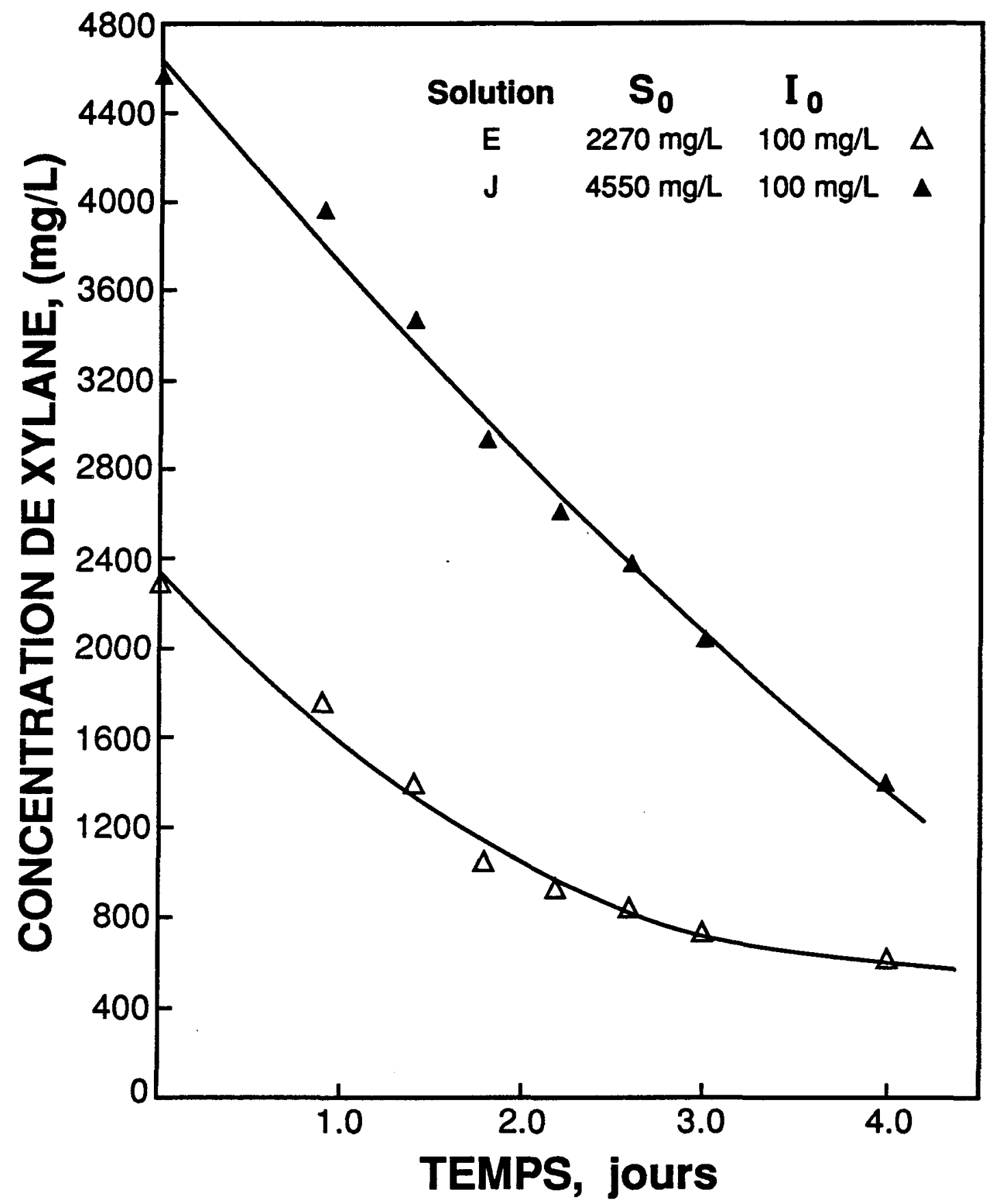

Figure 23: Variation de la concentration de xylane en fonction du temps pour les solutions E et J. 
le rapport $X / D C O$ varie légèrement en fonction du temps. Il faut se rappeler que la DCo est une mesure globale influencée directement par les concentrations résiduelles de xylane, d'acide déshydroabiétique et celles de tous les composés intermédiaires formés durant la digestion.

La figure 24 montre la variation de la concentration des cellules bactériennes pendant la digestion des solutions synthétiques. Les cellules bactériennes utilisent une partie de la matiere organique biodégradée pour se reproduire et une autre partie du substrat est transformée en biogaz. La croissance bactérienne est légèrement ralentie par une augmentation de la concentration de l'acide déshydroabiétique. En effet, cette substance est reconnue comme inhibitrice de la croissance bactérienne.

Contrairement à la xylane, l'acide déshydroabiétique est difficilement biodégradée par les bactéries anaérobies durant 4 jours de traitement. La concentration de cet inhibiteur varie de façon linéaire durant cet intervalle de 4 jours.

Les tableaux XIX, XX et XXI montrent egalement la valeur du $\mathrm{pH}$ durant les 4 premiers jours de la fermentation. Le pH atteint un minimum au début de la fermentation, puis augmente par la suite. Cette baisse du pH est due à la transformation, par les bactéries acidogènes, des substrats organiques biodégradés en acides gras: volatils (voir paragraphe 2.1.2). La solution $J$ présente, après 2.2 jours de digestion, un pH plus bas que celui des autres solutions. Cette faible valeur du pH de la solution $J$ est due a 


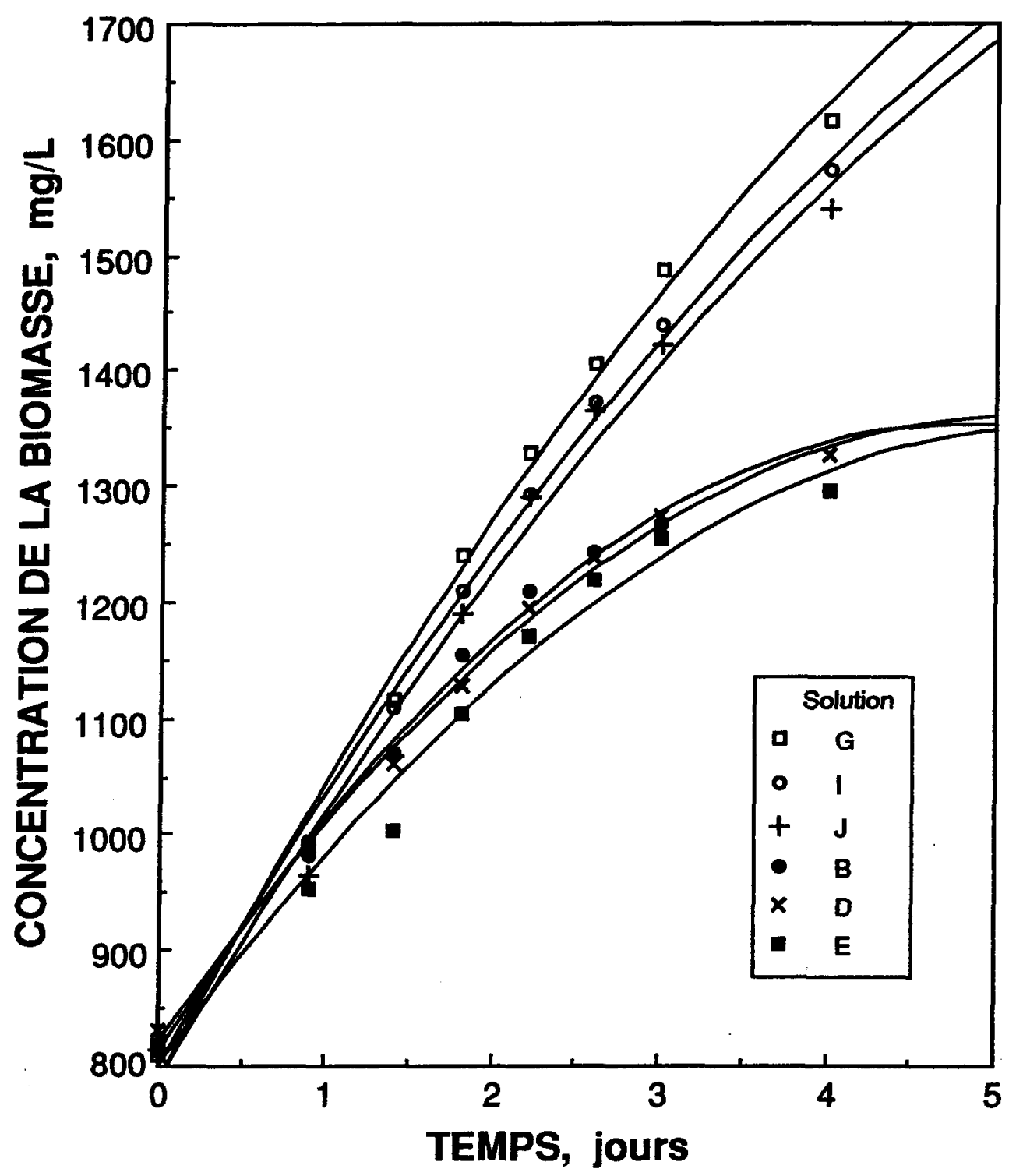

Figure 24: Variation de la concentration de la biomasse en fonction du temps pour les solutions B, D, E, G, I et $J$ 
la présence d'une grande concentration d'acide déshydro- abiétique$(100 \mathrm{mg} / \mathrm{L})$. Ce dernier est toxique pour les bactéries anaérobies. Les bactéries méthanogenes consommatrices des acides volatils sont grandement affectées par la toxicité des substrats (Gunnerson et stuckey, 1986a), d'où une accumulation d'acides volatils et une baisse du pH.

Le tableau XXII donne la composition moyenne en méthane du biogaz produit lors de la digestion anaérobie des differentes solutions synthetiques. Durant les 4 premiers jours de la fermentation, pour une meme solution synthétique, la composition moyenne en méthane du biogaz produit varie peu en fonction du temps (tableau XXII). Cependant, la teneur moyenne en méthane du biogaz diminue légèrement avec l'augmentation du rapport $C_{S} / C_{M}$. Les xylanes produisent un biogaz contenant $60 \%$ de méthane comparativement à $78 \%$ de méthane pour le méthanol (tableau VIII).

Les tableaux XXIII, XXIV et XXV montrent les valeurs calculees de $V^{\prime}$ (équation (2.1)), de $V$ (équation (2.4)), de dx/dt et de $\mu$ (équation (2.8)) en fonction du temps pour les solutions B et G, D, $I$ et $E$ et $J$. Les dérivés de $s$ et de $x$ par rapport au temps ont été calculées en évaluant, pour chacune des solutions et des deux variables, la dérivée d'une équation du second degré (pour $s$ ou $x$ vs le temps) obtenue par la méthode des moindres carrés.

Comme indiqué au paragraphe 2.2 .1 , il existe plusieurs modeles pour étudier la cinétique des réactions enzymatiques. Plusieurs 
Tableau XXII Concentration moyenne en méthane dans le biogaz ( $s$ en volume) produit en fonction du temps lors de la digestion anaerobie des solutions synthetiques.

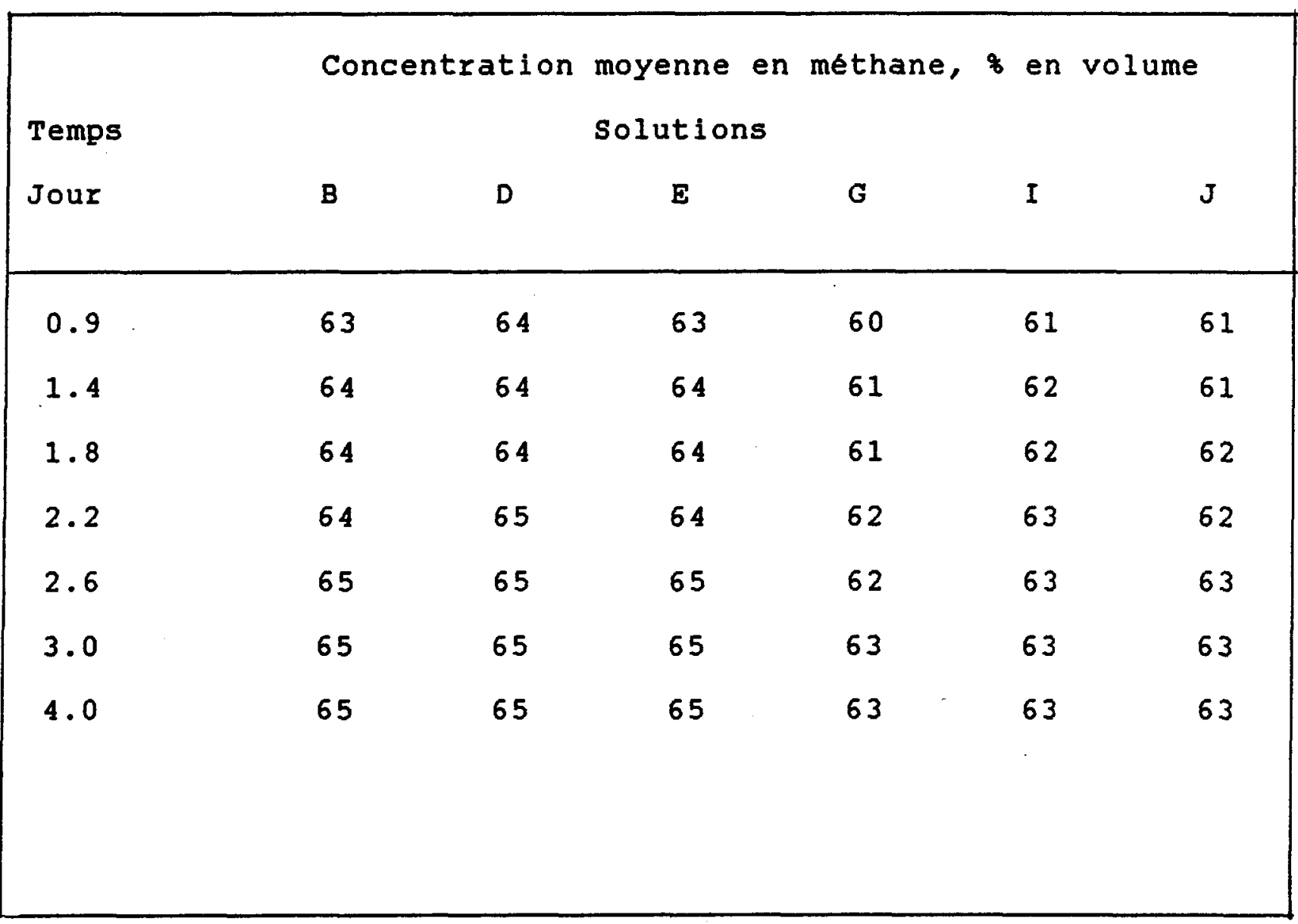


Tableau XXII Valeurs calculés de $V^{\prime}, v$, dx/dt et $\mu$ en fonction du temps pour les solutions B et $G$

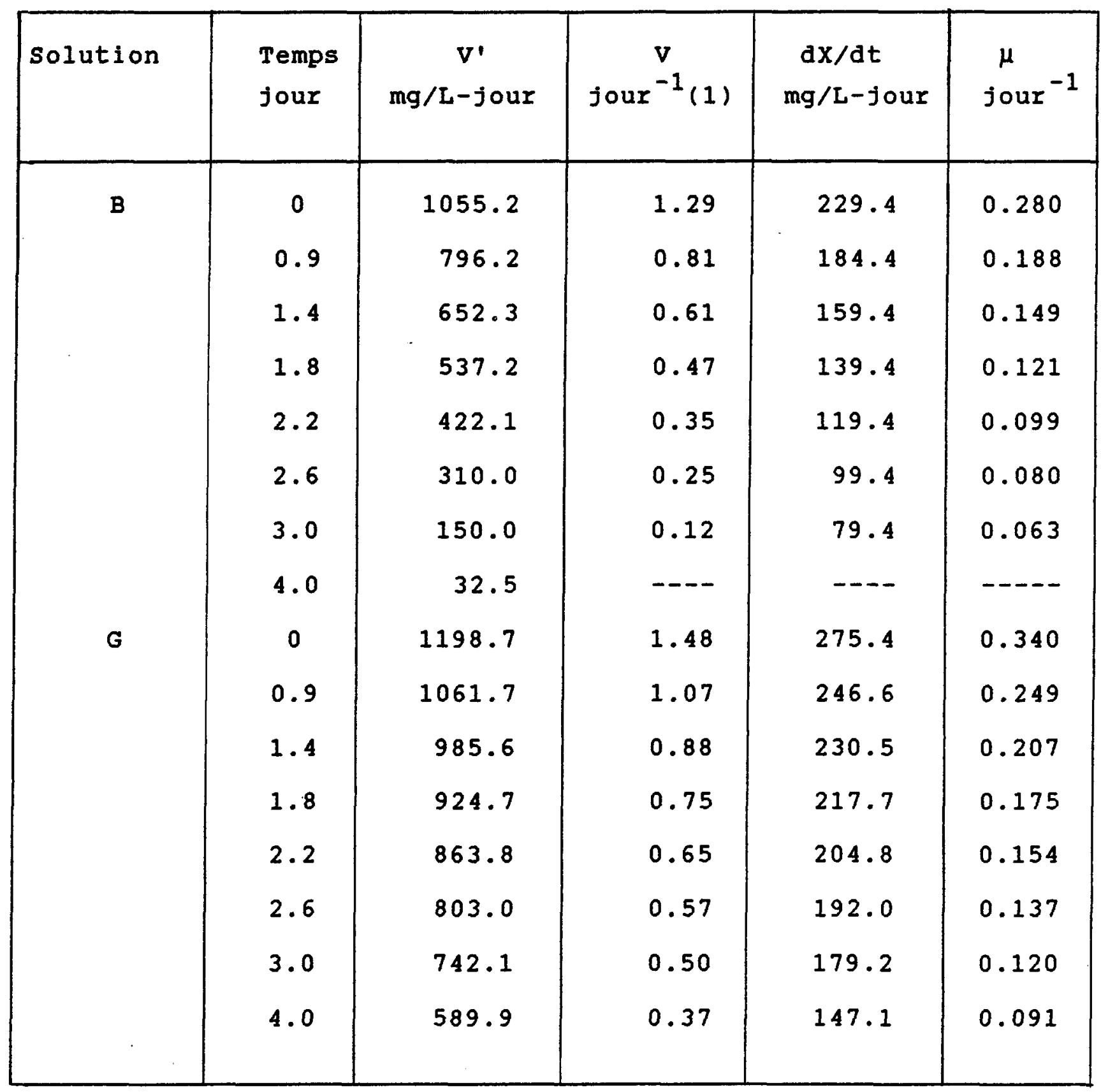

(1) Rigoureusement, les unités sont: mg de $x y l a n e / m g ~ d e$ bactéries -jour. 
Tableau XXIV Valeurs calculées de $V^{\prime}, v$, dx/dt et $\mu$ en fonction du temps pour les solutions $D$ et $I$.

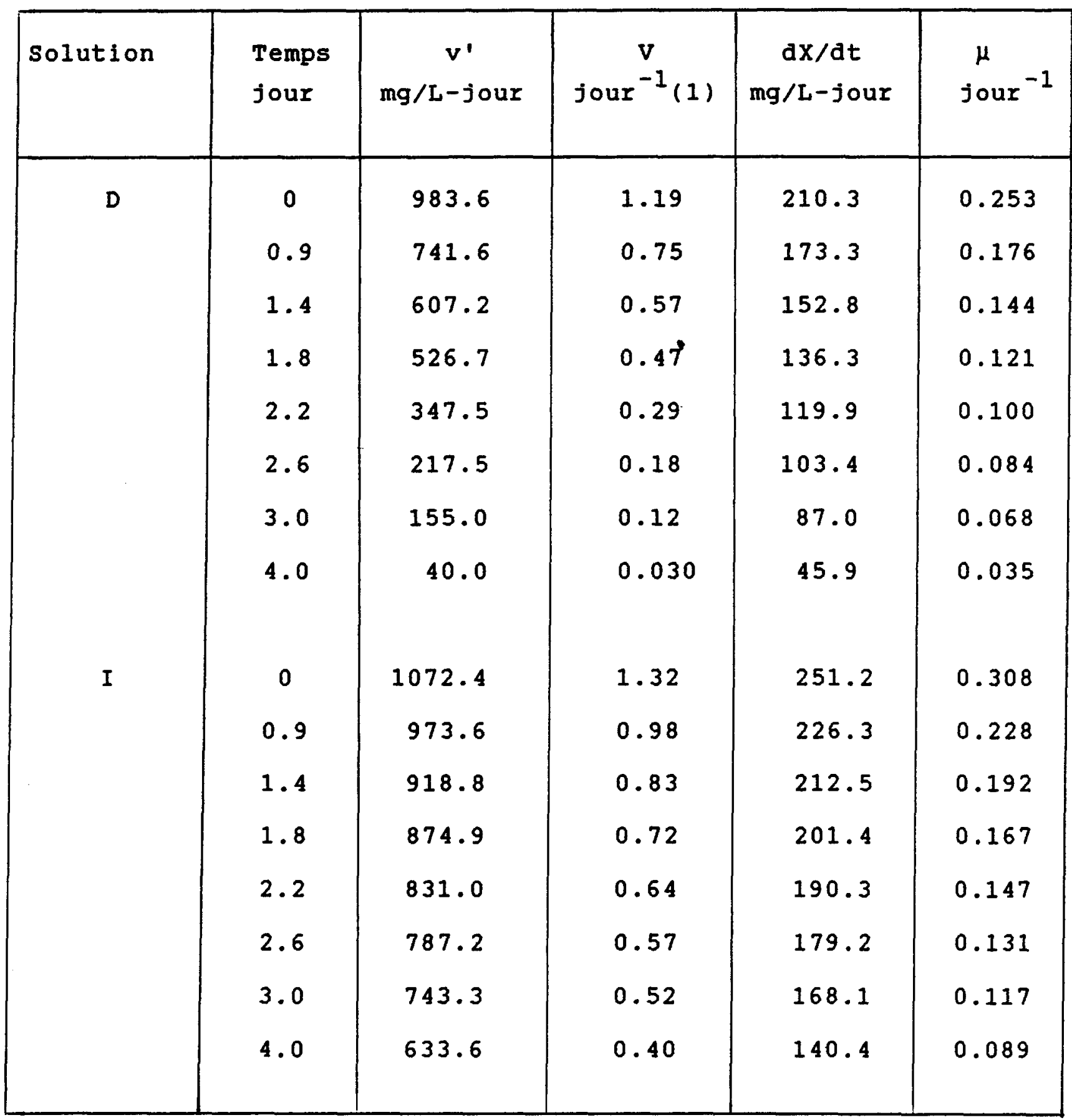

(1) Rigoureusement, les unités sont: mg de xylane/mg de bacteries -jour. 
Tableau XXV Valeurs calculées de $V^{\prime}, V$, dx/dt et $\mu$ en fonction du temps pour les solutions $E$ et $\mathrm{J}$.

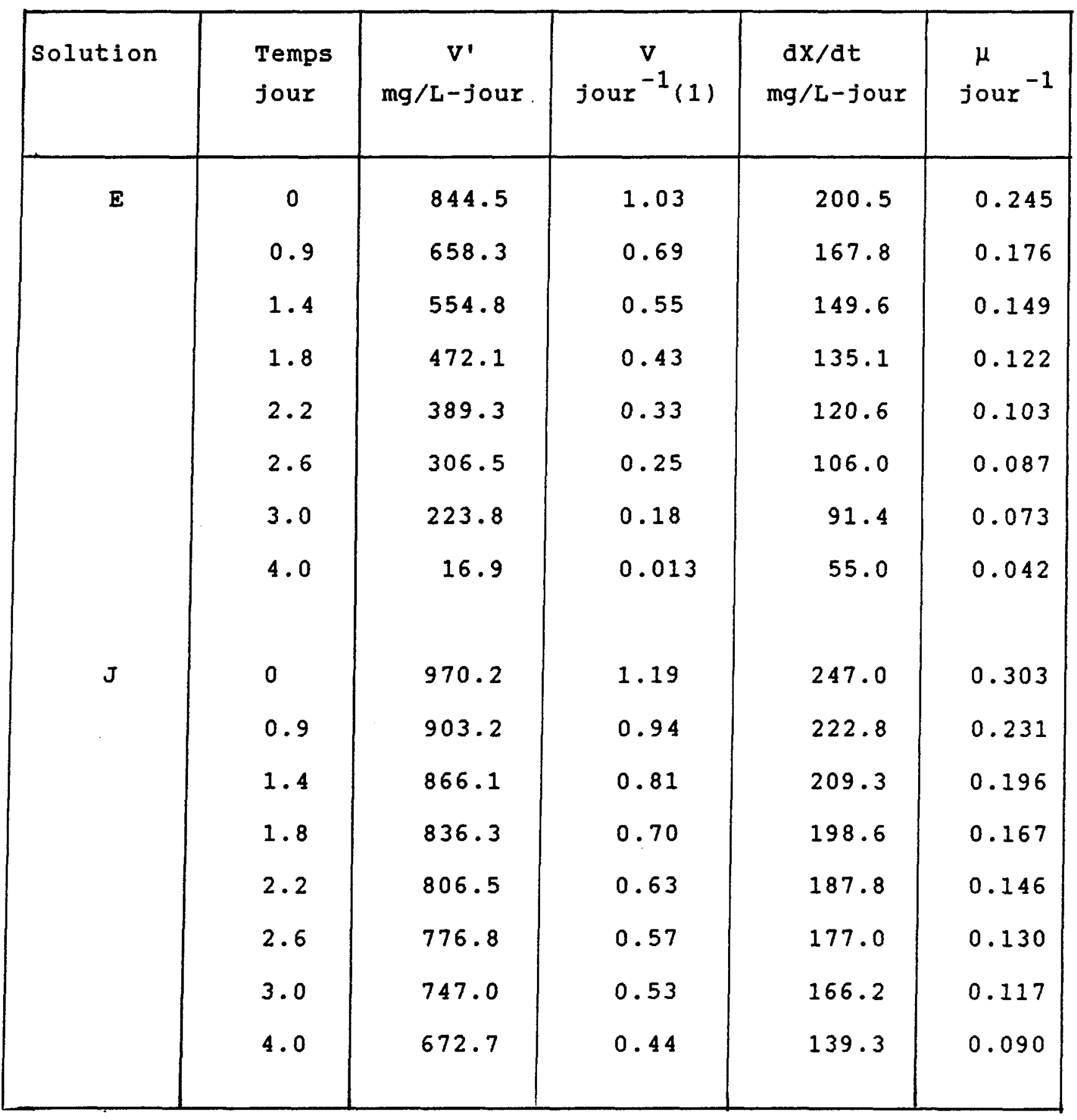

(1) Rigoureusement, les unités sont: mg de xylane/mg de bactéries -jour. 
de ces modeles dérivent de l'équation de Michaelis-Menten (équation (2.1)). Les modèles qui sont représentés respectivement par les equations $(2.1),(2.4),(2.6),(2.8)$ et $(2.10)$ ne conviennent pas pour représenter les valeurs calculées de $V^{\prime}, V$ ou $\mu$ pour les solutions utilisées. En effet, les graphiques de Lineweaver-Burk de ces modèles, c'est-à-dire les équations $(2.2),(2.5),(2.7)$, (2.9) et (2.11) ne donnent pas, pour chacune des paires de solutions, soit $B$ et $G, D$ et $I$ et $E$ et $J$, une droite unique. Par exemple, la solution $B$ ne differe de la solution $G$ que par la concentration initiale de xylane et de meme pour les deux autres paires. On doit donc s'attendre à ce que les résultats des solutions $B$ et $G$ soient regroupés autour d'une droite unique si on utilise un diagramme de Lineweaver-Burk et de même, pour les solutions $D$ et $I$ et $E$ et $J$.

Nous proposons deux équations modifiées pour représenter respectivement la vitesse specifique de biodégradation du xylane et la vitesse spécifique de croissance bacterienne en fonction de la concentration du substrat principal, soit le xylane, et de la concentration de la biomasse. Par analogie avec l'équation (2.6), nous proposons de remplacer le terme $s / X$ par $s / x^{2}$, pour représenter la vitesse spécifique de biodégradation du xylane, soit l'équation suivante:

$$
v=v_{m} \frac{\left(s / x^{2}\right)}{k_{1}+\left(s / x^{2}\right)}
$$

où V: mg xylane/mg biomasse -jour; 
$\mathrm{v}_{\mathrm{m}}$ : $\mathrm{mg}$ xylane/mg biomasse -jour;

S: mg xylane/L;

$X$ : mg biomasse/L;

$K_{1}$ : constante, mg xylane $-L /(m g \text { biomasse })^{2}$.

L'équation (5.1) peut s'écrire:

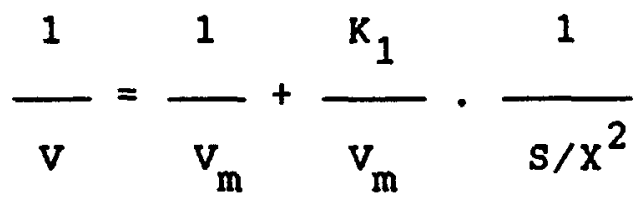

Le tableau XXVI regroupe les valeurs utilisees pour tracer les diagrammes de Lineweaver-Burk. Les figures 25,26 et 27 présentent ces résultats sous la forme de l'equation (5.2). Cing points ont été rejetés dans le cas ou la valeur de la concentration de xylane est faible. Dans ce cas, la valeur de -ds/dt devient petite et le terme $1 / \mathrm{V}$ augmente très rapidement.

L'équation (5.1) représente assez bien la vitesse spécifique de biodégradation de la xylane par comparaison avec les autres équations déjá mentionnées: (2.1), (2.4) et (2.6). Contrairement aux modeles original (équation (2.1)) et modifié (équation (2.3)) de Michaelis-Menten, l'équation (5.1) n'a pas le méme fondement microbiologique. L'équation (5.1) représente la vitesse spécifique de biodégradation de la xylane en présence d'un inhibiteur, lui aussi partiellement biodégradé, a l'aide d'une culture mixte de bacteries comprenant plusieurs especes. Les modeles cités auparavant ont été développés pour représenter la vitesse de biodégradation d'un seul substrat, avec ou sans inhibiteur, à l'aide d'une seule espèce bactérienne. 
Tableau XXVI Valeurs utilisées pour tracer les diagrammes Lineweaver-Burk dans le cas de la vitesse de biodégradation de la xylane.

\begin{tabular}{|c|c|c|c|c|c|}
\hline $1 /\left(s / x^{2}\right)$ & $1 / \mathrm{V}$ & $1 /\left(s / x^{2}\right)$ & $1 / \mathrm{V}$ & $1 /\left(s / x^{2}\right)$ & $I / V$ \\
\hline \multicolumn{2}{|c|}{ Solution B } & \multicolumn{2}{|c|}{ Solution D } & \multicolumn{2}{|c|}{ Solution $E$} \\
\hline 296.2 & 0.779 & 303.5 & 0.844 & 296.2 & 0.971 \\
\hline 660.5 & 1.233 & 627.2 & 1.329 & 523.1 & 1.449 \\
\hline 1040.8 & 1.640 & 939.9 & 1.749 & 730.4 & 1.809 \\
\hline 1775.6 & 2.148 & 1462.5 & 2.142 & 1185.5 & 2.340 \\
\hline 2320.1 & 2.865 & 1926.5 & 3.436 & 1493.0 & 3.011 \\
\hline 2910.5 & 4.005 & & & & \\
\hline \multicolumn{2}{|c|}{ Solution G } & \multicolumn{2}{|c|}{ Solution I } & \multicolumn{2}{|c|}{ Solution $\mathrm{J}$} \\
\hline 144.2 & 0.676 & 146.0 & 0.760 & 146.0 & 0.840 \\
\hline 264.5 & 0.931 & 259.5 & 1.020 & 235.7 & 1.068 \\
\hline 393.4 & 1.132 & 372.0 & 1.206 & 329.0 & 1.232 \\
\hline 583.4 & 1.342 & 523.9 & 1.382 & 483.3 & 1.423 \\
\hline 769.1 & 1.540 & 683.4 & 1.557 & 640.0 & 1.600 \\
\hline 987.0 & 1.749 & 856.9 & 1.744 & 788.3 & 1.755 \\
\hline 1332.0 & 2.004 & 1105.8 & 1.934 & 996.1 & 1.904 \\
\hline 2440.6 & 2.739 & 2009.1 & 2.481 & 1694.0 & 2.290 \\
\hline
\end{tabular}




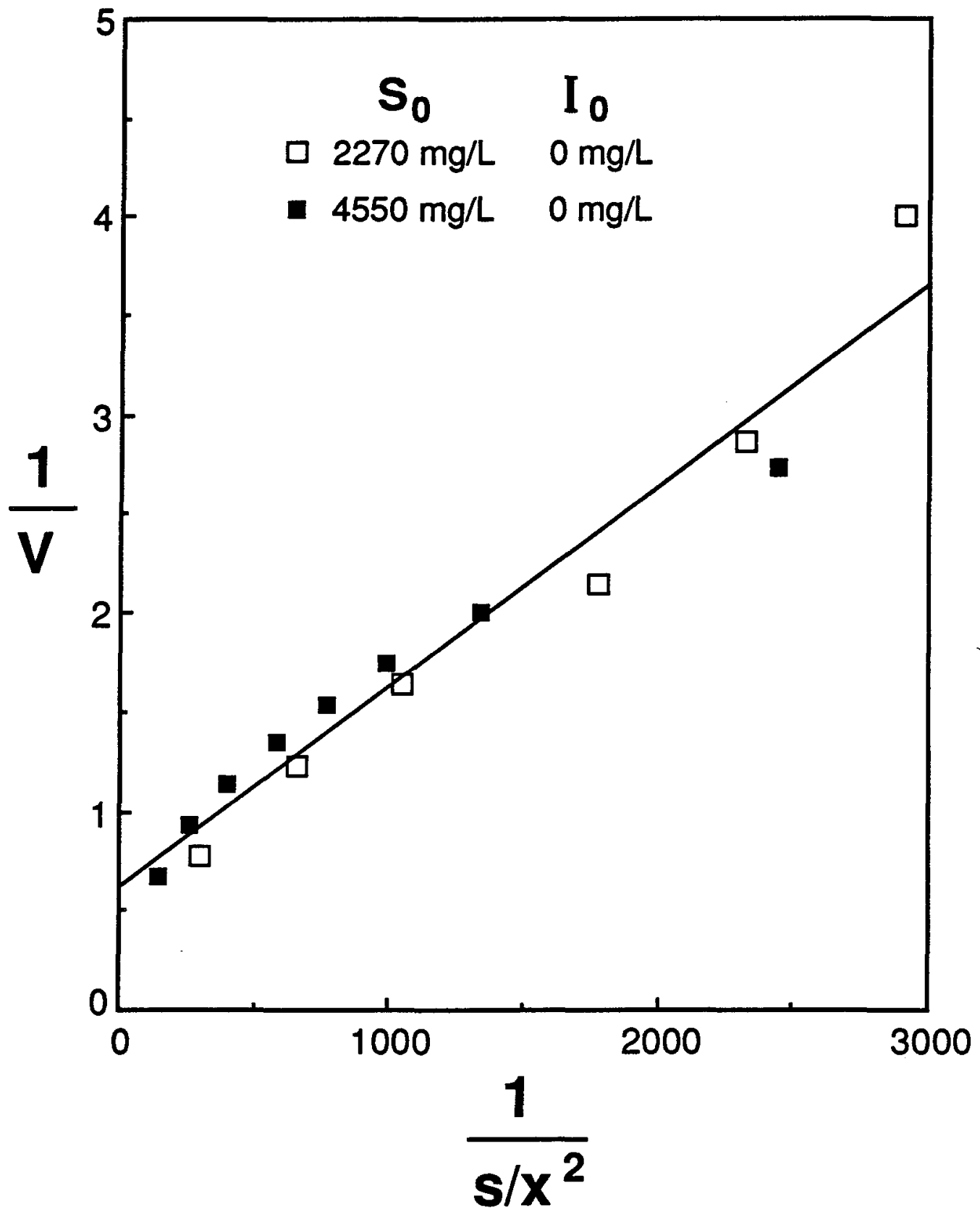

Figure 25: Graphique de Lineweaver-Burk, pour les solutions $B$ et $G\left(I_{0}=0 \mathrm{mg} / \mathrm{L}\right)$, à partir de l'équation 5.1 . 


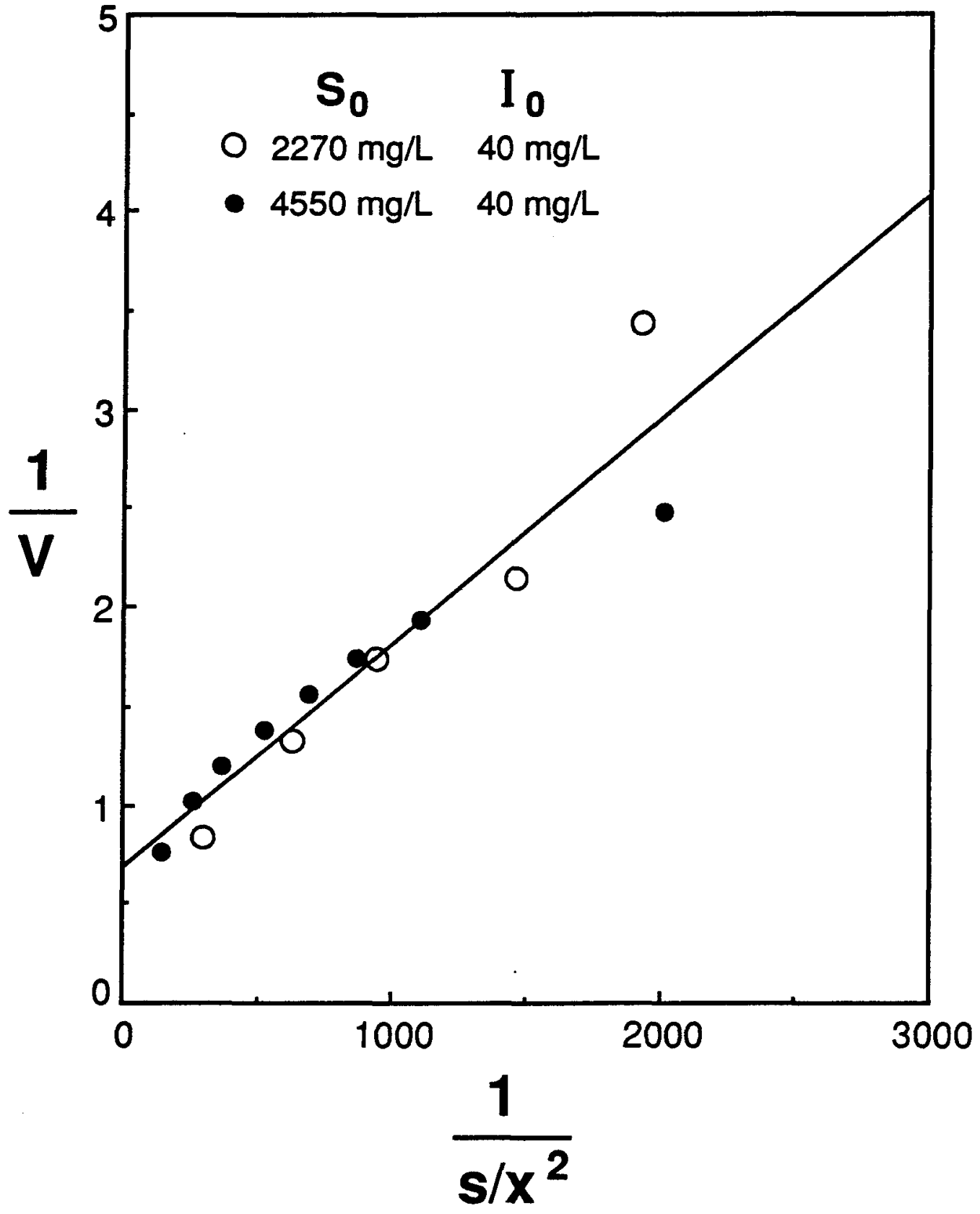

Figure 26: Graphique de Lineweaver-Burk, pour les solutions $D$ et $I\left(I_{0}=40 \mathrm{mg} / \mathrm{L}\right)$, à partir de l'équation 5.1 . 


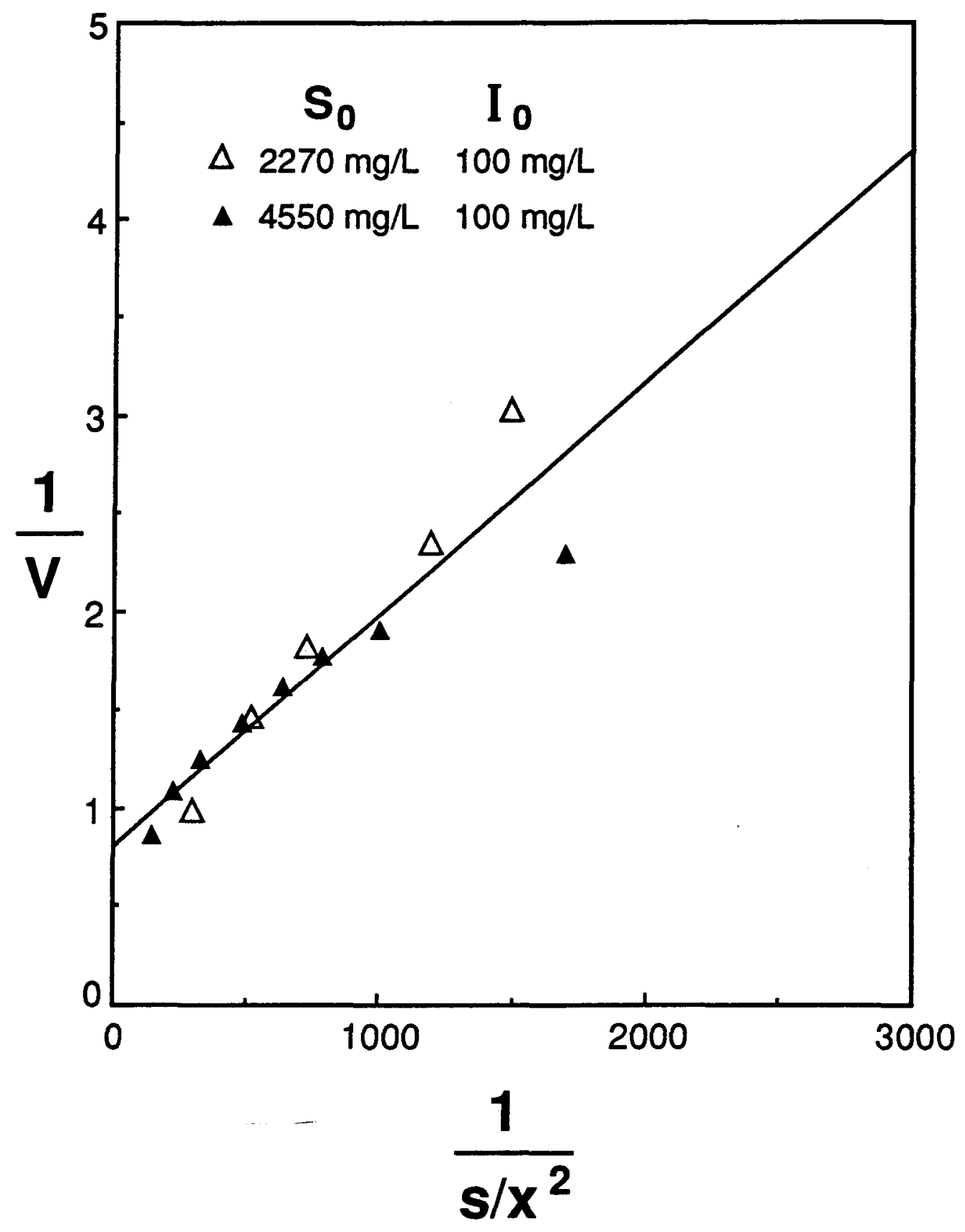

Figure 27: Graphique de Lineweaver-Burk, pour les solutions $E$ et $J\left(I_{0}=100 \mathrm{mg} / L\right)$, à partir de l'équation 5.1 . 
Par analogie avec l'équation (5.1), nous proposons de remplacer le terme $s / x$ du modele de Contois (équation (2.10)) par $s / x^{2}$, pour représenter la vitesse spécifique de croissance bactérienne, soit l'équation suivante:

$$
\mu=\mu_{m} \frac{s / x^{2}}{x_{2}+\left(s / x^{2}\right)}
$$

ou

$$
\frac{1}{\mu}=\frac{1}{\mu_{m}}+\frac{k_{2}}{\mu_{m}} \cdot \frac{1}{\left(s / x^{2}\right)}
$$

ou $\mu:$ jour $^{-1}$

$\mu_{m}:$ jour $^{-1}$

s : mg xylane/L

$\mathrm{X}$ : mg biomasse/L

$K_{2}$ : constante, $m g$ xylane $-L /(m g \text { biomasse })^{2}$

Le tableau XXVII regroupe les valeurs utilisées pour tracer les diagrammes de Lineweaver-Burk. Les figures 28 , 29 et 30 présentent ces résultats sous la forme de l'équation (5.4). Deux points ont été rejetés dans le cas ou la valeur de la concentration de la biomasse (X) n'augmente pratiquement plus. Dans ce cas, la valeur de dx/dt devient petite et le terme $1 / \mu$ augmente tres rapidement.

L'équation (5.3) représente assez bien la vitesse spécifique de croissance bactérienne, par comparaison avec les autres 
Tableau XXVII Valeurs utilisées pour tracer les diagrammes Lineweaver-Burk dans le cas de la vitesse de biodégradation de la croissance bactérienne.

\begin{tabular}{|c|c|c|c|c|c|}
\hline $1 /\left(s / x^{2}\right)$ & $1 / \mu$ & $1 /\left(s / x^{2}\right)$ & $1 / \mu$ & $1 /\left(s / x^{2}\right)$ & $1 / \mu$ \\
\hline \multicolumn{2}{|c|}{ Solution B } & \multicolumn{2}{|c|}{ Solution $\mathrm{D}$} & \multicolumn{2}{|c|}{ Solution $E$} \\
\hline 296.2 & 3.57 & 303.5 & 3.94 & 296.2 & 4.09 \\
\hline 660.5 & 5.32 & 627.2 & 5.70 & 523.1 & 5.69 \\
\hline 1040.8 & 6.71 & 939.9 & 6.96 & 730.4 & 6.71 \\
\hline 1775.6 & 8.27 & 1462.5 & 8.28 & 1185.5 & 8.18 \\
\hline 2320.1 & 10.12 & 1926.5 & 9.96 & 1493.0 & 9.73 \\
\hline 2910.5 & 12.42 & 2287.5 & 11.97 & 1769.0 & 11.51 \\
\hline 3567.3 & 15.96 & 2852.0 & 14.66 & 2187.5 & 13.68 \\
\hline \multicolumn{2}{|c|}{ Solution G } & \multicolumn{2}{|c|}{ solution I } & \multicolumn{2}{|c|}{ solution $\mathrm{J}$} \\
\hline 144.2 & 2.94 & 146.0 & 3.24 & 146.0 & 3.30 \\
\hline 264.5 & 4.01 & 259.5 & 4.39 & 235.7 & 4.33 \\
\hline 393.4 & 4.84 & 372.0 & 5.22 & 329.0 & 5.10 \\
\hline 583.4 & 5.70 & 523.9 & 6.01 & 483.3 & 6.00 \\
\hline 769.1 & 6.49 & 683.4 & 6.79 & 640.0 & 6.88 \\
\hline 987.0 & 7.32 & 856.9 & 7.66 & 788.3 & 7.71 \\
\hline 1332.0 & 8.30 & 1105.8 & 8.56 & 996.1 & 8.56 \\
\hline 2440.6 & 10.49 & 2009.1 & 11.20 & 1694.0 & 11.05 \\
\hline
\end{tabular}




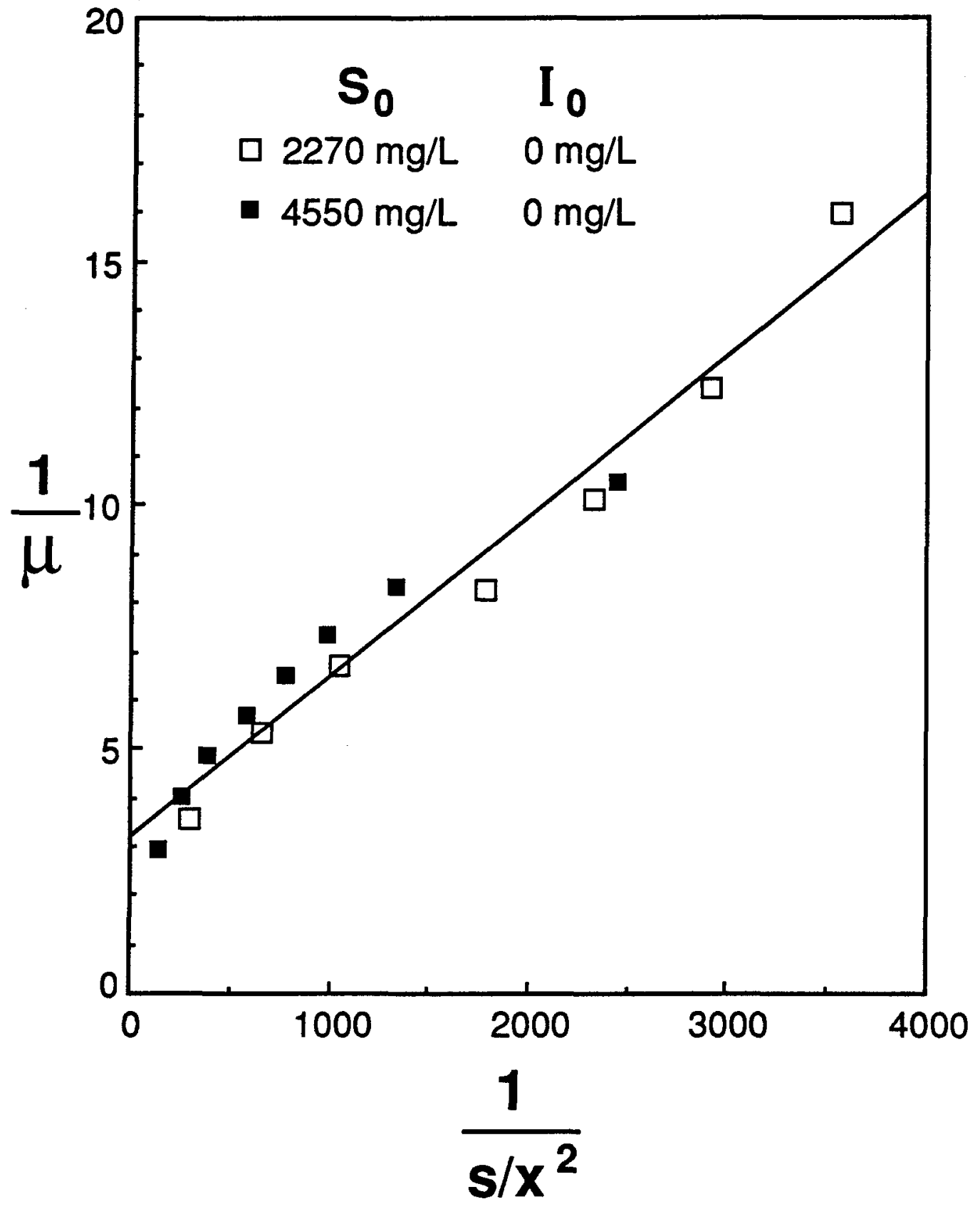

Figure 28: Graphique de Lineweaver-Burk, pour les solutions $B$ et $G\left(I_{0}=0 \mathrm{mg} / \mathrm{L}\right)$, à partir de l'équation 5.3 . 


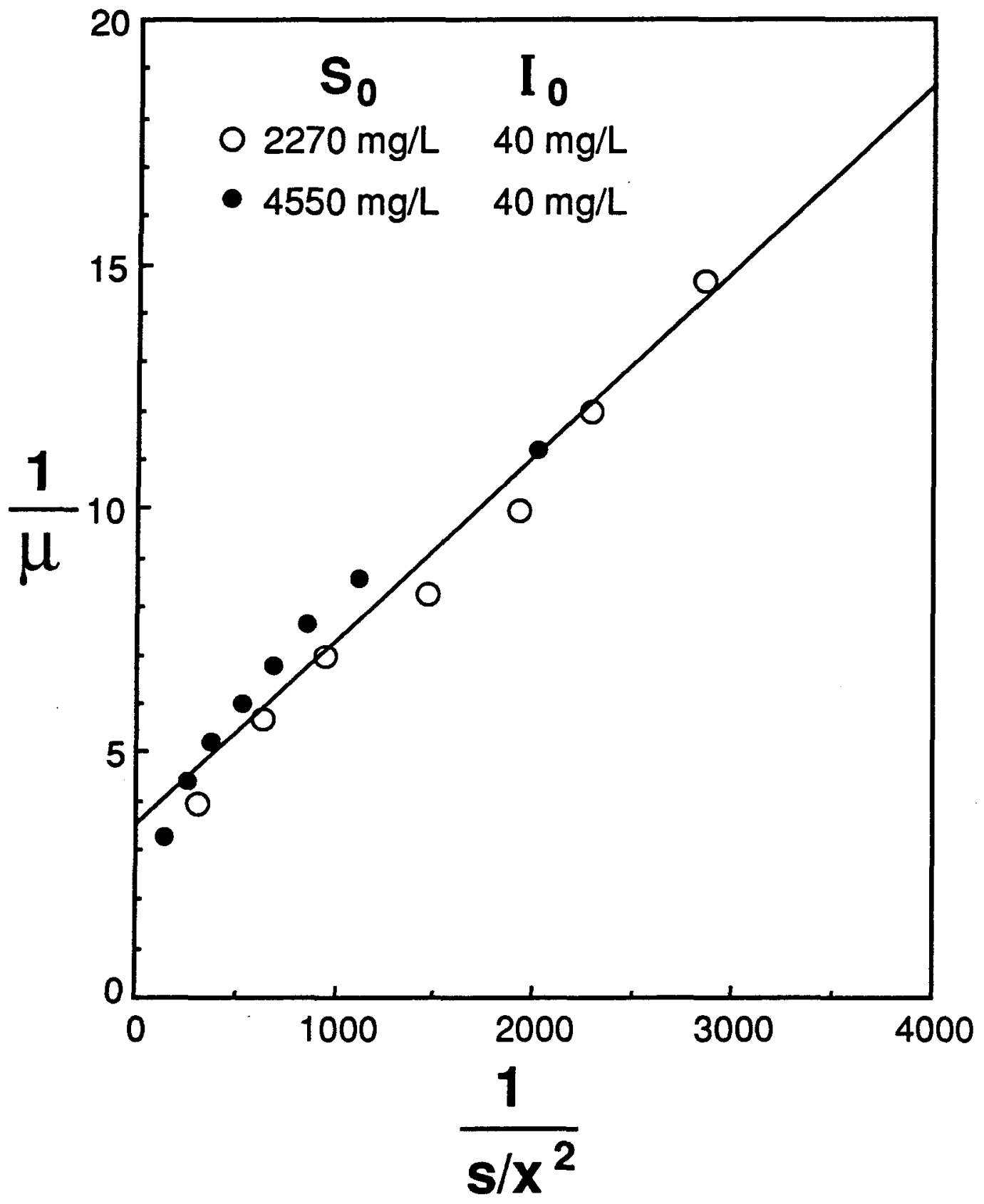

Figure 29: Graphique de Lineweaver-Burk, pour les solutions $D$ et $I\left(I_{0}=40 \mathrm{mg} / \mathrm{L}\right)$, à partir de l'équation 5.3 . 


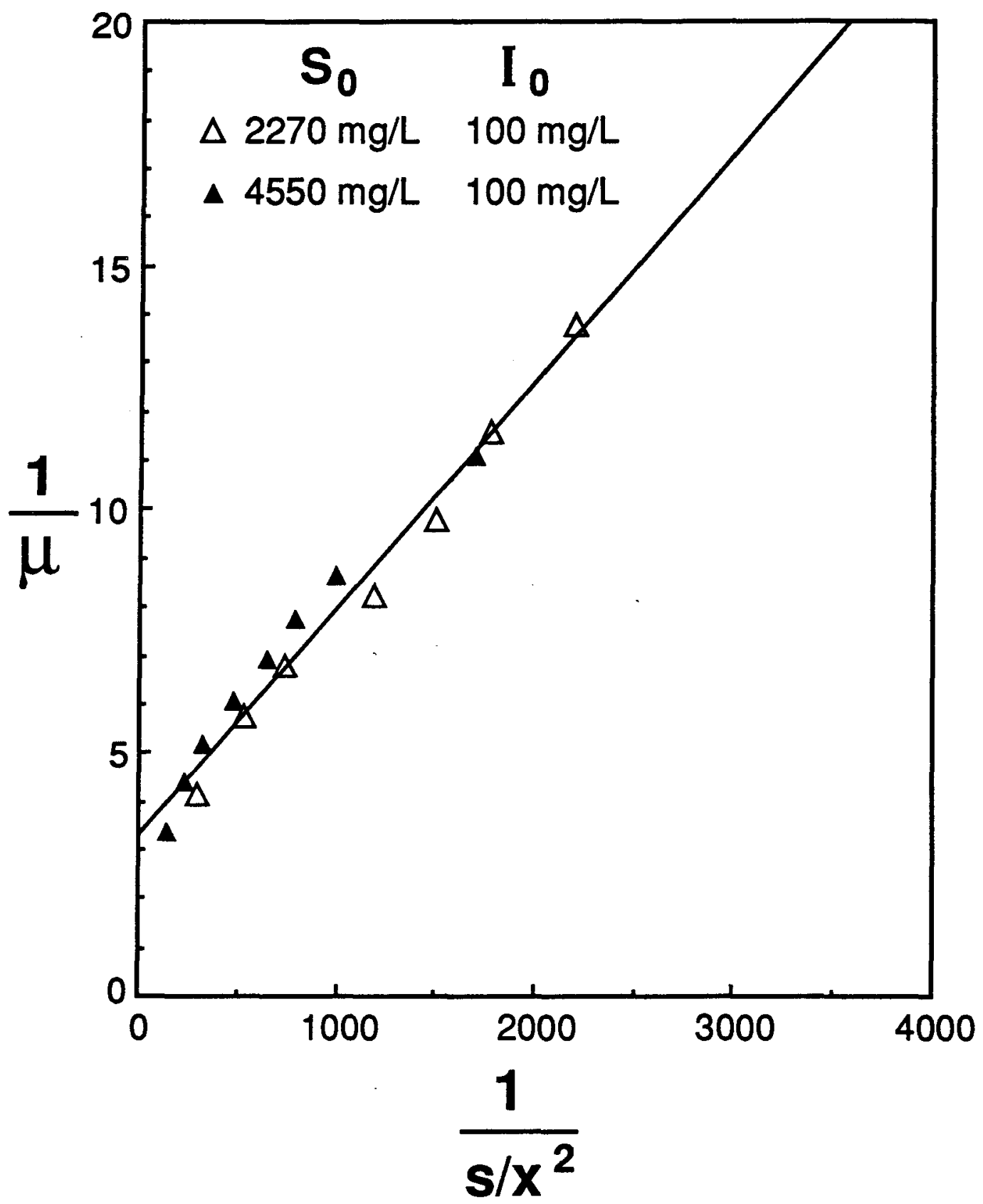

Figure 30: Graphique de Lineweaver-Burk, pour les solutions E et $J\left(I_{0}=100 \mathrm{mg} / \mathrm{L}\right)$, à partir de I'équation 5.3 . 
équations déjà mentionnées: (2.8) et (2.10). Comme pour l'équation précédente proposée, la comparaison de l'équation (5.3) avec l'équation (2.8) de Monod est difficile. L'équation de Monod (1942) a été développé pour représenter la croissance bactérienne d'une souche pure alors que le présent contexte expérimental est tout à fait différent.

Les constantes cinétiques $v_{m}, k_{1}, \mu_{m}$ et $k_{2}$ ont été calculées a partir des valeurs des ordonnés à l'origine et des pentes des droites des figures $25,26,27,28,29$ et 30 . Ces droites ont été obtenues par la méthode des moindres carrés.

Les tableaux XXVIII et XXIX montrent l'influence de la concentration initiale de l'acide déshydroabiétique sur les constantes cinetiques $v_{m}$ et $k_{1}$ de $l$ 'equation (5.1) ainsi que $\mu_{m}$ et $K_{2}$ de l'équation (5.3). L'acide déshydroabiétique a un effet inhibiteur car l'augmentation de sa concentration dans les solutions synthetiques provoque une variation des constantes cinétiques $v_{m}$ et $k_{1}$ ainsi que $\mu_{m}$ et $k_{2}$.

Dans le cas de la vitesse spécifique de biodégradation du substrat, l'augmentation de la concentration initiale (ou sa valeur moyenne) d'acide déshydroabiétique dans les solutions synthétiques provoque une diminution a la fois de $v_{m}$ et de $K_{I}$ par rapport aux phénomènes d'inhibition de réactions enzymatiques, on peut suggérer que de telles variations de $v_{m}$ et de $k_{1}$ impliquent une inhibition de type incompétitive. On ne peut guere pousser plus loin l'analyse car les effets des divers types d'inhibition (section 2.2.5) sur les constantes cinétiques découlent de l'équation 
Tableau XXVIII Valeurs des constantes cinétiques $v_{m}$ et $K_{1}$, en fonction de la concentration initiale de l'acide déshydroabiétique.

\begin{tabular}{|ccc|}
\hline$I_{0}$ & $\begin{array}{c}v_{m} \\
m g \text { xylane/ } \\
m g / L\end{array}$ & $\begin{array}{c}K_{1} \\
m g \text { xylane-L } / \\
(m g \text { biomasse) }\end{array}$ \\
\hline 0 (solutions B et G) & 1.62 & $1.63 \times 10^{-3}$ \\
40 (solutions D et I) & 1.46 & $1.65 \times 10^{-3}$ \\
100 (solutions E et J) & 1.25 & $1.49 \times 10^{-3}$ \\
\hline
\end{tabular}

Tableau XXIX Valeurs des constantes cinetiques $\mu_{m}$ et $k_{2}$ en fonction de la concentration initiale de l'acide déshydroabiétique.

\begin{tabular}{|ccc|}
\hline$I_{0}$ & $\mu_{\mathrm{m}}$ & $\begin{array}{c}\mathrm{K}_{2} \\
\mathrm{mg} \times y l \text { ane-L/ } \\
\text { (mg biomasse) }\end{array}$ \\
\hline 0 (solutions B et $G$ ) & jour $^{-1}$ & $1.03 \times 10^{-3}$ \\
40 (solutions D et $I$ ) & 0.31 & $1.08 \times 10^{-3}$ \\
100 (solutions E et $J$ ) & 0.30 & $1.41 \times 10^{-3}$ \\
\hline
\end{tabular}


originale de Michaelis-Menten (équation (2.1)). Dans cette équation, il s'agit de vitesse de biodégradation d'un substrat ( $V^{\prime}$ ) et non de sa vitesse spécifique $\left(V=V^{\prime} / X\right)$. De plus, l'équation de Michaelis-Menten ne contient pas le terme $s / x^{2}$.

Dans le cas de la vitesse spécifique de croissance bactérienne, l'augmentation de la concentration initiale (ou sa valeur moyenne) d'acide déshydroabiétique dans les solutions synthétiques cause une augmentation de $K_{2}$ alors que $\mu_{m}$ ne change pratiquement pas. Pour cette plage de concentration, l'acide déshydroabiétique diminue donc la vitèsse spécifique de croissance sans affecter appréciablement la vitesse spécifique maximale de croissance. Si on veut faire une analogie avec l'inhibition de réactions enzymatiques, on pourrait suggérer qu'il s'agit d'une inhibition de type competitif en ce qui concerne la croissance bactérienne.

\section{4 Rendement en biomasse}

Le rendement en biomasse $Y$ a une signification plutót limitée dans notre cas. Une solution synthétique est constituée initialement d'un substrat principal (xylane), d'un substrat secondaire (méthanol), d'un inhibiteur (acide déshydroabiétique) et d'une certaine quantité de biomasse. La biodégradation de la xylane implique nécessairement la formation de plusieurs substances intermediaires avant d'en arriver a la production finale du biogaz de sorte qu'il est plausible d'imaginer que la xylane n'est pas nécessairement la substance la plus directement assimilée.

L'utilisation de l'équation (2.13), en se basant sur la consommation de la xylane, conduit a des valeurs anormalement 
élevées pour $Y$, dépassant même l'unité, surtout pour les solutions synthétiques $B$, D et $E$. Dans ces cas, la valeur de (-ds/dt) devient petite (la xylane est presque completement épuisée) de sorte que l'assimilation se produit à partir de composés intermédiaires. Alors le rapport $(d x / d t) /(-d s / d t)$ augmente rapidement. Cette équation est utilisable pour le début de la biodégradation $\left(0.9 \leq t \leq 1.8\right.$ jours) dans $l e$ cas des solutions $B\left(I_{0}=0\right), D\left(I_{0}=40 \mathrm{mg} / L\right)$ et $E\left(I_{0}=100 \mathrm{mg} / L\right)$. Les valeurs de $Y$ sont alors comprises respectivement entre 0.23 et $0.26,0.23$ et 0.26 ainsi que 0.26 et $0.29 \mathrm{mg}$ biomasse/mg xylane. Basé sur ces résultats, le rendement $Y$ ne varie pas de façon significative face a une augmentation de la concentration initiale (ou moyenne) de l'acide déshydroabiétique.

Pour les solutions $G\left(I_{0}=0\right), I\left(I_{0}=40 \mathrm{mg} / \mathrm{L}\right)$ et $J\left(I_{0}=100 \mathrm{mg} / \mathrm{L}\right)$, les valeurs de $Y$, calculées à l'aide de l'équation (2.13), sont comprises, respectivement entre 0.23 et $0.25,0.23$ et 0.22 ainsi que 0.25 et $0.21 \mathrm{mg}$ biomasse/mg xylane, pour des valeurs de temps comprises entre 0 et 4 jours. La encore, la présence d'un inhibiteur n'influence pas de façon significative la valeur du rendement en biomasse.

Si on examine les valeurs de $Y$ par paire de solutions, c'esta-dire les solutions $B$ et $G$, $D$ et $I$ et $E$ et $J$, la variation du rapport de la concentration initiale de xylane/concentration initiale de méthanol- n'affecte pas non plus de façon significative ces valeurs de rendement. 
On peut se servir de l'équation (2.12) pour évaluer le rendement $Y$. De cette façon, on peut utiliser les valeurs de $\Delta X$ et $\Delta s$ pour toute la durée de l'essai, quelque soit la solution synthétique. Cette façon de faire contourne la possibilité que la valeur de (-ds/dt) devienne petite. Cette façon de calculer $Y$ correspond a la situation ou le substrat principal est relativement épuisé de même que les composés intermédiaires puisque à $t=4$ jours, la DCo résiduelle (tableaux XIX, XX et XXI) est également faible. Les valeurs de $Y$ calculées de cette façon pour les solutions $B, G$, $D, I, E$ et $J$ sont respectivement $0.25,0.23,0.28,0.23,0.28$ et $0.23 \mathrm{mg}$ biomasse/mg xylane. Comme précédemment, les valeurs du rendement sont peu affectées par la variation de la concentration d'acide déshydroabiétique et du rapport concentration initiale de xylane/concentration initiale de méthanol.

Quand il est difficile de suivre le changement de concentration du substrat principal ou d'un melange complexe, on peut se servir des valeurs de la DCo pour évaluer le rendement $Y$. Les valeurs ainsi obtenues, en se servant de l'equation (2.12), sont pour les solutions B, G, D, I, E et J, respectivement $0.18,0.19$, $0.18,0.19,0.18$ et $0.19 \mathrm{mg}$ biomasse/mg DCO. Compte tenu que 0.91 mg de xylane correspond à $1.0 \mathrm{mg}$ de DCO (tableau II), les valeurs de $Y$, basées sur la DCO, sont équivalentes aux précédentes qui sont basées sur la disparition de la xylane. Henze et Harremōes (1983) ont obtenu une valeur de $Y$ égale a $0.18 \mathrm{~kg}$ biomasse/kg DCo pour une 
culture combinée (acétogénèse et méthanogénèse) à $35^{\circ} \mathrm{C}$, ce qui est comparable aux résultats présentés ici. 


\section{CHAP I TRE VI}

\section{CONCLUSION}

Malgré sa faible participation a la poliution des cours d'eau, comparativement aux procédés chimiques et mi-chimiques, le procédé thermomécanique (PTM) génère des polluants pour les eaux réceptrices. Ces polluants sont principalement composés d'hyarates de carbone (particulièrement la cellulose et l'hémicellulose), de lignine et d'extraits du bois, tels les acides résiniques et les acides gras.

Une eau résiduaire synthétique est préparée pour simuler le traitement secondaire anaérobie d'un effluent PTM. La solution synthetique est constituée de deux composés majeurs. Le premier est la xylane représentant la partie biodégradable des eaux résiduaires PTM; le second est l'acide déshydroabiétique représentant la partie toxique. Ce dernier, étant peu soluble dans l'eau, est dissout dans le méthanol avant d'etre ajouté à la solution synthetique.

Les tests de traitabilité ont montré que la xylane est facilement biodégradée par digestion anaérobie; elle ne présente aucune toxicité pour la population bactérienne. Par contre, l'acide déshydroabiétique est toxique pour les bactéries anaérobies car I'augmentation de sa concentration de 0 à $200 \mathrm{mg} / \mathrm{L}$ dans 1 a solution synthétique, diminue la DCo réduite de l'ordre de $50 \%$ lors de la digestion. Le volume de méthane produit lors de la digestion 
est inversement proportionnel au rapport concentration xylane/concentration méthanol. Ce dernier produit un biogaz contenant $78 \%$ de méthane comparativement à $60 \%$ pour la xylane.

L'etude a montré que l'acclimatation des bactéries anaérobies aux différentes solutions traitées diminue considérablement la période de latence de l'activité bactérienne. Par contre, le degré d'acclimatation des bactérles aux solutions synthétiques n'a aucun effet sur la composition du biogaz produit pendant la digestion. Cette étude a donc montré que l'eau résiduaire synthétique choisie représente bien un effluent PTM réel.

Au cours de cette étude, deux équations modifiées sont proposées pour représenter respectivement la vitesse spécifique (V) de biodégradation de la xylane et la vitesse spécifique ( $\mu$ ) de la croissance bactérienne. Les deux équations sont:

$$
v=v_{m} \frac{\left(s / x^{2}\right)}{k_{2}+\left(s / x^{2}\right)}
$$

et

$$
\mu=\mu_{m} \frac{\left(s / x^{2}\right)}{k_{2}+\left(s / x^{2}\right)}
$$

L'acide déshydroabiétique a un effet inhibiteur sur la population bactérienne car l'augmentation de sa concentration dans les solutions synthétiques provoque une variation des constantes cinétiques $v_{m}$ et $k_{1}$ ainsi que $\mu_{m}$ et $k_{2}$ des deux équations 
proposées. L'étude a montré que le rendement en biomasse des différentes solutions synthétiques est de l'ordre de $0.18 \mathrm{mg}$ de biomasse formée/mg de DCo disparue.

Les traitements anaérobies, qui sont encore peu utilisés dans 1'industrie des pates et papiers, sont voués a un avenir prometteur si lion poursuit les études concernant, principalement, la détoxification des effluents. 


\section{ANNEXES}

ANNEXE A - Composition du bois

La partie du bois intéressant l'industrie papetiere est la fibre cellulosique. Les fibres sont souples; cependant le tronc des arbres est rigide car un produit enrobe les fibres, les soude les unes aux autres et leur confère de la rigidité. Cet enrobage est constitue d'une matiere thermoplastique naturelle appelée lignine (McCubbin, 1984d). La lignine est une substance macromoleculaire complexe et $r$ iche en carbone (figure 8); elle comporte différents groupements, dont le groupement méthoxyle qui est à l'origine de l'alcool méthylique, ou alcool de bois, obtenu par distillation. Le bois tendre contient $28 \%$ de lignine alors que le bois dur n'en contient que 22\% (Jansson et Back, 1975). La lignine a deux propriétés que l'industrie papetiere utilise dans les procédés de défibrage (McCubbin, 1984b):

- se ramollir par la chaleur; en chauffant le bois, la séparation des fibres par action mécanique devient facile et efficace; le procédé papetier thermomécanique utilise cette propriété;

- se dissoudre dans certains réactifs chimiques; la lignine étant dissoute, les fibres se séparent facilement.

Dans le premier cas, une pate mécanique à fibres rigides (car toujours enrobées de lignine) est obtenue. Dans le deuxieme cas, 
une pate chimique à fibres souples (la lignine étant éliminée) est obtenue.

Une fibre de bois est constituée de cellulose (figure 5) qui, traitée avec un acide, donne, aprés une dépolymérisation, un produit constitué uniquement de glucose. Pour constituer la cellulose, la nature peut assembler bout a bout jusqu'à 15000 de ces petites molécules. Les fibres sont groupées pour former un Eilament. La cellulose constitue 45 à $50 \%$ du bois (Eigure 31 )

Dans le bois, un autre produit appelé hémicellulose (figure 7) joue, en particulier, le role de liant entre les filaments. Les hémicelluloses sont constituées de plusieurs sucres, aussi bien à 6 qu'a 5 carbones, et ont la particularité - contrairement a la cellulose - de posséder des ramifications latérales (figure 7). Le degré de polymérisation des hémicelluloses est très inférieur à celui des molécules de la chaine cellulosique. L'hémicellulose est composée de deux grandes classes (figure 7), soient la xylane (constituée principalement de xylose) et la glucomannane (constituée en grande partie de mannose). L'importance de la xylane et de la glucomannane varie selon la nature du bois. Le bois tendre contient $60 \%$ de glucomannane et $40 \%$ de xylane tandis que le bois dur contient $90 \%$ de xylane et seulement $10 \%$ de glucomannane (Jansson et Back, 1975). Le bois tendre contient 25\% d'hémicellulose comparativement à $33 \%$ pour le bois dur (Jansson et Back, 1975).

Apres le broyage du bois, certains composés peuvent être extraits par un solvant neutre pour donner une solution colorée. Ce sont ces substances appelées "extraits de bois" qui sont 


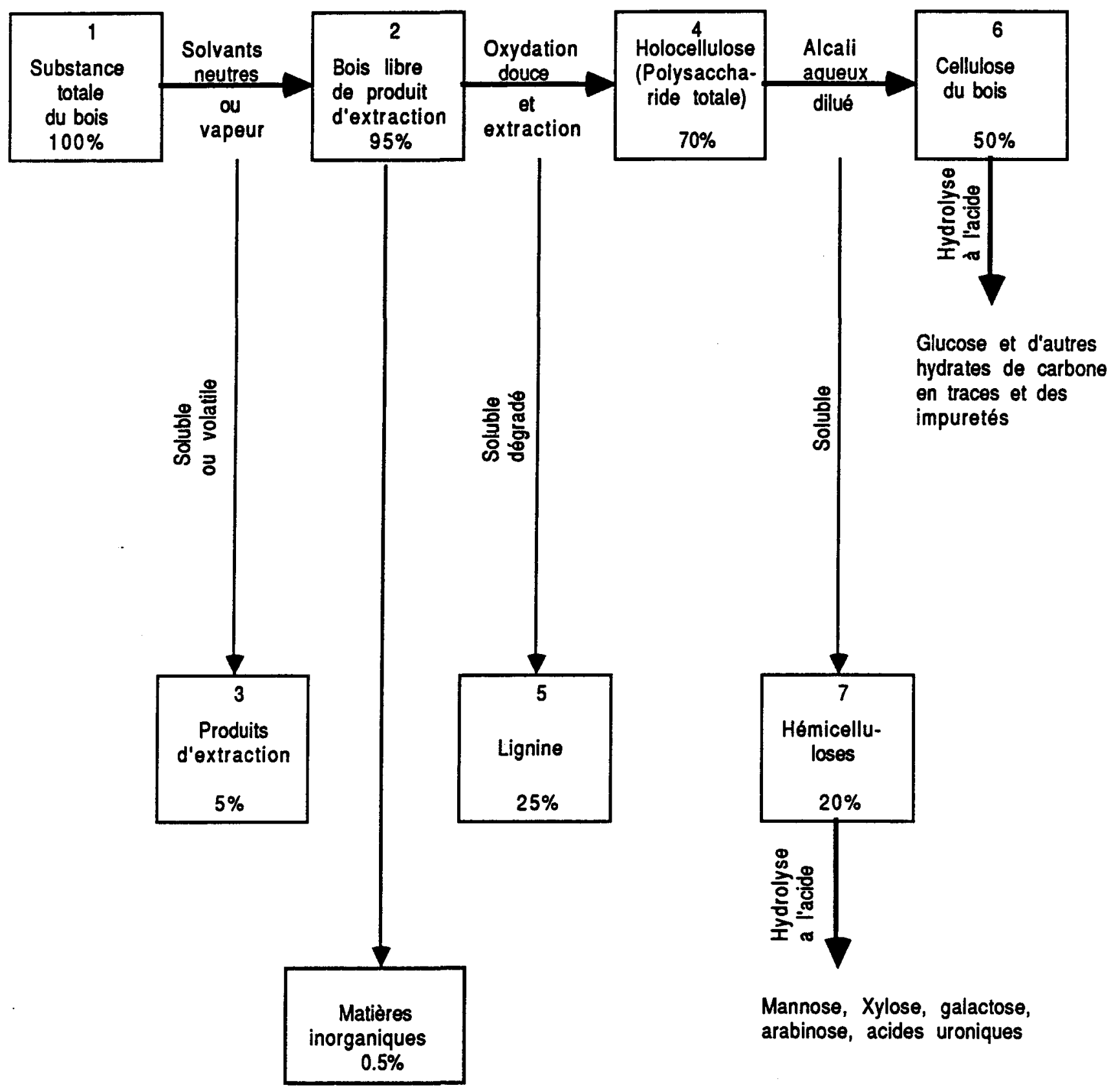

Figure 31 : Composés chimiques du bois (McCubbin, 1984d) 
responsables de la coloration des effluents de pate et papiers (McCubbin, 1984b). Ces extraits de bois peuvent contenir des matières volatiles toxiques tels les alcools, les acides résiniques et les acides gras.

Le bois est donc constitué de trois familles de composés chimiques majeures:

a) les hydrates de carbone (hémicellulose et cellulose);

b) les lignines;

c) les matières extractibles (acides résiniques, acides gras, etc...)

ANNEXE B - Procédé thermomécanique

Le procédé de raffinage des copeaux sous pression est pratiqué depuis 1932 (Peck, 1975; Leask, 1975). Mais jusqu'à dernièrement, ce procédé a eu une application limitée. Pendant les dernières années, les récents développements de la technologie et les lois environnementales des gouvernements ont favorisé le procédé thermomécanique (PTM). La majorité des installations de défibrage mécanique construites au Canada depuis 1973, fabrique de la pate thermomécanique (McCubbin, 1984b). Le procédé mécanique traditionnel n'avait pas eu le succès espéré parce que la désintégration du bois, a une température inférieure a $100^{\circ} \mathrm{C}$, est difficile a cause de la formation de morceaux de bois non récupérables (Smook, 1982). Des études ont montré qu'en opérant a des températures 
proches du point de ramolissement de la lignine, c'est-à-dire entre 120 et $135^{\circ} \mathrm{C}$, les fibres se séparent plus facilement (Leask, 1975).

Les operations de fabrication des pates thermomécaniques sont les suivantes (figure 32), (McCubbin, 1984b):

- les copeaux lavés sont introduits, par un convoyeur à vis, dans une chambre de préchauffage sous pression afin d'etre ramollis. Le conditionnement a la vapeur dure environ 3 minutes et se fait à une temperature de 120 a $130^{\circ} \mathrm{C}$, sous une pression de 150 à $200 \mathrm{kPa}$; l'énergie dégagée peut être récupérée pour le fonctionnement de la machine à papier;

- les copeaux ramollis sont défibrés dans un premier raffineur à disque sous pression;

- les fragments non défibrés sont ensuite envoyés dans un deuxième raffineur.

La fibre de la pate PTM, comparativement à celle obtenue par procédé mécanique classique, est plus longue, plus solide (déchirement), un peu moins blanche et un peu moins opaque. L'énergie requise pour le précédé PTM est nettement plus élevée que celle requise pour le procédé mécanique classique (McCubbin, 1984b). Les avantages du procédé thermomécanique sont:

- résistance suffisante des fibres permettant de réduire substantiellement la proportion de pate chimique dans la fabrication du papier journal;

- consommation nulle de produit chimique;

- rendement élevé d'utilisation du bois; 
COPEAUX

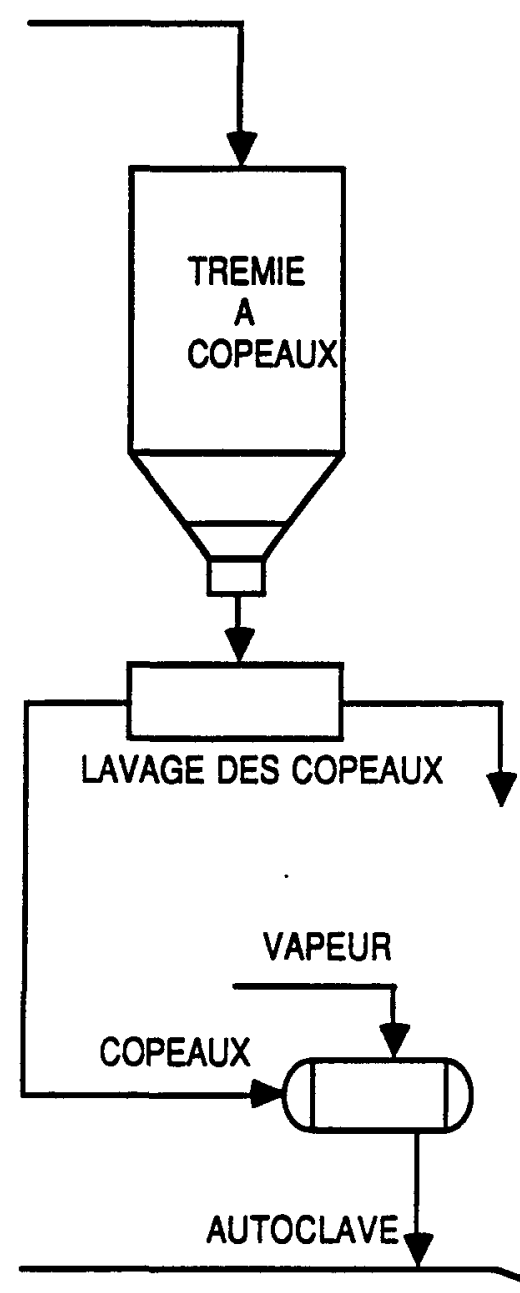

REJETS

RAFFINEUR DES REFUS

PREMIERE

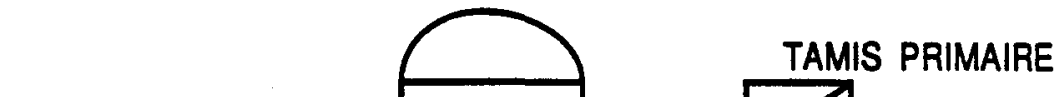

TAMIS PRIMAIRE
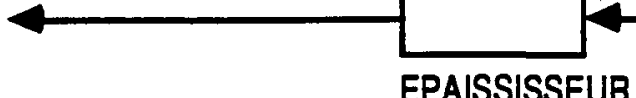

EPAISSISSEUR

REFUS

1
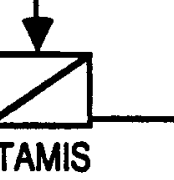

SECONDAIRE

MATIERE EPUREE

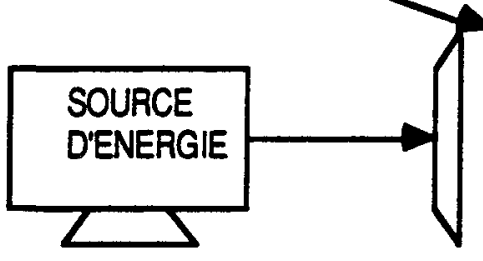

ETAPE

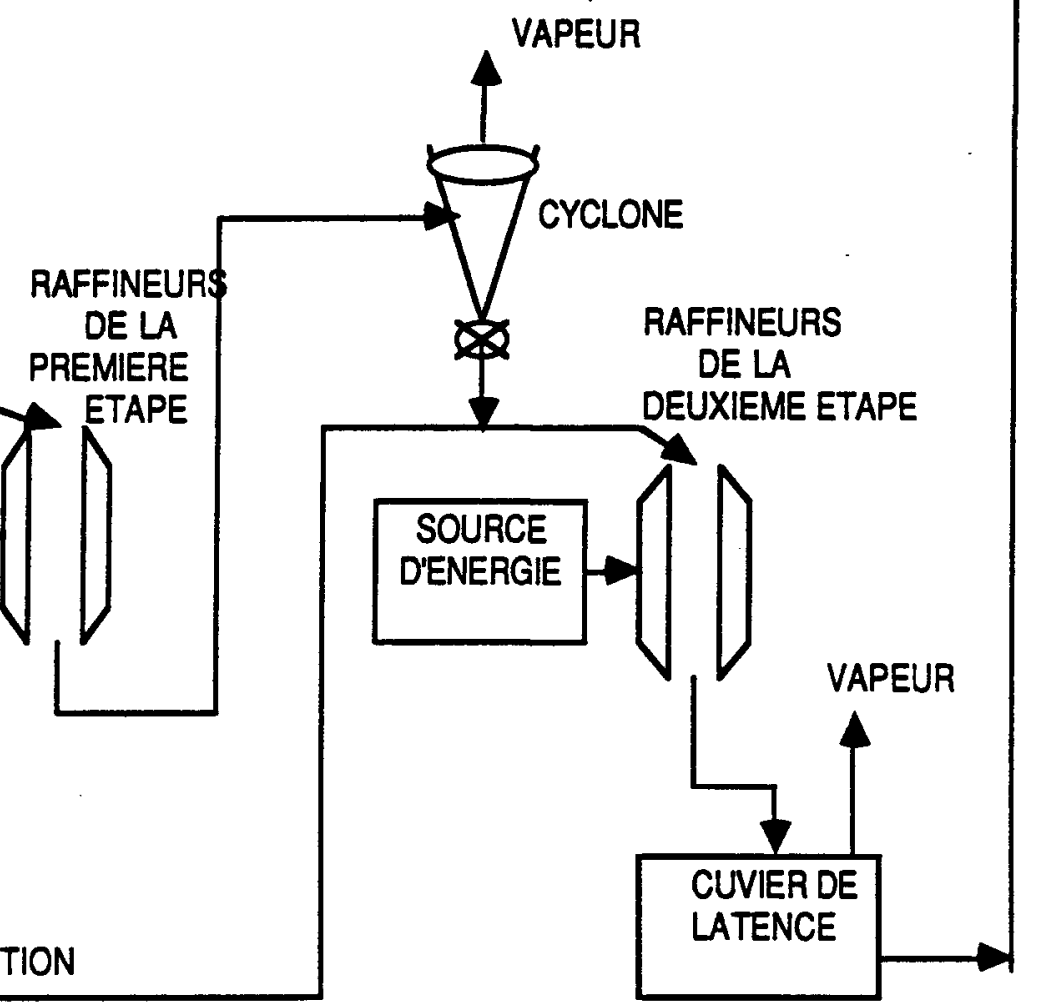

(

REFUS

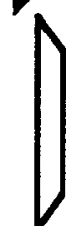

SYSTEME D'EPURATION

(EN 3 OU 4 ETAPES)

EAU DE DILUTION

Figure 32: Procédé thermomécanique classique 
- génération de faibles charges de matieres organiques dans les effluents; ce qui le rend énormément moins polluant pour le milieux récepteur que les procédés chimiques (Couil lard, 1979). 


\section{BIBLIOGRAPHIE}

AIBA, S.; HUMPHREY, A.E. et MILLIS, N.F. (1965)

"Biochemical Engineering", Academic Press, New-York.

ANDERSON, G.K.; DONNELLY, T. et MCKEOWN, K.J. (1982)

"Identification and control of inhibition in the Anaerobic Treatment Industrial Wastewaters"; Process Biochemistry, 17(4): 28-32.

ANDERSON, G.K. et SENERATNE, A.U. (1985)

"Cost of Anaerobic Processes in the Pulp and Paper Industry"; water Science Technology, 17: 241-254.

\section{APHA - AWWA - WPCF (1980)}

"standard Methods for the Examination of Water and Wastewaters"; American Public Health Association, 15ième édition, washington, D.C.

ASSOCIATION CANADIENNE DES PRODUCTEURS DE PATES ET RAPIERS - ACPPP (1988)

"Tables de statistiques 1987", 41ieme édition, Montréal, Québec, Février 1988,42 pages.

BAILEY, E.B. et OLLIS, D.F. (1977)

"The Kinetics of Enzyme-Catalysed Reactions"; Biochemical Engeneering Fundamentals, McGraw-Hill, NewYork, 78-154.

B.C. REASEARCH (1973)

"Isolation of Toxic Constituents of Kraft Pulp Mill Effluent", Environnement Canada, Projet CPAR 11-4: 113. 
BEAK CONSULTANTS LIMITED (1988)

"Treatability of CTMP/TMP Wastewaters"; Wastewater Technology Centre, Burlington, Ontario, Environnement Canada, Rapport WTC-BIO- 02-88: 1-15.

BETTS, J.M. (1984)

"Rapport sur l'état actuel de la dépollution de l'eau dans l'industrie canadienne des pates et papiers"; Environnement Canada, Rapport SPE 1/PF/1, 1-8.

BISARIA, V.S. et GHOSE, T.K. (1981)

"Biodegradation of Cellulosic Materials: Substractes, Microorganisms, Enzymes, and Products"; Enzyme Microbiology and Technology, 3: 90-104.

BLUM, D.J.W.; HERGENROEDER, R.; PARKIN, G. et SPEECE, R.E. (1985)

"Anaerobic Treatment of Phenol: Degradability, Toxicity and Kinetics"; Comptes-rendus de "Environnemental Engineering specialty Conference, Boston, 598-605.

BREEZONIK, P.L. (1972)

"Chemical Kinetics and Dynamics in Natural water Systems"; Water and Pollution Handbook, Ciaccio L.L., Marcel Dekker Inc., New-York, 3: 831-913.

COCCI, A.A.; LANDINE, R.C.; VIRARAGHAVAN, T. et BROWN, G.J. (1982)

"Anaerobic Treatment of Pulp and Paper Wastes"; Pulp and Paper Canada, 83(9): 70-73. 
COHEN, A.; BREURE, A.M.,; Van ANDEL, J.G. et Van DEURSEN, A. (1982)

"Influence of Phase Separation on the Anaerobic Digestion of Glucose - II stability and Kinetic Responses to Shock Loadings"; water Research, 16: 449-455.

CONTOIS, D. (1959)

"Kinetics of Bacterial Growth Relationship Between Population Density and specific Growth Rate of Continuous Cultures"; Journal of General Microbiology, $21: 40-50$

CORNACCHIO, L.; HALL, E.R. et TREVORS, J.T. (1986)

"Modified Serum Bottle Testing Procedures for Industrial Wastewaters"; "Technology Transfer Workshop on Laboratory Scale Anaerobic Treatability Testing Technics, Wastewater Technology Center, Burlington, Ontario, Environnement Canada, 17-32.

COUILLARD, D. (1979)

"Sources et caractéristiques des eaux usées issues des différents procédés. de l'industrie des pates et papiers"; The science of the total Environment, 12: $169-198$.

COUILLARD, D. (1980)

"Evaluation de la pollution et des répercussions des rejets des industries des pates et papiers sur la vie aquatique"; The science of the Total Environment, 14: $167-185$. 
COUILLARD, D. et TRUDEL, R. (1981)

"Influence des rejets d'usines de pates et papiers sur les microinvertébrés, les bactéries et l'eutrophisation d'une rivière"; Water Research, 15: 1331-1342.

COUILLARD, D. (1987)

"Traitements secondaires biologiques des eaux usées"; Notes de cours de l'unité EAU-7243.4, INRS-Eau, Université du Québec, Québec, 130 pages.

DEKKER， R.F.H. (1985)

"Biodegradation of the Hemicelluloses"; Biosynthesis and Biodegradation of Wood Components, Takayoshi Higuchi, Academic Press Inc., New-York, 505-533.

ECKENFELDER, W.W. (1982)

"Procédé de traitement des eaux résiduaires"; L'eau dans l'industrie: Pollution, traitement, recherche de la qualité, Entreprise Moderne d'Edition, Paris, 121-124. FERGUSON, J.F.; JURGENSEN, S.L. et BENJAMIN, M.M. (1985) "Treatability of Thermomechanical Pulping Process Effluents with Anaerobic Biological Reactors"; Comptesrendus de "Environmental Conference", Atlanta, 83-92.

GRADY, C.P.L. et LIM, H.C. (1980a)

"Anaerobic Digestion and Anaerobic Contact"; Biological Wastewaters Treatment: Theory and Application, Marcel Dekker Inc., New-York, 833-879. 
GRADY, C.P.L. et IIM, H.C. (1980b)

"Metabolism - The Key of Biochemical Transformation"; Biological Wastewaters Treatment: Theory and Application, Marcel Dekker Inc., New-York, 230-268. GREEN, M., SHELEF, G. et MORAINE, R. (1981)

"Chemical and Biochemical Oxygen Demand as Indicators of Biodegradable Substrate Concentration"; Wat. Pollut. Control, 60: 655-658.

GUNNERSON, C.G. et STUCKEY, D.C. (1986a)

"Fundamentals of Anaerobic Digestion"; Anaerobic Digestion: Principles and Practices for Biogas systems, World Bank, Washington, D.C., Technical Paper, 49:8-16. GUNNERSON, C.G. et STUCKEY, D.C. (1986b)

"Fundamental Considerations in Anaerobic Digestion"; Anaerobic Digestion. Principles and Practices for Biogas Systems, World Bank, Washington, D.C., Technical Paper, 49: 103-131.

GUNNERSON, C.G. et STUCKEY, D.C. (1986C)

"Introduction and Overview"; Anaerobic Digestion: Principles and Practices for Biogas Systems, World Bank, Washington, D.C., Technical Paper, 49: 1-7.

GUNNERSON, C.G. et STUCKEY, D.C. (1986d)

"Outputs and their Uses"; Anaerobic Digestion: Principles and Practices for Biogas Systems, World Bank, Washington, D.C., Technical Paper, 49: 57-67. 
HAKULINEN, R. et SALKINOJA-SALONEN, M.S. (1982)

"Treatment of Pulp and Paper Industry Wastewaters in Anaerobic Fluidised Bed Reactor"; Process Blochemistry, $17(2): 18-22$.

HAWKES, F.R. et HAWKES, D.L. (1987)

"Anaerobic Digestion"; Basic Biotechnology, BU'Lock, J. et Kristiansen, B.; Academic Press, London, 337-347. HEMINGWAY, R.W. et GREAVES, H. (1973)

"Biodegradation of Resin Acid Sodium Salts"; TAPPI, $56(12): 189-192$.

HENZE, M. et HARREMŌES, P. (1983)

"Anaerobic Treatment of Wastewater in Fixed Film Reactors - a Litterature Review"; Water Science Technology, 15 $(8-9): 1-101$

HERBERT, D.; PHIPPS, P.J. et STRANGE, R.E. (1971)

"Chemical Analysis of Microbials Cells"; Methods in Microbiology, Norris J.R. et Ribbons D.W., Academic Press, New-York, 5B: 272-277.

HOLMBOM, B. $(1980)$

"A Procedure for Analysis of Toxic Compounds in Pulp and Paper Mill Wastewaters"; Paperi Ja Puu, 9: 523-531.

HOWARD, T.E. et MOUNTEITH, D.D. (1977)

"Site of Action of Chemicals from Pulp Mill Effluent that are Toxic to Fish"; Environnement Canada, Rapport CPAR $488-1: 20-35$ 
JANSSON, U.M.B. et BACK, E.L. (1975)

"Chemical Characterization of Fiber Board Mill Effluent"; Wood Science, 8(2): 112-121.

JUNNA, J.; LAMNI, R. et MIETTINEN, V. (1982)

"Removal of Organic and Toxic Substances from Debarking and Kraft $P u l p$ Bleaching Effluents by Activated Sludge Treatment"; Wesientvtkimuslaitoksen Julkaisuja, 49: 1729.

KHAN, A.W.; MILLER S.S. et MURRAY, W.D. (1983)

"Development of a Two-phase Combination Fermenter for the Conversion of Cellulose to Methane"; Biotechnology and Bioengineering, 25: 1571-1579.

KINNER, N.E. et LESZKIEWICZ, C.G. (1985)

"Evaluation of the Effects of Temperature and oxygen Concentration on Lignin Biodegradation"; Comptes-rendus de "Specialty Conference", Boston, 75-84.

LARSSON, S.A.; ÖSTMAN, B.A.L. et BACK, E.L. (1975)

"Biochemical and Chemical oxygen Demands of Carbohydrates with Different Degrees of Polymerization"; Environmental Science and Technology, $9(2): 160-162$.

LEACH, J.M. et THAKORE, A.N. (1975)

"Identification and Analysis of Toxic Constituents in Mechanical Pulping Effluents"; Comptes-rendus de "International Mechanical pulping Conference", partie II, San-Francisco, California: 18-24. 
LEACH, J.M. et THAKORE, A.N. (1977)

"Compounds Toxic to Fish in Pulp Mill Waste streams"; Progress water Technology, 9: 787-798.

LEACH, J.M.; CHUNG, L.T.K. et MEIER, H.P. (1979)

"Can Pulp Mill Effluent Toxicity Be Estimated From Chemical Analyses"; TAPPI, 62(12): 71-74.

LEASK, R.A. (1975)

"A Review of Thermo-mechanical Pulping"; Paper Trade Journal, 2: 71-73.

LEASK, R.A. et KEAYS, J.L. (1979)

"TMP Survey"; Pulp and Paper Canada, 80(3): 21-22.

LESTER, J.N.; BULL, M.A. et STERRITT, R.M. (1984)

"An Evaluation of Single and separated Phase Anaerobic Industrial waste water Treatment in Fluidized Bed Reactors"; Biotechnology and Bioengineering, 26: 10541065 .

LIN, C.Y.; NOIKE, T.; SATO, K. ET MATSUMOTO, J.(1987)

"Temperature Characteristics of the Methanogenesis Process in Anaerobic Digestion"; Water Science Technology, $19: 299-310$.

LUONSI, A.; VUORIRANTA, P. et HYNNINEN, P. (1986)

"Reduction of Pulp and Paper Industry Effluent Loading"; Water Science Technology, 18: 109-125. 
MALY, J. et FADRUS, H. (1971)

"Influence of Temperature on Anarobic Digestion"; Journal of Water Pollution Control Federation, 43 (4): 641650 .

MCCUBBIN, N. (1984a)

"Systemes de réduction du bois en pate"; Etat présent de 1 'industrie des pates et papiers et des mesures de protection de l'environnement. Environnement Canada, Rapport SPE 3-EP-84-2F: $20-36$

MCCUBBIN, N. (1984b)

"Défibrage"; Techniques de base de l'industrie des pates et papiers et ses pratiques de protection de l'environnement, Environnement Canada, Rapport SPE 6EP-83-1F: $28-68$.

MCCUBBIN, N. (1984C)

"Méthodes de traitements des eaux usées"; Techniques de base de l'industrie des pates et papiers, et ses pratiques de protection de l'environnement, Environnement Canada, Rapport SPE 6-EP-83-1F: 140-161. MCCUBBIN, N. (1984d)

"Chimie du bois"; Techniques de base de l'industrie des pates et papiers, et ses pratiques de protection de I'environnement, Environnement Canada, Rapport SPE 6EP-83-1F: $195-209$. 
MCLEAY, D. (1987)

"Composition toxique de l'effluent de pates et papiers, des eaux réceptrices et des sédiments"; Enquête bibliographique sur la toxicité des effluents de l'industrie des pates et papiers pour les biocénoses aquatiques, Environnement Canada, Rapport SPE 4-PF-1: 1-35.

MONOD, J. (1942)

"Recherches sur la croissance des cultures bactériennes"; Hermann et cie, Paris.

NOIKE, T.; ENDO, G.; CHANG, J.; YAGUCHI, J. et MATSUMATO, J. (1985) "Characteristics of Carbohydrate Degradation and the Rate-limiting step in Anaerobic Digestion"; Biotechnology and Bioengineering, 27: 1482-1489.

OIKARI, A.B.; HOLMBOM, B.; ANAS, E. et BISTER, H. (1980)

"Distribution in Recipient Lake and Bioaccumulation in Fish of Resin Acids from Kraft Pulp Mill Wastewaters; Paperi Ja Puu, 62: 193-196.

OLTHOF, M. et OLESZKIEWICZ, J. (1982)

"Anaerobic Treatment of Industrial Wastewaters"; Chemical Engineering, 11: 121-126.

OWEN, W.F.; STUCKEY, D.C.; HEALY, J.B.; YOUNG, L.J. et MCCARTHY, P.L. (1979)

"Bioassay for Monitoring Biochemical Methane Potential and Anaerobic Toxicity"; Water Research, 13: 485-492. 
PECK, R.R. (1975)

"Because TMP is Able to Solve Current Pulping Problems, Big Growth is Seen"; Paper Trade Journal, 6: 56-58. RICHARDSON, D.E.; O'GRADY, B.V. et BREMNER, J.B. (1983)

"Analysis of Dehydroabietic Acid in Paper Industry Effluent by High-performance Liquid Chromatography"; Journal of Chromatography, 268: 341-346.

SALKINOJA-SALONEN, M.S.; APAJALAHTI, J.; SILAKOSKI, L. et HAKULINEN, R. (1984)

"Anaerobic Fluidised Bed for the Purification of Effluents from Chemical and Mechanical Pulping"; Biotechnology Advances, 2: 357-375.

SCRIBAN, R., éd. (1984)

"Partie III, Le génie enzymatique"; Biotechnologie (2ième éd.), Technique et Documentation-Lavoisier, Paris.

SERVIZI, J.A. et GORDON, R.W. (1986)

"Detoxification of TMP and CTMP Effluents Alternatings in a Pilot Scale Aerated Lagoon"; Pulp and Paper Canada, $87(11): 42-46$.

SERVIZI, J.A.; MARTENS, D.W. et GORDON, R.W. (1986)

"Microbiological Detoxification of Resin Acids"; Water Pollution Research Journal of Canada, 21(1): 119-129. SHERE, S.M. et DALY, P.G. (1982)

"High Rate Biological Treatment of TMP Effluent"; Pulp and Paper Canada, 83(3): 62-66. 
SMOOK, G.A. (1982)

"Mechanical Pulping"; Handbook for Pulp and Paper Technologists, Canadian Pulp and Paper Association, Montréal, Québec, 50-65.

STENBERG, L.E. et NORBERG, G. (1977)

"Effluents from the Manufacture of Thermomechanical Pulp"; Paperi Ja Puu, 10: 652-658.

STRONACH, S.M.; RUDD, T. et LESTER, J.N. (1986)

"The Biochemistry of Anaerobic Digestion"; Anaerobic Digestion Processes in Industrial Wastewater Treatment, spring-Verlag, Berlin: 1-20.

SUIDAN, M.T.; CROSS, W.H.; TONG, M. et CALVERT, J.W. (1981)

"Anaerobic Carbon Filter for Degradation of Phenols"; Journal of Environmental Engineering, 107: 563-579.

SUNDSTROM, W. et KLEI, H. (1979)

"Biological Mechanisms and Kinetics"; Wastewater Treatment, Englewood, C., Prentice-Hall, New-York: 75105

TCHOBANOGLOUS, G. (1979)

"Biological Unit Processes"; Wastewater Engineering Treatment/Disposal/Reuse, Metcalf and Eddy Inc., McGrawHill Series in water Resources and Environmental Engineering, New-York: 393-572. 
THURLEY, D.S. et RICHARDSON, D.E. (1978)

"Use of the Activated Sludge Process in the Treatment of Thermomechanical Pulping Effluents"; Appita, 32(2): 103108 .

TIEDJE, J.; BOYD, A.S.; KRUMME, M.L. et DWYER, D.F. (1986)

"Kinetics of Phenol Biodegradation by Immobilised Methanogenic Consortium"; Applied and Environmental Microbiology, 52(2): 345-351.

WEBB, L.J. (1984)

"Anaerobic Biological Treatment of Wastewaters from the Pulp and Paper Industry"; Biotechnology Advances, 2: 273-299.

WELANDER, T. et ANDERSON, P.E. (1985)

"Anaerobic Treatment of Wastewaters from the Production of Chemithermomechanical Pulp"; Water Science Technology, 17: 103-111.

WONG, A. (1977)

"Quality of Effluents from Mechanical Pulping Processes"; Pulp and Paper Canda, 78(6): 103-107.

ZEIKUS, J.W.; WELLSTEIN, A.L. et KICK, T.K. (1982)

"Molecular Basis for the Biodegradive Recalcitrance of Lignin in Anaerobic Environments"; FEMS Microbiology Letters, 15: 1983-1987. 